\title{
Stellenwert des supraklavikulären Insellappens in der rekonstruktiven Kopf-Hals-Tumorchirurgie
}

\author{
INAUGURAL-DISSERTATION \\ zur Erlangung des Doktorgrades \\ der Medizinischen Fakultät der \\ Georg-August-Universität zu Göttingen \\ vorgelegt von \\ Jennifer Lee Spiegel \\ aus \\ München
}

Göttingen 2019 
Dekan:

\section{Betreuungsausschuss}

Betreuer/in

Ko-Betreuer/in:

\section{Prüfungskommission}

Referent/in

Ko-Referent/in:

Drittreferent/in:
Prof. Dr. rer. nat. H. K. Kroemer

Prof. Dr. med. M. Canis

Priv.-Doz. Dr. med. G. Felmerer

Datum der mündlichen Prüfung: 
Hiermit erkläre ich, die Dissertation mit dem Titel „Stellenwert des supraklavikulären Insellappens in der rekonstruktiven Kopf-Hals-Tumorchirurgie“ eigenständig angefertigt und keine anderen als die von mir angegebenen Quellen und Hilfsmittel verwendet zu haben.

Göttingen, den .............. 
Teile dieser Doktorarbeit wurden bereits in wissenschaftlichen Magazinen und auf Konferenzen in Form von Vorträgen und Abstracts vorgestellt.

\section{Originalarbeiten:}

Spiegel JL, Pilavakis Y, Canis M, Welz C (2018): Shoulder Morbidity in Patients after Head and Neck Reconstruction with the Pedicled Supraclavicular Island Flap. Plast Reconstr Surg Glob Open $\underline{6}$, e1711

Welz C, Canis M, Schwenk-Zieger S, Spiegel JL, Weiss BG, Pilavakis Y (2017): Oral Cancer Reconstruction Using the Supraclavicular Artery Island Flap: Comparison to Free Radial Forearm Flap. J Oral Maxillofac Surg 75, 2261-2269

\section{Präsentationen:}

Spiegel JL, Welz C, Canis M, Jakob M. Lebensqualität von Patienten nach Rekonstruktion mit dem gestielten supraklavikulären Inseltransplantat (SCAIF) im Vergleich zum freien Radialistransplantat (RFFF). 123. Jahrestagung 2019 der Vereinigung Westdeutscher HalsNasen-Ohrenärzte, 29.03.2019, Neuss

Spiegel JL, Welz C, Canis M, Pilavakis Y. Schultermorbidität nach Rekonstruktion von Tumordefekten mit dem axial gestielten supraklavikulären Insellappen (SCAIF). 89. Jahrestagung der Deutschen Gesellschaft für Hals-Nasen-Ohrenheilkunde, Kopf- und Hals-Chirurgie, 12.05.2018, Lübeck

Welz C, Canis M, Spiegel JL, Pilavakis Y. Rekonstruktion von Tumordefekten der Mundhöhle und des Oropharynx mit dem supraclavikulär gestielten Inseltransplantat: Ein Vergleich mit dem freien Radialistransplantat. 88. Jahrestagung der Deutschen Gesellschaft für HalsNasen-Ohrenheilkunde, Kopf- und Hals-Chirurgie, 27.05.2017, Erfurt

\section{Preise:}

Henning-Hildmann-Posterpreis; Jahrestagung 2019 der Vereinigung Westdeutscher HalsNasen-Ohrenärzte, 29.-30.03.2019, Neuss mit dem Beitrag: Spiegel JL, Welz C, Canis M, Jakob M. „Lebensqualität von Patienten nach Rekonstruktion mit dem gestielten supraklavikulären Inseltransplantat (SCAIF) im Vergleich zum freien Radialistransplantat $(\mathrm{RFFF})^{،}$ 


\section{Inhaltsverzeichnis}

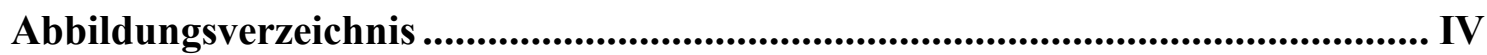

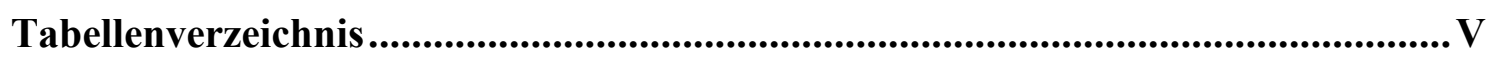

Abkürzungsverzeichnis .............................................................................................. VI

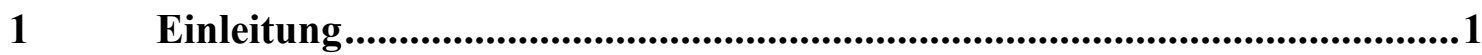

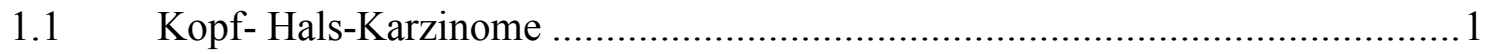

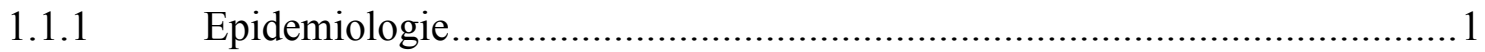

1.1.2 Histologie: Plattenepithelkarzinome und ihre Risikofaktoren .....................2

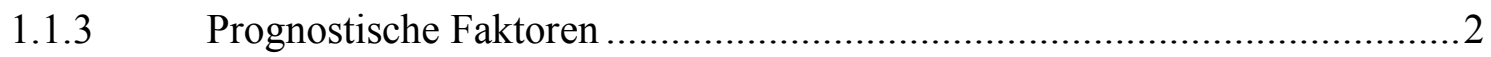

1.1.4 Einteilung und Tumorklassifikation .............................................. 3

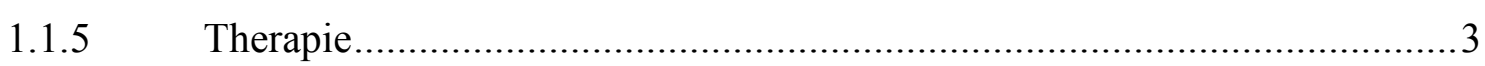

1.2 Gewebetransfer in der rekonstruktiven Kopf-Hals-Chirurgie ......................... 4

1.3 Das gestielte supraklavikuläre Gewebetransplantat ....................................5

1.3.1 Grundlagen und Entwicklung des Gewebetransplantats...........................5

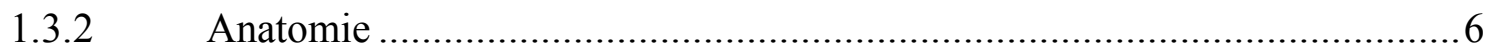

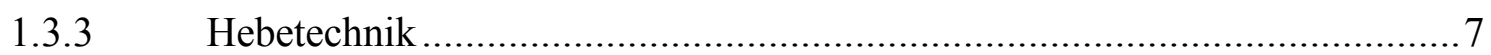

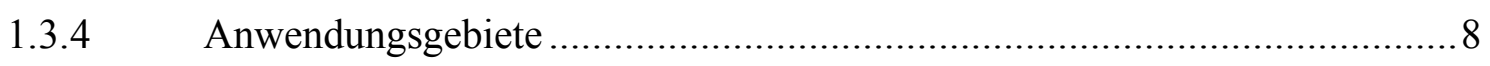

1.4 Postoperative Morbidität..........................................................................

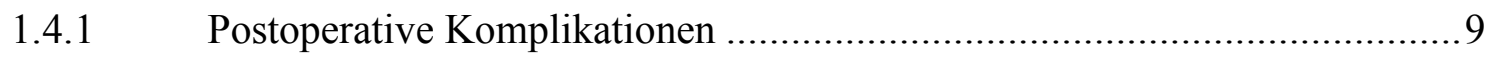

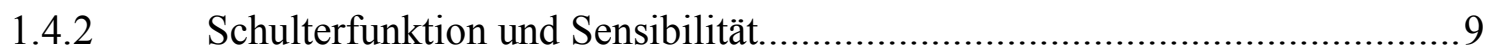

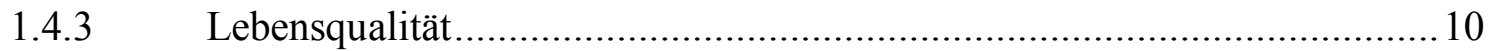

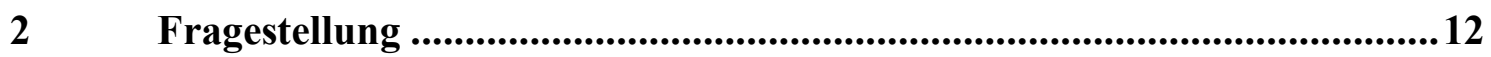

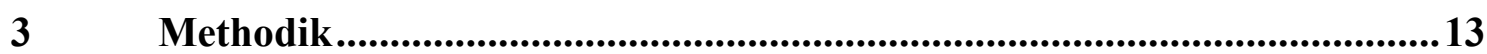

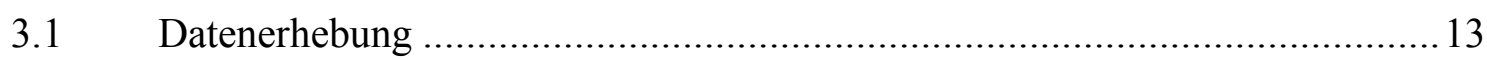

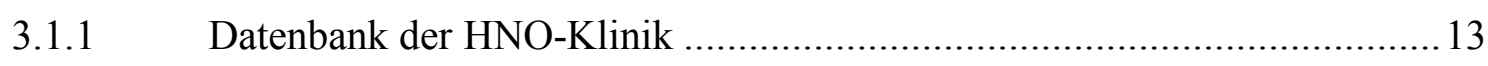

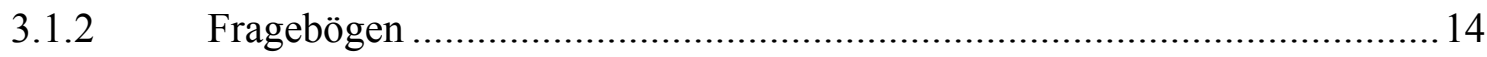

3.2 Patientenkollektiv und Parameter................................................................. 14

3.3 Analyse der prä-, peri- und postoperativen Daten...................................... 14

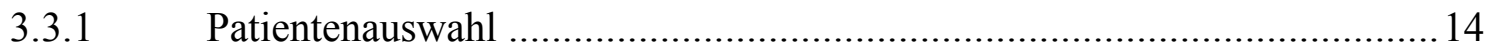

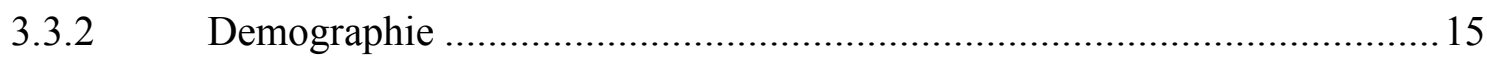

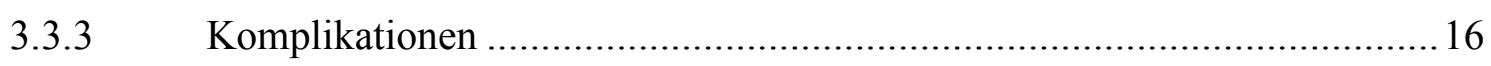

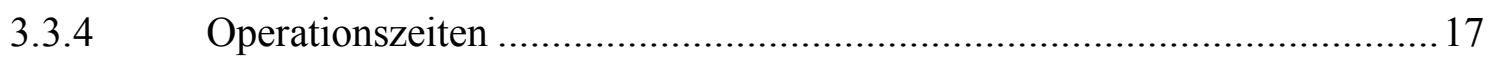

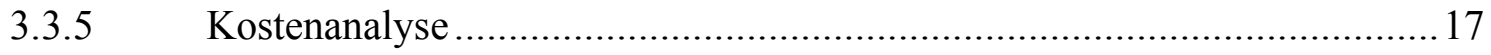

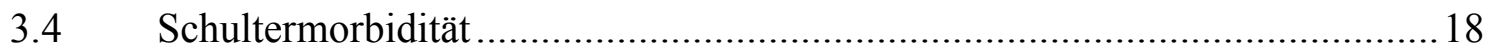




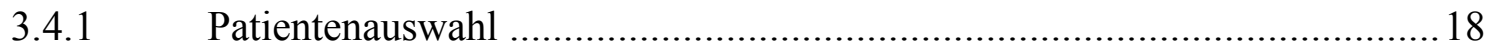

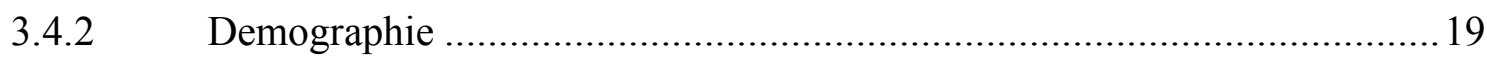

Fragebögen und Untersuchungen ..................................................... 19

Constant-Murley-Score ................................................................. 19

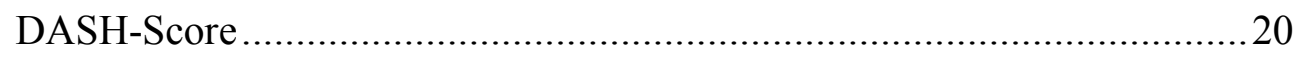

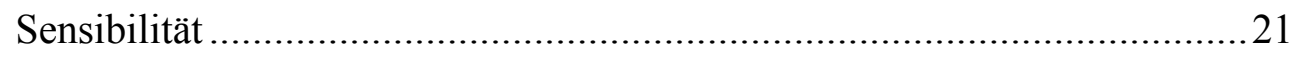

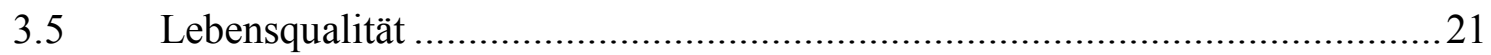

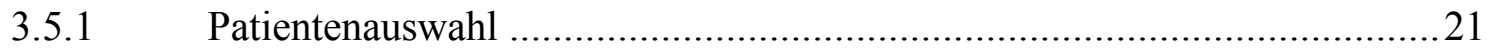

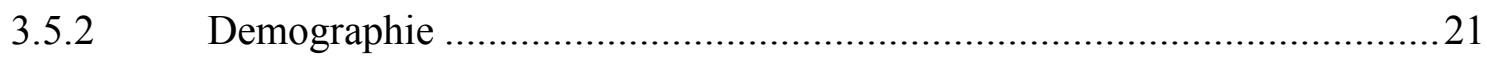

3.5.3 Fragebögen zur Lebensqualität der EORTC …..................................... 22

3.6 Management der Tumorpatienten ........................................................... 25

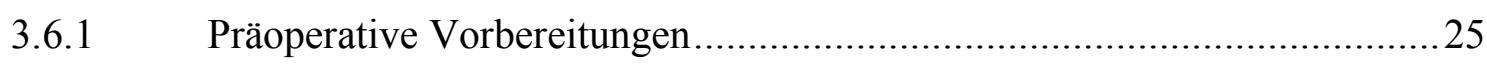

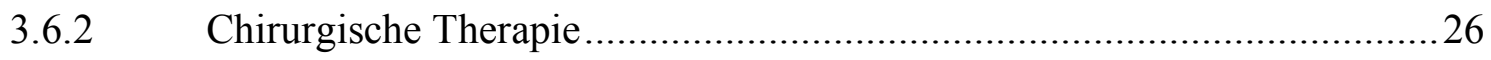

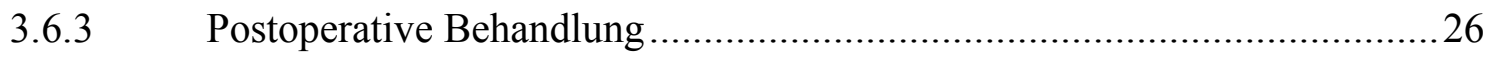

Postoperative Überwachung auf der Intensivstation................................26

Verbandswechsel und Wundpflege..................................................26

Postoperative Funktionsevaluation und ,Schlucktraining“......................26

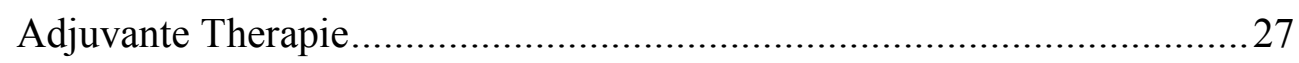

Nachstationäre Betreuung ............................................................. 27

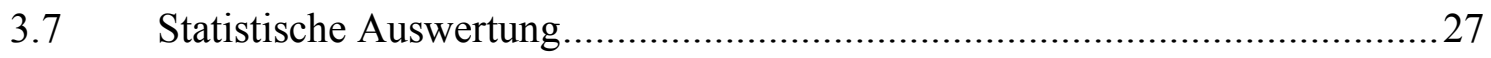

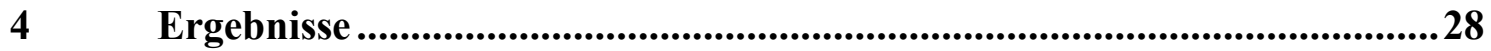

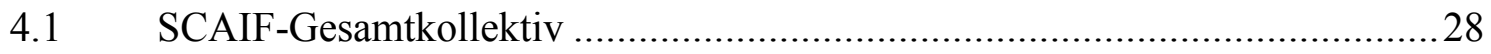

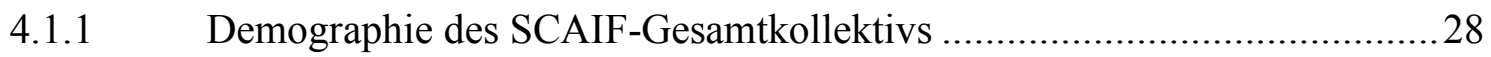

4.1.2 Perioperative Daten und Personalkosten des SCAIF-Gesamtkollektivs...... 31

4.1.3 Postoperative Morbidität: Schluckfunktion und Komplikationen der Spender-

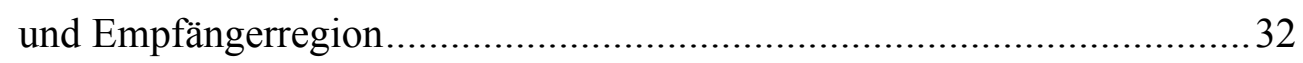

4.1.4 Outcome: Kaplan-Meier-Schätzer-Überlebenskurven............................... 34

4.2 Analyse der prä-, peri- und postoperativen Daten: Vergleich des SCAIFs mit

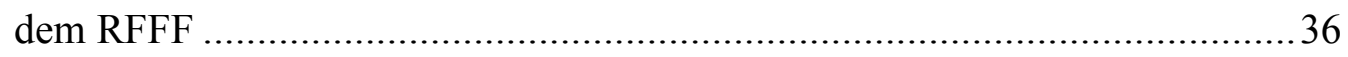

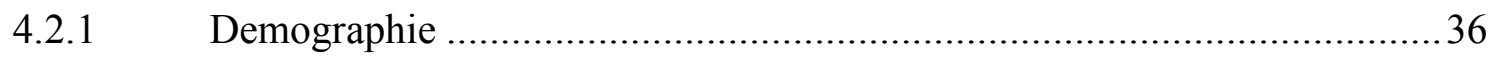

4.2.2 Perioperative Daten Vergleich SCAIF- versus RFFF-Gruppe .................... 38

4.2.3 Kostenkalkulation Vergleich SCAIF- versus RFFF-Gruppe ....................... 39

4.2.4 Postoperative Morbidität: Komplikationen der Spender- und Empfängerregionen.................................................................. 40 


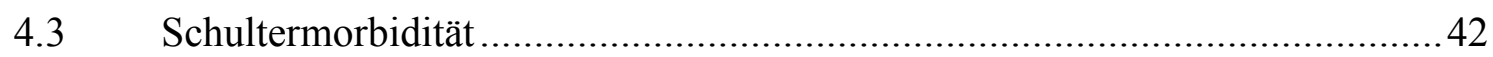

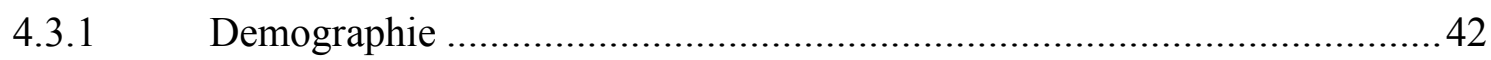

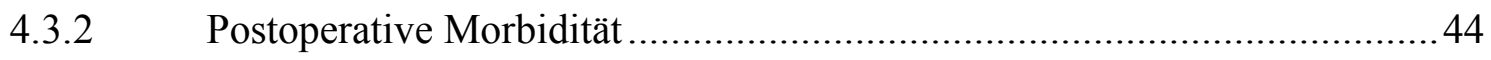

Komplikationen, N. accessorius und Affektion der dominanten Extremität44 Schultermorbidität....................................................................... 44

4.4 Analyse der Lebensqualität im Vergleich SCAIF versus RFFF .....................50

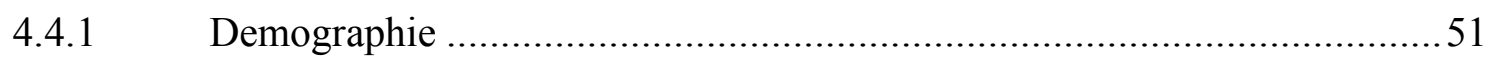

4.4.2 Auswertung der Lebensqualitätsfragebögen .......................................53

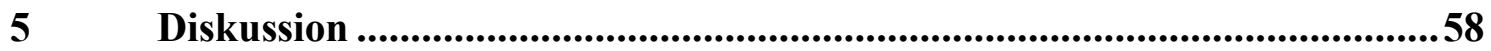

5.1 Analyse der prä-, peri- und postoperativen Daten: SCAIF versus RFFF .........59

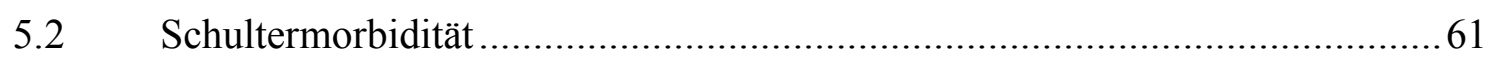

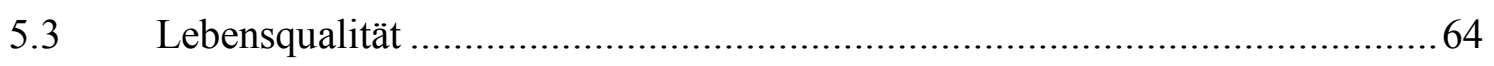

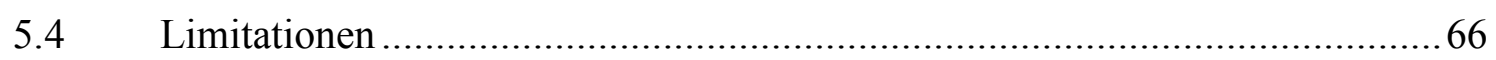

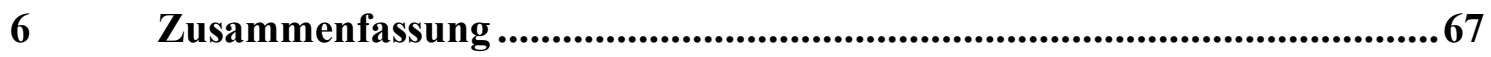

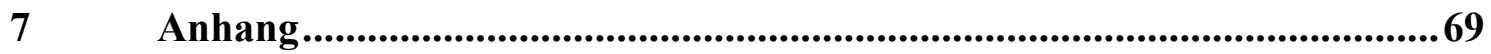

$8 \quad$ Literaturverzeichnis............................................................70 


\section{Abbildungsverzeichnis}

Abbildung 1: Topographie der A. supraclavicularis. 6

Abbildung 2: Präparationstechnik des SCAIFs. .................................................... 8

Abbildung 3: Kaplan-Meier-Schätzer Überlebenskurve der SCAIF-Patienten............... 35

Abbildung 4: SCAIF versus RFFF, Vergleich der Operationszeiten............................ 39

Abbildung 5: Kostenanalyse, Vergleich SCAIF versus RFFF ................................. 40

Abbildung 6: Gesamter Constant-Murley-Score, Vergleich Spender- zur Gegenseite .. 45

Abbildung 7: Schmerzempfindung, Vergleich Spender- zur Gegenseite ..................... 46

Abbildung 8: Kraft, Vergleich Spender- zur Gegenseite ........................................ 47

Abbildung 9: DASH-Score der Spenderschulter .................................................... 50

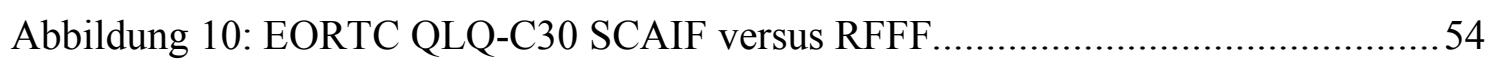

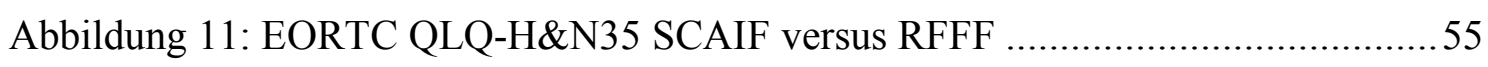




\section{Tabellenverzeichnis}

Tabelle 1: Epidemiologische Kennzahlen für bösartige Kopf-Halstumoren. 1

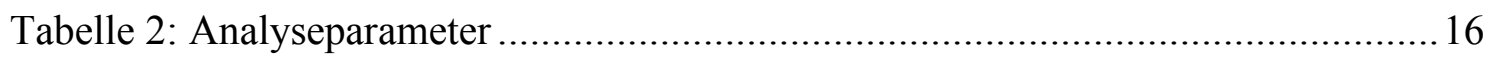

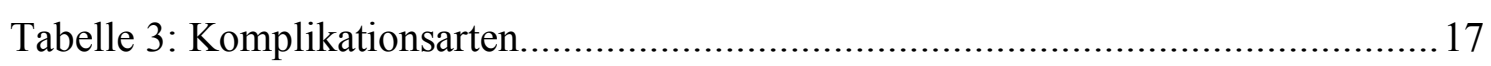

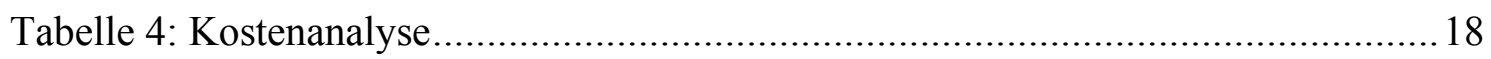

Tabelle 5: Analyseparameter des Constant-Murley-Scores .......................................20

Tabelle 6: Analyseparameter des Fragebogens QLQ-C30 Version 3.0 der EORTC.....23

Tabelle 7: Analyseparameter des Fragebogens QLQ-H\&N35 der EORTC ..................24

Tabelle 8: SCAIF-Gesamtkollektiv Demographie................................................ 29

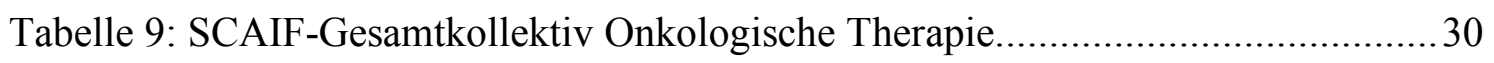

Tabelle 10: SCAIF-Gesamtkollektiv vorangegangene Therapie.................................. 30

Tabelle 11: SCAIF-Gesamtkollektiv Perioperative Daten ........................................ 31

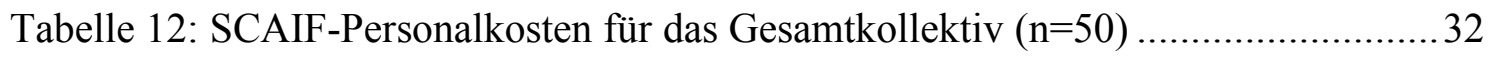

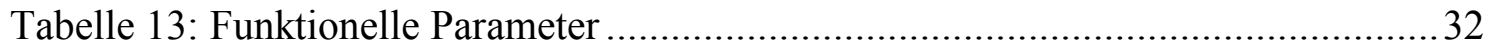

Tabelle 14: SCAIF-Komplikationen der Spender- und Empfängerregion...................... 34

Tabelle 15: SCAIF versus RFFF ökonomische Analyse; Demographie und Verlauf.... 37

Tabelle 16: SCAIF versus RFFF ökonomische Analyse; Sublokalisationen ................... 37

Tabelle 17: SCAIF versus RFFF ökonomische Analyse; Perioperative Daten .............. 38

Tabelle 18: SCAIF versus RFFF: Komplikationen der Empfängerregion.................... 41

Tabelle 19: SCAIF versus RFFF: Komplikationen der Spenderregion ....................... 42

Tabelle 20: SCAIF-Schultermorbidität; Demographie .......................................... 43

Tabelle 21: SCAIF-Schultermorbidität; Komplikationen ...................................... 44

Tabelle 22: SCAIF-Schultermorbidität; Funktionalität............................................ 44

Tabelle 23: SCAIF-Schultermorbidität; Bewegungsumfang .................................. 48

Tabelle 24: SCAIF-Schultermorbidität; Alltägliche Aktivitäten................................ 49

Tabelle 25: SCAIF versus RFFF Lebensqualität; Demographie ................................ 52

Tabelle 26: SCAIF versus RFFF Lebensqualität; Tumorlokalisationen........................53

Tabelle 27: SCAIF versus RFFF: EORTC QLQ-C30 und EORTC QLQ-H\&N35........56

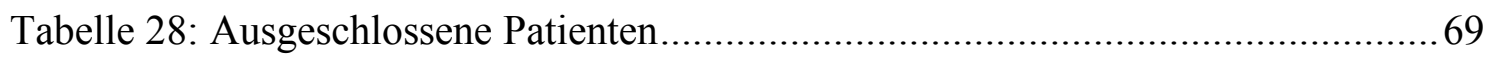




\section{Abkürzungsverzeichnis}

\begin{tabular}{|c|c|}
\hline A. & Arteria-Arterie \\
\hline AJCC & American Joint Committee on Cancer \\
\hline ALT & anterior lateral thigh flap - anterolateraler Oberschenkellappen \\
\hline BWK & Brustwirbelkörper \\
\hline $\mathrm{CO}_{2}$ & Kohlenstoffdioxid \\
\hline $\mathrm{CT}$ & Computertomographie \\
\hline DASH & Disabilities of the Arm, Shoulder and Hand Outcome Measure \\
\hline EBV & Epstein-Barr Virus \\
\hline ECE & extracapsular extension - extrakapsuläre Ausbreitung \\
\hline EORTC & European Organisation for Research and Treatment of Cancer \\
\hline GEKID & Gesellschaft der epidemiologischen Krebsregister in Deutschland e.V. \\
\hline $\mathrm{HNO}$ & Hals-Nasen-Ohrenheilkunde \\
\hline HPV & Humanes Papillomavirus \\
\hline LWK & Lendenwirbelkörper \\
\hline M. & Musculus - Muskel \\
\hline $\max$. & maximal \\
\hline MKG & Mund-Kiefer-Gesichtschirurgie \\
\hline N. & Nervus - Nerv \\
\hline PECA & Plattenepithelkarzinom \\
\hline PEG & perkutane endoskopische Gastrostomie \\
\hline PMF & pectoral muscle flap - gestielter Pectoralislappen \\
\hline RFFF & $\begin{array}{l}\text { radial free forearm flap - freies Gewebetransplantat von der } A \text {. } \\
\text { radialis }\end{array}$ \\
\hline RCT & Radiochemotherapie \\
\hline RKI & Robert Koch-Institut \\
\hline RT & Radiotherapie \\
\hline SCAIF & $\begin{array}{l}\text { supraclavicular artery island flap - gestielter supraklavikulärer } \\
\text { Insellappen }\end{array}$ \\
\hline SD & standard deviation - Standardabweichung \\
\hline TLM & Transorale Lasermikrochirurgie \\
\hline TNM & tumor, nodus, metastasis - Tumor, nodaler Status, Fernmetastasen \\
\hline TORS & transoral robotic surgery - transorale Robotor-assistierte Chirurgie \\
\hline UICC & Union for International Cancer Control \\
\hline UMG & Universitätsmedizin Göttingen \\
\hline V. & Vena - Vene \\
\hline VAC & vacuum-assisted closure \\
\hline
\end{tabular}




\section{$1 \quad$ Einleitung}

\subsection{Kopf- Hals-Karzinome}

\subsubsection{Epidemiologie}

Bösartige Tumoren der oberen Luft- und Speisewege stehen derzeit in Deutschland an sechster Stelle aller Krebserkrankungen. Im Allgemeinen sind mehr Männer als Frauen betroffen. Die von der Gesellschaft der epidemiologischen Krebsregister in Deutschland e. V. (GEKID 2016) veröffentlichten Zahlen für das Jahr 2013 zeigen eine Inzidenzrate von 18,8 für männliche und 6,0 für weibliche Neuerkrankungen auf 100.000 Einwohner im Jahr 2013 für Malignome im Mund-Rachenbereich. Bei Larynxalignomen waren es 5,3 Männer und 0,8 Frauen auf 100.000 Einwohner (GEKID 2016). Die Zahlen für absolute Neuerkrankungen, mittlere Erkrankungsalter, Sterbefälle, mittleres Sterbealter, sowie 5- und 10-Jahresüberleben können aus Tabelle 1 entnommen werden (Zentrum für Krebsregisterdaten 2016). Über die letzten 15 Jahre haben sich die Morbiditäts- und Mortalitätsraten für Mundhöhlen- und Rachenmalignome nicht wesentlich verändert. Bei Frauen zeigte sich eine in der Tendenz steigende Inzidenz, und bei Männern ein diskreter Rückgang der Mortalität. Patienten mit einem Kopf-Hals-Karzinom im Frühstadium machen etwa 30-40\% aus und haben ein 5-Jahresüberleben von 70-90\% (Robert KochInstitut 2016).

Tabelle 1: Epidemiologische Kennzahlen für bösartige Kopf-Halstumoren. Epidemiologie 2012/2013, Bericht über das Krebsgeschehen in Deutschland 2016, Robert Koch-Institut (Robert Koch-Institut 2016).

\begin{tabular}{lrl}
\hline & Frauen & Männer \\
\hline Neuerkrankungen (n) & 4.532 & 12.992 \\
Mittleres Erkrankungsalter (a) & 66,2 & 63,8 \\
Sterbefälle (n) & 1.698 & 5.494 \\
Mittleres Sterbealter (a) & 71,0 & 65,4 \\
5-Jahresüberleben (\%) & 61 & 51 \\
10-Jahresüberleben (\%) & 50 & 39 \\
\hline
\end{tabular}




\subsubsection{Histologie: Plattenepithelkarzinome und ihre Risikofaktoren}

Histopathologisch handelt es sich bei Kopf-Hals-Karzinomen in mehr als 90\% um Plattenepithelkarzinome (Friemel et al. 2016); (Parfenov et al. 2014). Als Hauptrisikofaktoren für die Entstehung von Plattenepithelkarzinome spielen langjähriger Nikotin- und Alkoholkonsum eine entscheidende Rolle (Ihrler und Weiler 2009); (Ahrens et al. 2014), (Bunnell et al. 2010); (Warnakulasuriya 2009), wobei vor allem beim Nikotinkonsum die Dauer der Exposition im Vordergrund steht (Lubin et al. 2009). Für einen Teil der Oropharynxkarzinome, teilweise bis zu 60\%, gilt die transformierende Wirkung des humanen Papilloma-Virus (HPV) als gesicherte Genese. Studien haben ergeben, dass etwa 25\% aller Kopf-Halskarzinome durch HPV ausgelöst werden (Dayyani et al. 2010); (Ihrler und Weiler 2009); (Mork et al. 2001); (Strome et al. 2002). Zudem scheint eine schlechte Mundhygiene das Risiko für die Entstehung von Plattenepithelkarzinomen in der Mundhöhle signifikant zu erhöhen. (Ahrens et al. 2014); (Friemel et al. 2016); (Chang et al. 2013); (Eliot et al. 2013); (Meurmann 2010).

\subsubsection{Prognostische Faktoren}

Bei Plattenepithelkarzinomen reicht die Einteilung der Differenzierung von gut differenziert (G1) bis undifferenziert (G4), wobei etwa 90\% der invasiven Plattenepithelkarzinome im oberen Aerodigestivtrakt mit einem G2-Grading bestimmt werden. Je geringer der histopathologische Differenzierungsgrad, desto schlechter ist die Prognose des Patienten. Neben dem Tumordurchmesser spielen die Infiltrationstiefe und das Tumorvolumen eine prognostische Rolle (Plataniotis et al. 2004; Woolgar 2006). Die lokale Kontrolle und Entscheidung zur adjuvanten postoperativen Therapie ist abhängig vom Resektionsstatus und beeinflusst ebenfalls die Prognose.

Als weitere Faktoren gelten der Nachweis von Angioinvasion von Lymph- und Blutgefäßen als prognostisch ungünstig und korrelieren mit einer hohen Rate an lymphogener und hämatogener Metastasierung. Ebenso hat sich der Nachweis einer Perineuralscheideninvasion als negativer Prognosefaktor etabliert, welcher mit einer erhöhten Rate an lokoregionären Rezidiven und Fernmetastasen einhergeht (Woolgar 2006). Bei Vorliegen einer extrakapsulären Infiltration von Lymphknotenmetastasen ist sowohl die Rate an Lokalrezidiven als auch die Häufigkeit von Fernmetasen erhöht (Greenberg et al. 2003). 
Es ist bekannt, dass die Prognose vom Tumorstadium abhängt. Je größer der Tumor (T04) oder das Halslymphknotenstadium (N0-3), desto schlechter die Prognose. Bei primärer Fernmetastasierung ergibt sich eine eingeschränkte Überlebensrate von deutlich unter einem Jahr. Die UICC gibt eine Stadieneinteilung vor, welche sich an der Prognose orientiert (Amin et al. 2017).

\subsubsection{Einteilung und Tumorklassifikation}

Die Einteilungssystematik der Kopf-Halsmalignome erfolgt nach der TNMKlassifikationen der American Joint Committee on Cancer (AJCC) und der Union for International Cancer Control (UICC) (Amin et al. 2017). „, $\mathrm{T}^{“}$ (tumor) beschreibt die Tumorausdehnung des Primärtumors und ist Regionen spezifisch, „N“ (nodus) den Halslymphknotenstatus und „M““ (metastasis) das Vorliegen von Fernmetastasen.

\subsubsection{Therapie}

Das Therapiekonzept wird im Rahmen einer multidisziplinären Herangehensweise festgelegt. Das Votum dieser Tumorkonferenz legt unter Berücksichtigung von Tumorlokalisation, Tumorausdehnung, individuellen Faktoren (wie Alter, Komorbiditäten, persönliche Behandlungswünsche) und funktionellen sowie Morbiditätsaspekten das offizielle klinische TNM-Stadium und weitere therapeutische Prozedere der Patienten fest. Eine interdisziplinäre Entscheidungsfindung beeinflusst therapeutische Ergebnisse signifikant (Fleissig et al. 2006); (Stalfors und Westin 2007); (Westin und Stalfors 2008); (Wheless et al. 2010). Die meisten HNO-Abteilungen verfügen über ein Tumorregister, spezielle Tumorsprechstunden, interdisziplinäre Tumorboards, onkologische Studien und Evaluation der Lebensqualität (Kimmeyer 2016).

Die Wahl der jeweiligen Therapie hängt von der Tumorlokalisation, Zugänglichkeit und der assoziierten Morbidität und posttherapeutischen Funktionalität ab. Minimal invasive Techniken, wie die transorale Lasermikrochirurgie (transoral laser microsurgery - TLM) für die Behandlung von Hypopharynx- und Larynxkarzinomen konnten funktionelle Ergebnisse substantiell verbessern und Morbiditätsraten senken (Weiss et al. 2017). Insgesamt wird ein multimodales Therapiekonzept (Tumorresektion mit adjuvanter Radiotherapie (RT) oder kombinierten Radiochemotherapie (RCT)) favorisiert, welches vor allem in der Behandlung von fortgeschrittenen Kopf-Halskarzinomen eingesetzt wird. 
Dadurch wird die Wahrscheinlichkeit für ein langfristiges tumorfreies Überleben signifikant erhöht (Furness et al. 2010); (Pignon et al. 2009). Konservative Therapiekonzepte werden bei älteren Patienten oder Patienten mit eingeschränktem Allgemeinzustand sowie inoperablen oder ausgedehnten Befunden, bei denen kein akzeptables funktionelles Ergebnis zu erwarten ist bevorzugt. (Pignon et al. 2009). Zur Behandlung von Halslymphknotenmetastasen ist eine Neck Dissection (ND) indiziert, korrespondierend mit der TNM-Klassifikation mit anschließender adjuvanter Behandlung. Bei Patienten mit Restbefunden nach erfolgter primärer RT oder RCT muss die Möglichkeit einer Salvagechirurgie diskutiert werden. Bei Vorliegen von Fernmetastasen werden Therapiemodalität wie palliative Chemotherapie, Immuntherapie und/oder supportive Therapie angewandt (Gedlicka et al. 2002); (Langer et al. 2004); (Schöffski et al. 1999); (Shin et al. 2001); (Vermorken et al. 2008).

\subsection{Gewebetransfer in der rekonstruktiven Kopf-Hals-Chirurgie}

Die Anwendung moderner Techniken, wie der TLM, ermöglicht eine präzise Resektion der Tumoren mit maximaler Schonung nicht-befallener, für den Erhalt von Funktion und Ästhetik bedeutender Schleimhaut. Dennoch entstehen abhängig von der Tumorausdehnung derart große Defekte, dass postoperativ insbesondere Sprech- und Schluckfunktion erheblich beeinträchtigt sein können. In diesen Fällen müssen die Tumordefekte durch rekonstruktive Techniken gedeckt werden, um die Funktion wiederherzustellen.

Dafür ist das Wissen und Handhabung der vollen Bandbreite von Rekonstruktionsmöglichkeiten notwendig. Dies reicht von einfachen lokalen Plastiken bis zu freien Fernlappenplastiken. Je nach Größe und anatomischer Lage werden unterschiedliche Rekonstruktionstechniken bevorzugt (Gurtner und Evans 2000). Traditionelle Techniken, wie lokale Lappen oder Transplantate, werden für kleine kutane oder mukosale Defekte verwendet. Autogene Rekonstruktionen mit einem gestielten oder freien Gewebelappen werden bei größeren, komplexen Defekten nach Trauma oder chirurgischer Intervention angewandt. Diverse Studien konnte eine solide Blutversorgung freier Gewebetransplante beobachten, die somit mit einer besseren Wunddeckung einhergehen (Ariyan 1979); (Gurtner und Evans 2000). Als derzeitiger Goldstandard zur Deckung größerer Defekte in der rekonstruktiven Kopf-Hals-Chirurgie gilt das freie 
radiale Unterarmtransplantat (radial free forearm flap = RFFF) (Mühlbauer et al. 1982); (Gurtner und Evans 2000); (Hurvitz et al. 2006). Hierbei handelt es sich um ein fasziokutanes Transplantat, welches von der A. radialis gespeist wird. Die Arterie wird präpariert, abgesetzt und mikrochirurgisch mit einem Anschlussgefäß im Halsbereich anastomosiert.

In manchen Fällen kann auf Grund von Komorbiditäten, eingeschränktem Gefäßstatus oder anatomischen Abnormitäten ein RFFF nicht angewandt werden. Dann können diverse gestielte Gewebelappen als Alternativoption eingesetzt werden (Gurtner und Evans 2000); (Hurvitz et al. 2006). Gestielte Präparate haben den Vorteil, dass keine Notwendigkeit zur mikrovaskulären Anastomose besteht, was somit kürzere Hebe- und Einnahtzeiten zur Folge hat. Trotz dieser Vorteile wird von einer höheren Inzidenz von partieller Nekrose, Dehiszenzen und Fistelbildung berichtet (Heth et al. 2002); (Mehta et al. 1996); (Tsue et al. 1997). Besonders häufig wurde in der letzten Dekade der gestielte Pectoralis-Major-Lappen (pectoral muscle flap - PMF) bei Kopf-Halsdefekten verwendet. Dieser ist jedoch auf Grund seiner Dicke und des verhältnismäßig kurzen Stiels nur begrenzt einsetzbar (Granzow et al. 2013a).

Der axial gestielte Gewebelappen der A. supraclavicularis (supraclavicular island flap= SCAIF) hat sich in den letzten Jahren als sehr praktikable Alternative erwiesen und wurde bisher für der Rekonstruktion von sternalen, zervikalen, oromandibulären und posterolateralen Schädelbasis- und Pharynxwanddefekten verwendet (Anand et al. 2011); (Chiu et al. 2009); (Emerick et al. 2014); (Granzow et al. 2013a); (Welz et al. 2017). Die Präparation ist verhältnismäßig unkompliziert und benötigt keine Resektion größerer nervaler Strukturen. Somit kann der N. accessorius geschont werden, und es müssen lediglich kleine supraklavikuläre Hautäste bei der Lappenhebung durchtrennt werden.

\subsection{Das gestielte supraklavikuläre Gewebetransplantat}

\subsubsection{Grundlagen und Entwicklung des Gewebetransplantats}

Im Jahre 1979 beschrieb Lamberty als Erster den SCAIF als einen axial gestielten Lappen (Lamberty 1979). Während der achtziger und neunziger Jahre wurde diese Rekonstruktionstechnik auf Grund hoher Inzidenz von Nekrosen und schlechter Funktionsfähigkeit zunächst wenig verwendet. Zudem war die Durchführung des PMFs und RFFFs sehr verbreitet (Blevins und Luce 1980). Für die Behandlung von mentosternalen Kontrakturen nach Verbrennungen verwendeten Pallua et al. in den 90er- 
Jahren eine ähnliche Schulterlappenplastik und erweiterten die Indikation auf den rekonstruktiven onkologischen Bereich (Pallua et al. 1996); (Pallua und Noah 1999). Ab den frühen 2000er-Jahren gewann die Technik durch Veröffentlichungen wie von Di Benedetto (Di Benedetto et al. 2005) oder (Granzow et al. 2013a) mehr an Beliebtheit.

\subsubsection{Anatomie}

Der axial gestielte supraklavikuläre Insellappen wird von der A. supraclavicularis gespeist und entspringt in etwa 93\% der Fälle aus der A. transversa cervicis und in 7\% aus der A. suprascapularis. Der Abgang liegt unterhalb des Venter inferior des $M$. omohyoideus und versorgt das supraklavikuläre Fettpolster.

\section{Abbildung 1: Topographie der A. supraclavicularis.}

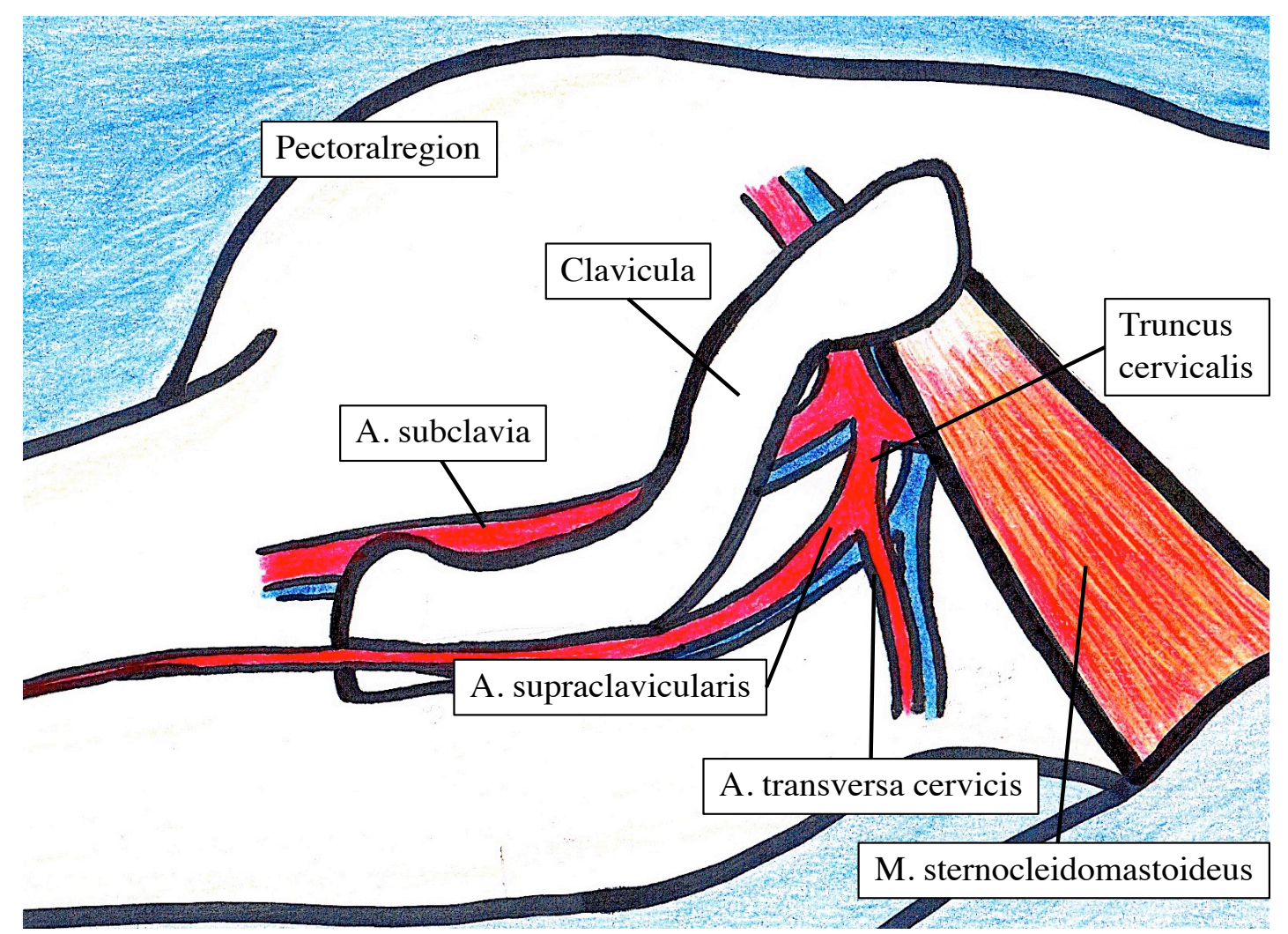

A. $=$ Arteria $;$ SCAIF $=$ supraclavicular artery island flap;

Im Mittel beträgt der Durchmesser der A. supraclavicularis 1,0 bis 1,5 mm und dieses erreicht die tiefe Faszie direkt dorsal des medialen oder mittleren Drittels der Clavicula. Danach verläuft die Arterie unmittelbar lateral des Acromioklavikulargelenks, wo sie sich in ihre Äste aufteilt. Die Äste verlaufen oberhalb des M. deltoideus und anastomosieren mit den kutanen Ästen der A. circumflexa humeri posterior. Während des Großteils des 
Verlaufes liegt das Gefäß meist der Ebene der tiefen Faszie. Sie durchbricht die tiefe Muskelfaszie ventral des M. trapezius, oberhalb der Clavicula und verläuft danach direkt superfiziell des lateralen Clavicula-Drittels.

\subsubsection{Hebetechnik}

Zur Vorbereitung der Lappenhebung wird zunächst die benötigte Länge am Defekt ausgemessen. Danach erfolgt das Anzeichnen der anatomischen Landmarken: Clavicula, M. sternocleidomastoideus und der dorsale Rand des M. trapezius. Nach typischer anatomischer Lage findet sich die A. supraclavicularis (siehe Abbildung 1) in einem Dreieck, welches von der Clavicula, Hinterrand des M. sternocleidomastoideus und $V$. jugularis externa gebildet wird. Mit einem Dopplersonographiegerät wird der Gefäßstiel aufgesucht, in 1-2 cm-Schritten nach lateral verfolgt und markiert. Um eine ausreichende Versorgung des Lappens zu gewährleisten, kann die Transplantatlänge maximal $5 \mathrm{~cm}$ distal des zuletzt doppler-sonographisch detektierten Punkt betragen (siehe Abbildung 2). Ein Primärverschluss ist bei Transplantatbreiten bis $\mathrm{zu} 7-8 \mathrm{~cm}$ ohne Komplikationen möglich (Granzow et al. 2013b). Nach der subfaszialen Präparation des Transplantates wird ein zervikaler Hauttunnel gebildet. Es empfiehlt sich, den Gefäßstiel in Fett eingebettet zu lassen, um ein Abknicken des Stiels zu verhindern. Je nach Notwendigkeit wird die benötigte Fläche deepithelialisiert, an die entsprechende Defektstelle eingeschlagen und zum Teil mit Vorlegenähten eingebracht (Bruchhage et al. 2017); (Giordano et al. 2016); (Granzow et al. 2013a).

Die Spenderregion anterior und posterior des Defekts wird mobilisiert und nach Einlage von zwei bis drei Redondrainagen primär verschlossen. Die Schulterregion wird final mit einem Druckverband versorgt. Im Bereich des Stiels werden weder Drainagen noch ein Verband angelegt, um unnötigen Druck auf den Stiel und die daraus resultierenden Minderperfusion des Lappens zu vermeiden. 
Abbildung 2: Präparationstechnik des SCAIFs.

(A) Anzeichnen der Landmarken, Aufsuchen des Abgangs der A. supraclavicularis und Doppler-sonographisches Verfolgen der Arterie. (B) Ausmessen der benötigten Transplantatlänge. (C) Fertige Anzeichnung der Landmarken und des Transplantats. (D) Präpariertes Transplantat nach Deepithealisierung.
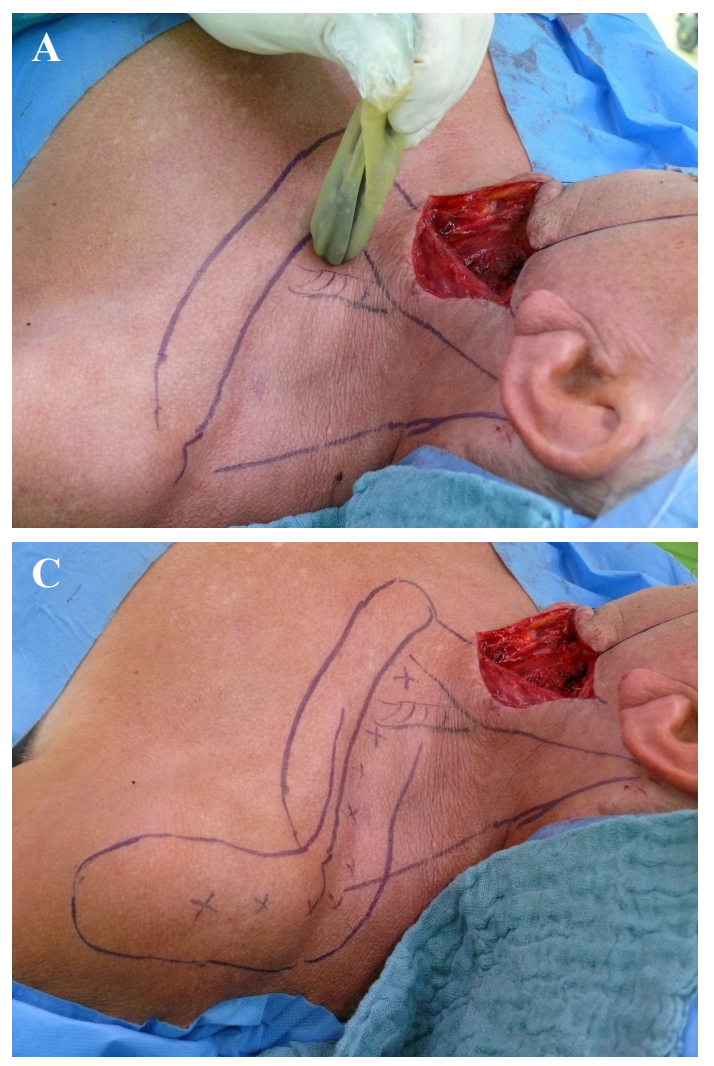

A. $=$ Arteria $; \mathrm{SCAIF}=$ supraclavicular artery island flap;
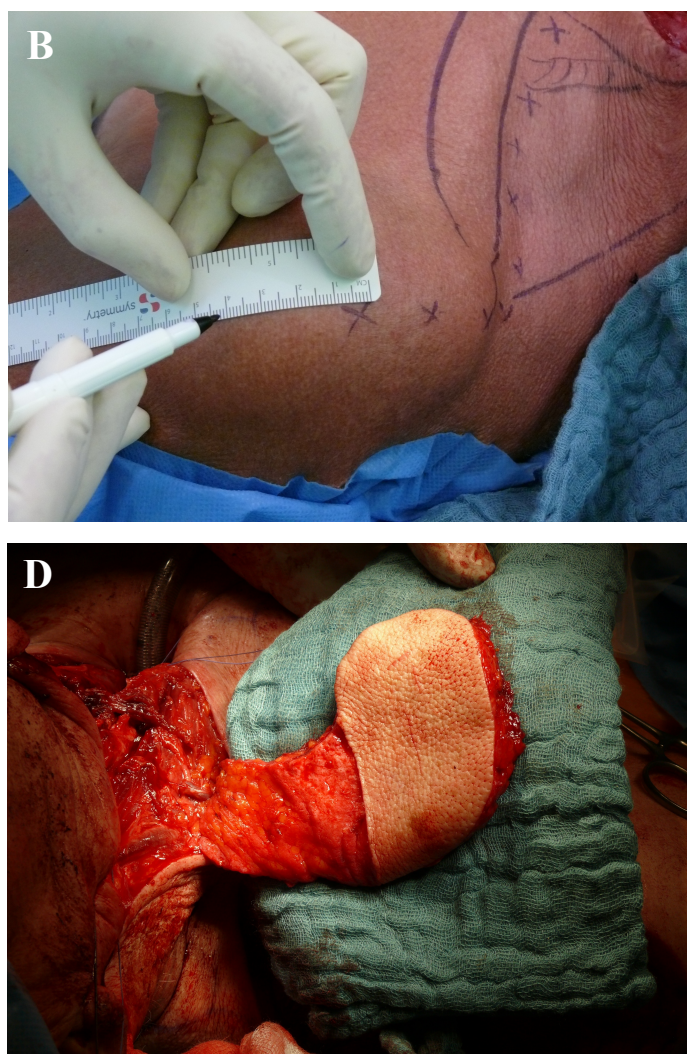

\subsubsection{Anwendungsgebiete}

Das breite Anwendungsgebiet des SCAIF umfasst die Rekonstruktion von thorakalen und fazialen Defekten (Epps et al. 2011); (Giordano et al. 2016); (Kozin, et al. 2016), inklusive Kontourdeformitäten im Bereich der Parotis (Ver Haalen, et al. 2010); (Giordano et al. 2016); (Kozin, et al. 2016); (Bertelsen et al. 2017) Behandlung von mentosternalen Kontrakturen (Ver Haalen et al. 2010), Rekonstruktion von Defekten der Pharynxhinterwand (Chiu et al. 2009); (Chiu et al. 2010); (Giordano et al. 2016); (Kozin et al. 2016); (Welz et al. 2017) und Defektrekonstruktion nach Hemiglossektomien (Granzow et al. 2013b); (Giordano et al. 2016); (Welz et al. 2017).

Eine relative Kontraindikation für eine Rekonstruktion mit dem SCAIF besteht bei Z. $\mathrm{n}$. Radiotherapie im Bereich des vaskulären Stiels (Granzow et al. 2013a). 


\subsection{Postoperative Morbidität}

\subsubsection{Postoperative Komplikationen}

Die Langzeitmorbidität im Bereich der Spenderregion ist einer der wichtigsten Faktoren, der vor dem Entschluss zur Rekonstruktionstechnik berücksichtigt werden sollte. Verschiedene Studien untersuchten die Morbidität der Spenderregion für die einzelnen Lappentechniken, die zur Rekonstruktion von Defekten bei der Tumorresektion von Kopf-Halskarzinomen angewendet werden. Insbesondere wurden die etablierten Techniken, wie der PMF, der Deltopectoralislappen, der Trapeziuslappen und mikrovaskuläre Transplantate, wie der RFFF oder der anterolaterale Oberschenkellappen (anterior lateral thigh flap - ALT), untersucht (Bardsley et al. 1990); (Brown et al. 2014); (Brown et al. 1999); (Hekner et al. 2013); (Bonaparte et al. 2001); (Cappiello et al. 2005); (Orlik et al. 2014); (Refos et al. 2016); (Richardson et al. 1997); (Shah et al. 1990); (Skoner et al. 2003). Studien, die Komplikationsraten nach SCAIF-Operation untersuchten, konnten geringe Komplikationsraten mit geringer Mortalität und Infektionsraten zeigen (Emerick et al. 2014); (Granzow et al. 2013a); (Chiu et al. 2009); (Giordano et al. 2014); (Giordano et al. 2016); (Goyal et al. 2016); (Kozin et al. 2016). Die Unterteilung der Komplikationen erfolgt meist in geringgradige (= minor) und höhergradige (= major) Komplikationen. Minor-Komplikationen kommen anhand konservativen Maßnahmen zur Abheilung. Dahingegen benötigen MajorKomplikationen eine chirurgische Intervention. Es ist bekannt, dass kardiovaskuläre Risikofaktoren und Rauchen den Wundheilungsprozess negativ beeinflussen (Pluvy et al. 2015a); (Pluvy et al. 2015b).

\subsubsection{Schulterfunktion und Sensibilität}

Die Objektivierung der Schulterfunktion erfolgt durch Messung von Bewegungsumfang und Kraftprüfung (Strome et al. 2002). In der Schulterregion verlaufen viele Nerven, welche im Schulter- und Armbereich eine sowohl motorische als auch sensible Funktion innehaben. Motorische Nerven, aus dem Plexus brachialis stammend, verlaufen muskelnah in der Tiefe. Dahingegen zeigen die sensiblen Nn. supraclaviculares einen sehr oberflächlichen Verlauf. Über den genauen Verlauf der Nn. supraclaviculares anhand anatomischer Landmarken ist auf Grund einer hohen Variabilität nicht viel bekannt. Somit ist eine Durchtrennung dieser Hautäste bei der Präparation des SCAIF 
kaum vermeidbar. Eine Schonung der motorischen Nerven gelingt durch die profunde anatomische Lage derselben (Drake 2009); (Havet et al. 2007); (Nathe et al. 2011). Insgesamt ist die Präparation des SCAIFs jedoch schonend und resultiert somit in einer geringgeradigen funktionellen Einschränkung mit Erhalt der Kraft und des Bewegungsausmaßes (Herr et al. 2014).

Das Auftreten von Phantomschmerzen und -sensibilitäten nach rekonstruktiven Lappenoperationen wurde bisher nur in wenigen Studien untersucht und kontrovers diskutiert (Giummarra et al. 2007). In einer Studie mit 50 Patienten von Sandu et al. (Sandu et al. 2012) wurde bereits von Empfindungen im Bereich der Schulter berichtet, wenn die Hautinsel berührt wurde, oder auch beim Essen. Granzow et al. dahingegen konnten keine Empfindungen beobachten (Granzow et al. 2013a). Da der SCAIF sehr oberflächlich der Muskeln präpariert wird, kann es durch die subkutane und kutane Narbenbildung zu Adhäsionen im Bereich des M. deltoideus und trapezius kommen. Diese Adhäsionen sowie die partielle Fibrosierung der darunterliegenden Muskeln können zu Einschränkungen in der Schultermobilität führen und das Risiko für eine adhäsive Kapsulitis und myofasziale Schmerzen erhöhen (Bradley et al. 2011).

\subsubsection{Lebensqualität}

Das primäre Ziel der chirurgischen Therapie ist die vollständige Entfernung des Tumors im Gesunden, um so die bestmöglichen Voraussetzungen für ein tumorfreies Überleben zu schaffen. In den letzten Jahren gewinnt jedoch auch die Lebensqualität des Patienten immer mehr an Bedeutung und fließt in das multimodale Therapiekonzept ein (Chandu et al. 2006).

Die World Health Organization (WHO) definiert Lebensqualität als „die Wahrnehmung eines Individuums ihrer Position im Leben im Zusammenhang mit Kultur- und Wertsystemen, in denen sie [Individuen] leben, in Kombination mit ihren Zielen, Erwartungen, Standards und Angelegenheiten“ (WHO 1997). Die Bedeutsamkeit der Lebensqualität wird zunehmend registriert und heutzutage als ein wichtiger weiterer Endpunkt eingesetzt, gemeinsam mit Ansprech- und Überlebensrate (Heutte et al. 2014); (So et al. 2012).

Die Anwendung einer kombinierten multimodalen Therapie, welche, wie oben bereits erwähnt, die Tumorresektion, Chemotherapie und Strahlentherapie umfasst, erreichte in den letzten Jahren eine steigende lokoregionäre Kontrolle von Kopf-Halstumoren und hatte funktionell einen großen Einfluss (Murphy 2009); (Murphy et al. 2007). Kopf-Hals- 
Malignome wachsen in einer strukturell sehr komplexen und funktionell wichtigen Region. Einschränkungen innerhalb dieser Region sowohl durch die Erkrankung selbst als auch durch die Behandlung können grundlegende Funktionen, wie das Schlucken und Sprechen, beeinflussen und somit einen tiefgreifenden Einfluss auf die soziale Interaktionen und den psychischen Zustand eines Patienten haben (Melo-Filho et al. 2013).

Neben der vollständigen Tumorresektion steht somit die Wiederherstellung der ästhetisch funktionellen Integrität des Patienten im Vordergrund. Dies erfordert ein hohes Maß an plastisch-rekonstruktivem Wissen und der Fähigkeiten mit gegebenenfalls der Anwendung von freien oder gestielten Gewebetransplantaten zu Rekonstruktion der betroffenen Region und Wiederherstellung der Funktion. 


\section{$2 \quad$ Fragestellung}

Der SCAIF hat in der rekonstruktiven Kopf-Halstumorchirurgie innerhalb der letzten 10 Jahre immer mehr an Bedeutung erfahren. Mit dieser Rekonstruktionstechnik scheint es zu gelingen, die Vorteile von gestielten und freien Transplantaten zu vereinigen. Jedoch gibt es noch keine Untersuchungen zum Stellenwert des SCAIFs in der heutigen Rekonstruktionschirurgie.

Mit dieser Arbeit soll der Stellenwert des SCAIFs im Vergleich zur Goldstandardmethode, dem RFFF, in der rekonstruktiven Kopf-Halstumorchirurgie wissenschaftlich erarbeitet werden und anhand der folgenden Fragestellungen beurteilt werden:

- Wie ist der Therapieerfolg und die Einsetzbarkeit des SCAIFs im Vergleich zum RFFF einzuschätzen? Auswertung und Vergleich der prä-, peri- und postoperativen Daten, Komplikationen, Operationskosten und Intensivstationsaufenthalte.

- Wie hoch ist die postoperative Morbidität der Spenderregion nach SCAIFRekonstruktion? Vergleich der Schultermorbidität im Vergleich zur nicht operierten Seite hinsichtlich des Bewegungsumfangs, Schmerzempfindens, Kraft und Zurechtkommens im Alltag.

- Wie die Lebensqualität bei Patienten nach SCAIF- Operation im Vergleich zu Patienten nach RFFF-Rekonstruktion? 


\section{$3 \quad$ Methodik}

Die Studie basiert auf einer retrospektiven Analyse aller verfügbaren klinischen Daten über gestielte und freie Gewebetransplantate, welche im Zeitraum von Januar 2011 bis Mai 2017 im Bereich der HNO an der Universitätsmedizin Göttingen (UMG) stattgefunden haben. Das positive Votum der Ethikkommission der UMG lag seit 05.08.2015 dazu vor. Die Datenerhebung erfolgte aus klinikinternen Informationsplattformen und Patientenakten. Zur Untersuchung der Lebensqualität und Schulterfunktion wurden retrospektiv Fragebögen erstellt und ausgewertet. Dabei wurden die Datensätze mittels des Statistikprogramms $R$ Version 3.3.3 ( $R$ Foundation for Statistical Computing, Wien, Österreich) ausgewertet.

\subsection{Datenerhebung}

Als Datengrundlage diente eine Liste von Patienten, die an der Klinik und Poliklinik für HNO der UMG auf Grund einer Tumoroperation ein freies oder ein gestieltes Gewebetransplantat erhalten hatten. In eine Excel-Tabelle wurden alle patientenbezogenen Daten eingetragen.

\subsubsection{Datenbank der HNO-Klinik}

Patientendaten wurden aus den bereits bestehenden Datensätzen, den elektronischen und den Papierakten der HNO-Klinik der UMG bezogen. Vervollständigt wurden die Daten mit Informationen aus folgenden Quellen:

- ixserv:

Eine klinikinterne webbasierte Integrations- und Kommunikationsplattform; es wurden hieraus Daten zu Demographie und Tumorerkrankung akquiriert.

- WinOP/OPAS:

Das klinikinterne Operationsdokumentationsprogramm der UMG; hieraus wurden Daten zu den Operationszeiten und Operationspersonal erstellt;

- Tumorakten der HNO-Klinik:

Die daraus gesammelten Daten reichten von prä- und postoperativer Morbidität über perioperative Daten zu Operationszeiten und Transplantatgröße bis zu postoperativer Betreuung und Management 


\subsubsection{Fragebögen}

Zur Erfassung der postoperativen Morbidität wurden die Schulterfunktion und Lebensqualität der Patienten im Rahmen des stationären Primäraufenthaltes und der ambulanten Tumornachsorge retrospektiv evaluiert. Die Fragebögen wurden den Patienten im Rahmen der Tumornachsorgesprechstunde ausgehändigt. Patienten, die ihre Tumornachsorge heimatnah erhielten, wurden auf postalischem Wege kontaktiert.

\subsection{Patientenkollektiv und Parameter}

Eingeschlossen in die Analyse wurden konsekutiv alle Patienten, die im Rahmen eines kurativen onkologischen Therapiekonzepts zur rekonstruktiven Kopf-Halschirurgie mit einem SCAIF ab Januar 2011 versorgt wurden. Stichtag war hierbei der 31.05.2017. Zudem wurden Patienten eingeschlossen, die im Rahmen einer kurativen Therapie eines Plattenepithelkarzinoms des Oropharynx und der Mundhöhle zur Defektdeckung und Rekonstruktion einen RFFF erhielten.

Von der Auswertung ausgeschlossen wurden dahingegen RFFF-Patienten anderweitiger Tumorlokalisation und Techniken zur Defektdeckung, dem ALT, dem PMF oder dem Submentallappen. Des Weiteren schlossen wir Patienten aus, bei denen im Rahmen eines palliativen Therapiekonzepts eine Defektdeckung durchgeführt wurde und/oder kein Kopf-Halsmalignom vorlag (z. B. bei Larynxpapillomatose). Patienten, die letztlich nicht transplantiert wurden oder mehr als ein Gewebetransplant erhielten, wurden ebenfalls von der Auswertung ausgeschlossen. Eine detaillierte Auflistung der Gründe für den Ausschluss der einzelnen Patienten ist im Anhang (siehe Tabelle 28 im Anhang) dargestellt.

\subsection{Analyse der prä-, peri- und postoperativen Daten}

\subsubsection{Patientenauswahl}

Für die Auswertung hinsichtlich der prä-, peri- und postoperativen Daten erfolgte ein Vergleich zwischen SCAIF- und RFFF-Patienten. Einschlusskriterien waren fortgeschrittene Karzinome im Bereich des Oropharynx und der Mundhöhle (Stadium III und IV) sowie Operationen, die in einer kurativen Absicht durchgeführt wurden. Eingeschlossen wurden auch Patienten mit einem Zweitkarzinom, Rezidiv oder solche, die eine vorherigen Radiochemotherapie erhalten hatten. Patienten, die in einer 
Palliativsituation waren oder bei denen die Rekonstruktionsoperation nicht in kurativer Absicht durchgeführt wurde, wurden von der Auswertung ausgeschlossen. Insgesamt ergaben sich somit 50 Patienten, an denen jeweils bei 25 Patienten eine SCAIF-Operation oder eine RFFF-Operation durchgeführt worden war.

\subsubsection{Demographie}

Die ermittelten demographischen Daten wurden nach Alter, Geschlecht, Nebendiagnosen, Noxenanamnese mit Nikotin- und Alkoholkonsum sowie Indikation zur Lappenoperation unterteilt. Die Informationen zur Tumorerkrankungen gliederten sich in Histologie, Lokalisation und TNM-Klassifikation nach der siebten Version der UICC (Bierley et al. 2016). Ebenfalls analysiert, wurden a priori durchgeführte Operationen und Bestrahlung in der betroffenen Körperregion, das Vorliegen einer vorherigen Tumorerkrankung im Sinne eines Rezidivs oder Zweittumors sowie die Dauer des stationären und Intensivstationsaufenthalts. Im Weiteren wurden Funktionalität und klinischer Erfolg des Eingriffs durch Analyse etwaiger angefallener Komplikationen mit der erfolgten Therapie, Anlage einer perkutanen endoskopischen Gastrostomie (PEG-) Sonde und phoniatrischer Nachbetreuung ermittelt. Alle Analyseparameter sind zur Übersicht in Tabelle 2 aufgeführt. 


\section{Tabelle 2: Analyseparameter}

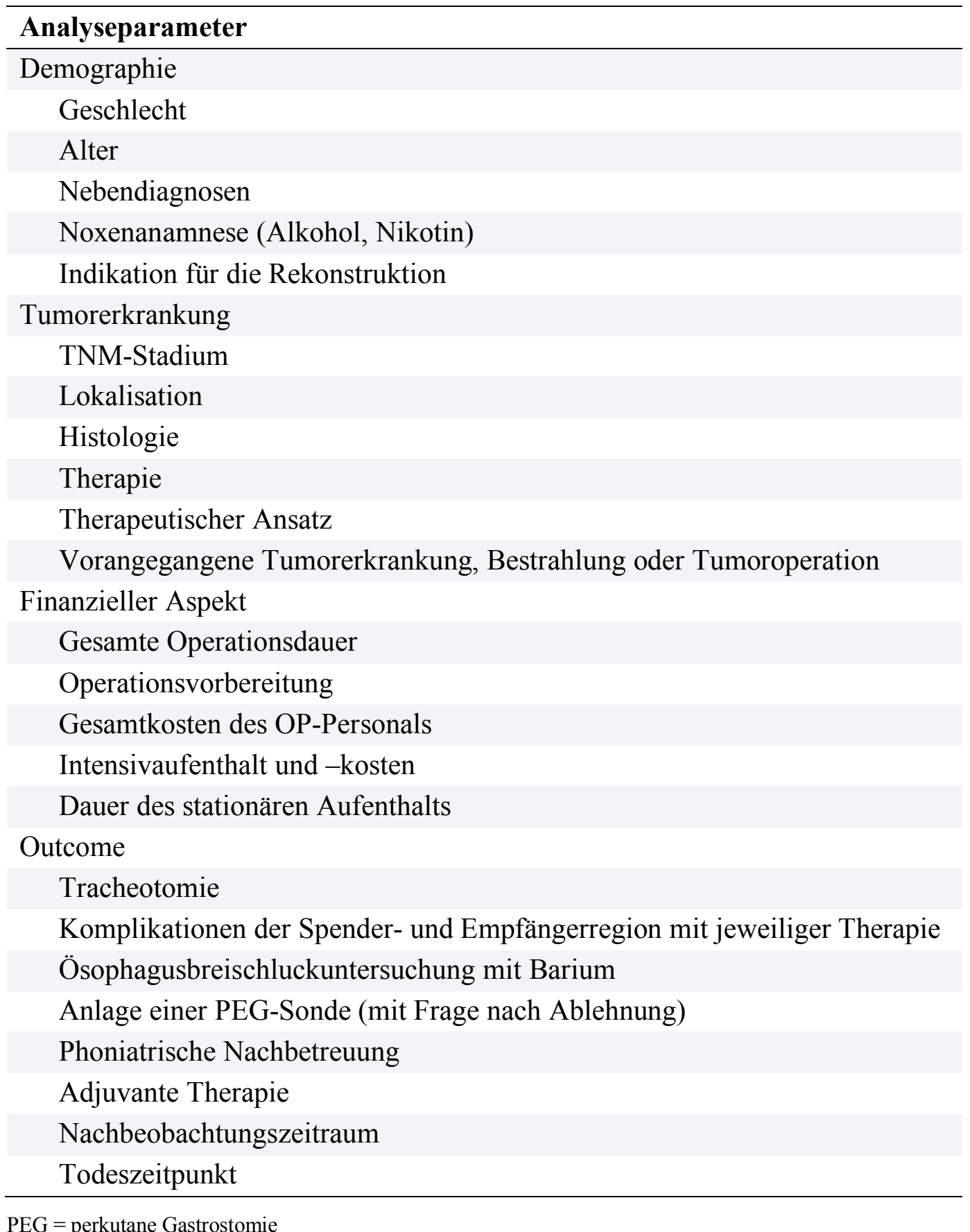

\subsubsection{Komplikationen}

Es erfolgte eine Auswertung der Komplikationen der Spender- und Empfängerregion mit jeweiliger Therapie. Die Komplikationen wurden in höhergradige - major- und geringgradige - minor- unterteilt. Als major wurden solche eingestuft, die eine operative Intervention und Revision benötigten. Minor-Komplikationen waren solche, die unter 
einer konservativen Behandlung abheilten. In Tabelle 3 sind die verschiedenen Komplikationen aufgelistet.

\section{Tabelle 3: Komplikationsarten}

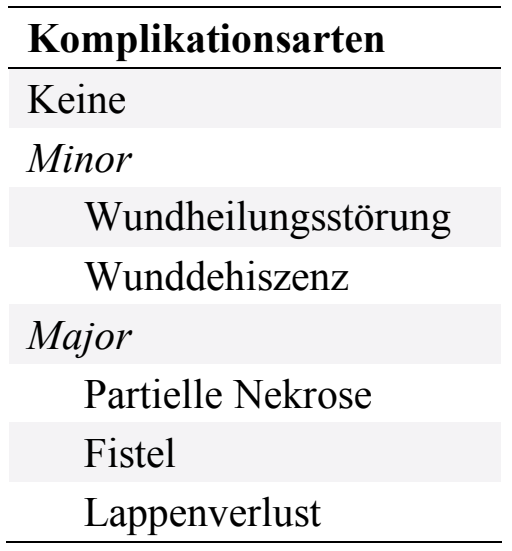

\subsubsection{Operationszeiten}

Zum Vergleich der Operationsdauer wurde die Gesamtoperationsdauer, Lappenoperationsdauer und Lappenhebezeiten erhoben und zwischen den Patientengruppen verglichen.

\subsubsection{Kostenanalyse}

Zur Ermittlung der Kosten für die beiden verschiedenen Rekonstruktionsarten erfolgte eine Errechnung des Lohns für den Operateur (Oberarzt), Assistent der Operation (Assistenzarzt), OP-Pfleger, Anästhesist und Anästhesiepfleger pro Stunde. In Tabelle 4 sind die OP-Teams der jeweiligen Eingriffsart aufgeführt. Die Kosten pro Stunde wurde für die SCAIF-Operation mit 128,40 € berechnet, für die Rekonstruktion mit dem RFFF waren es $128,40 €$ plus $89,72 €$. 
Tabelle 4: Kostenanalyse

\begin{tabular}{|c|c|c|c|c|}
\hline Art der Rekonstruktion & Medizinisches Personal & $\mathbf{n}$ & $\operatorname{Lohn} / \mathbf{h}(€)$ & Kosten/h (€) \\
\hline \multicolumn{5}{|l|}{ SCAIF } \\
\hline & Operateur (Oberarzt) & 1 & 41,80 & \\
\hline & Assistent (Assistenzarzt) & 1 & 26,41 & \\
\hline & OP-Pfleger & 2 & 21,51 & \\
\hline & Anästhesist & 1 & 26,41 & \\
\hline & Anästhesiepfleger & 1 & 12,25 & \\
\hline & & & $\rightarrow$ & 128,40 \\
\hline \multicolumn{5}{|l|}{ RFFF } \\
\hline \multirow[t]{6}{*}{ Gesamt-OP-Zeit } & Operateur (Oberarzt) & 1 & 41,80 & \\
\hline & Assistent (Assistenzarzt) & 1 & 26,41 & \\
\hline & OP-Pfleger & 2 & 21,51 & \\
\hline & Anästhesist & 1 & 26,41 & \\
\hline & Anästhesiepfleger & 1 & 12,25 & \\
\hline & & & $\rightarrow$ & 128,40 \\
\hline \multirow[t]{4}{*}{ Lappen-OP-Zeit } & Operateur (Oberarzt) & 1 & 41,80 & \\
\hline & Assistent (Assistenzarzt) & 1 & 26,41 & \\
\hline & OP-Pfleger & 1 & 21,51 & \\
\hline & & & $\rightarrow$ & 89,72 \\
\hline
\end{tabular}

$\mathrm{RFFF}=$ radial free forearm flap; SCAIF = supraclavicular island flap;

\subsection{Schultermorbidität}

\subsubsection{Patientenauswahl}

Zur Untersuchung der Schultermorbidität wurden alle Patienten analysiert, die im Rahmen eines kurativen onkologischen Therapiekonzeptes (Tumorresektion oder Fistelverschluss) bei fortgeschrittenem UICC-Stadium eines Kopfhalskarzinoms zur Defektrekonstruktion mit einem gestielten SCAIF versorgt wurden. Bei all diesen Patienten wurde eine ipsilaterale ND, entweder simultan oder a priori zur SCAIFRekonstruktion, durchgeführt. Der postoperative Nachbeobachtungszeitraum waren mindestens vier Monate. Einschlusskriterien umfassten eine kurative Therapieintention, ein histologisch gesichertes Plattenepithelkarzinom und ein Nachbeobachtungszeitraum von mehr als vier Monate. Patienten, bei denen mehr als eine Lappenoperation durchgeführt wurde, wurden von der Analyse ausgeschlossen. Nach Anwendung der Einund Ausschlusskriterien konnten 20 Patienten für die Auswertung generiert werden. 


\subsubsection{Demographie}

Postoperativ wurden die in Tabelle 2 aufgeführten Parameter ausgewertet. Die Daten umfassten die Demographie, die Vorerkrankungen mit Noxenanamnese die postoperativen Komplikationsraten der Spender- und Empfängerregion mit anschließender Behandlung der Komplikationen.

\subsubsection{Fragebögen und Untersuchungen}

Zur Evaluation der postoperativen Schulterfunktion wurden zwei verschiedene Fragebögen verwendet. Ein Fragebogen orientierte sich an dem Score nach C. R. Constant und A. H. Murley (Constant-Murley-Score), welcher sich auf die Funktion der Schulter nach Bewegungsausmaß, Kraft und Schmerz konzentrierte. Der Disabilities of the Arm, Shoulder and Hand Outcome Measure (DASH-) Fragebogen setzte sich mit der Einschränkung der gesamten oberen Extremität im Alltag auseinander. Im Rahmen der Tumornachsorgesprechstunde wurden in der HNO-Klinik der UMG den Patienten die Fragebögen ausgehändigt und eine Bewegungs- und Kraftprüfung durchgeführt. Zudem erhoben wir anamnestisch Sensibilitätsstörungen im Donor-Gebiet.

\section{Constant-Murley-Score}

Die Untersuchung umfasste Bewegungsausmaß, Kraft und Sensibilität im Vergleich zur kontralateralen Extremität. Zudem wurden Fragebögen ausgewertet, welche die subjektive Funktionalität im Alltag widerspiegelten. Dazu verwendeten wir den Constant-Murley-Score, welcher europaweit ein Standardinstrument für die Evaluation der Schulterfunktion darstellt (Constant und Murley 1987). Die Kategorien gliedern sich in Schmerz, Alltagsaktivitäten, Motilität und Kraft. Alle Parameter sind in Tabelle 5 aufgelistet.

Die Auswertung des Constant-Murley-Scores richtete sich nach einem Punktesystem. Die maximale Punktzahl betrug 100 und entsprach dem Fehlen einer Einschränkung. 
Tabelle 5: Analyseparameter des Constant-Murley-Scores

\begin{tabular}{|c|c|c|}
\hline \multicolumn{3}{|c|}{ Constant-Murley-Score } \\
\hline Parameter & Einteilung & Punkte \\
\hline Schmerz & kein“, „mittel“, „mäßig“, „starke Schmerzen“ & $0-15$ \\
\hline Alltagsaktivitäten & & $\max .20$ \\
\hline Arbeitsfähigkeit & ,0\%“, ,,25\%“, ,,50\%“", ,75\%“", ,,100\%“" & $0-4$ \\
\hline Freizeitfähigkeit & $\begin{array}{l}\text { „gar nicht“, „,stark“, „deutlich“, „leicht } \\
\text { eingeschränkt", „,uneingeschränkt" }\end{array}$ & $0-4$ \\
\hline Schlaffähigkeit & $\begin{array}{l}\text { „Sehr starke Probleme“, „Erwachen mit } \\
\text { Wiedereinschlafen“, „ungestörter Schlaf möglich“ }\end{array}$ & $0-2$ \\
\hline Handreichweite & $\begin{array}{l}\text { „Gürtellinie“, „Xiphoid““, „Hals“, „Scheitel““, „über } \\
\text { den Kopf hinaus“ }\end{array}$ & $2-10$ \\
\hline Motilität & & $\max .40$ \\
\hline Flexion & 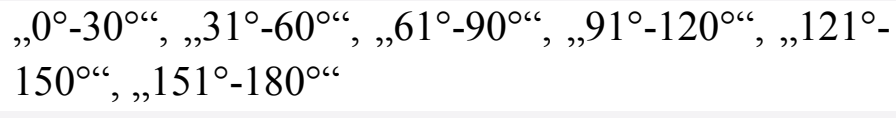 & $0-10$ \\
\hline Abduktion & 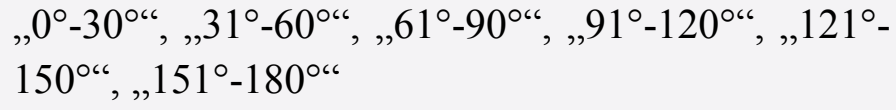 & $0-10$ \\
\hline Außenrotation & $\begin{array}{l}\text { „Hand auf den Scheitel, Ellenbogen nach vorne“", } \\
\text { „Hand auf den Scheitel, Ellenbogen zur Seite“, } \\
\text { „Hand am Hinterkopf, Ellenbogen nach vorne“, } \\
\text { „Hand am Hinterkopf, Ellenbogen zu Seite“, } \\
\text { „uneingeschränkte Überkopfbeweglichkeit" }\end{array}$ & $0-10$ \\
\hline Innenrotation & $\begin{array}{l}\text { „Handrücken auf Außenseite des Oberschenkels“, } \\
\text { „Handrücken auf Gesäß““, } \\
\text { „Handrücken auf lumbosakralem Übergang“, } \\
\text { „Handrücken auf Gürtellinie 3. LWK“, „Handrücken } \\
\text { auf 12. Brustwirbel“", } \\
\text { „Handrücken zwischen die Schulterblättern““ }\end{array}$ & $0-10$ \\
\hline Kraft & „1 Punkt entspricht 1 Pfund $(=0,45 \mathrm{~kg}) "$ & $0-25$ \\
\hline Gesamt & & 100 \\
\hline
\end{tabular}

LWK $=$ Lendenwirbelkörper

\section{DASH-Score}

Der DASH-Fragebogen eruierte verschiedene Alltagstätigkeiten und Beschwerden der oberen Extremität. Es handelte sich hierbei um 30 Fragen, die vom Patienten selbst beantwortet wurden, und diente der Quantifizierung der Einschränkungen. 
Der Interpretationswert wurde anhand der folgenden Formel errechnet:

$$
\text { Score }=25\left(1-\frac{\text { Summe der } n \text { Antwortpunkte }}{n}\right)
$$

Besonders hohe Werte entsprachen einer starken Einschränkung (Germann et al. 1999); (Kennedy et al. 2011); (Dowrick et al. 2005).

\section{Sensibilität}

Zusätzlich wurden die Patienten nach der Sensibilität im Operationsgebiet befragt. Dabei wurden die Qualitäten Schmerz, Taubheit, Kribbelparästhesie und Temperaturmissempfindung erfragt.

\subsection{Lebensqualität}

\subsubsection{Patientenauswahl}

Alle dieser Patienten litten an einem fortgeschrittenen Oropharynx- oder Mundhöhlenkarzinom und erhielten eine transorale mikrochirurgische Laserresektion des Tumors mit bilateraler ND und eine Defektrekonstruktion mittels SCAIF oder RFFF. Bei keinem der Patienten dieser Kohorte lag vor Diagnose des Kopfhalskarzinoms ein Rezidiv oder Zweitkarzinom, eine Voroperation oder Bestrahlung in der Kopf-Halsregion vor. Es wurden alle Patienten ausgeschlossen, die eine cN3-Halslymphknotenmetastasen, Fernmetastase oder histologisch kein Plattenepithelkarzinom aufwiesen. Insgesamt 24 Patienten konnten für diese Auswertung damit akquiriert werden, 12 SCAIF- und 12 RFFF-Patienten.

\subsubsection{Demographie}

Um eine Vergleichsanalyse der Lebensqualität anzustellen, wurden postoperativ die oben aufgeführten Parameter (siehe Tabelle 2) zwischen den beiden Kohorten (SCAIF und RFFF-Kohorte) verglichen. Die Daten umfassten die Demographie, die Vorerkrankungen mit Noxenanamnese, die postoperativen Komplikationsraten der Spender- und Empfängerregion mit anschließender Behandlung der Komplikationen. Der 
Nachbeobachtungszeitraum lag im Mittel bei 22,3 Monaten $( \pm 13,1)$, mit einem Minimum von 4 Monaten.

\subsubsection{Fragebögen zur Lebensqualität der EORTC}

Zur Evaluierung der Lebensqualität wurden Fragebögen mit Fragen über verschiedene Bereiche aus dem Alltag ausgewertet. Erstellt wurden die Fragebögen durch die European Organisation for Research and Treatment of Cancer (EORTC) (Aaronson et al. 1993), eine internationale nicht profitable Organisation, die es sich zum Ziel gemacht hat, onkologische Forschung in Europa voranzutreiben (Fayers et al. 2001); (Hurvitz et al. 2006).

Wir verwendeten zwei Fragenbögen der EORTC, den QLQ-C30 Version 3.0 und den QLQ-H\&N35.

\section{Fragebogen QLQ-C30}

Der QLQ-C30 Version 3.0 kann zur Eruierung der Lebensqualität von diversen onkologischen Erkrankung angewendet werden. Die untersuchten Parameter gliedern sich in drei große Bereiche: „Allgemeinzustand“, „Funktionen“ und „Symptome“. Die Auflistung aller Parameter im Detail sind Tabelle 6 zu entnehmen. 
Tabelle 6: Analyseparameter des Fragebogens QLQ-C30 Version 3.0 der EORTC

\begin{tabular}{lcc}
\hline EORTC QLQ-C30 Version 3.0 & & \\
Parameter & Punkte & Anzahl der Fragen \\
\hline Allgemeinzustand/Lebensqualität & $1-7$ & 2 \\
Funktionelle Parameter & & 5 \\
$\quad$ Körperliche Funktion & $1-4$ & 2 \\
Rollenfunktion & $1-4$ & 4 \\
Emotionale Funktion & $1-4$ & 2 \\
Kognitive Funktion & $1-4$ & 2 \\
Soziale Funktion & $1-4$ & \\
Symptom-bezogene Parameter & & 3 \\
Erschöpfung & $1-4$ & 2 \\
Übelkeit und Erbrechen & $1-4$ & 2 \\
Schmerzen & $1-4$ & 1 \\
Dyspnoe & $1-4$ & 1 \\
Schlaflosigkeit & $1-4$ & 1 \\
Obstipation & $1-4$ & 1 \\
Diarrhö & $1-4$ & 1 \\
Finanzielle Schwierigkeiten & $1-4$ & 30 \\
Gesamt & & \\
\hline
\end{tabular}

EORTC = European Organisation for Research and Treatment of Cancer

\section{Fragebogen QLQ-H\&N35}

Der Fragebogen QLQ-H\&N35 diente als Ergänzung zum QLQ-C30 Version 3.0 zur Untersuchung der Lebensqualität bei Patienten mit Kopf-Hals-Malignomen. Er erfasste mit 35 Symptom-spezifischen Fragen Schmerzen, Schluckfunktion, Geschmacksfunktion, Geruchsfunktion, Sprachfunktion, Essen in Gesellschaft, sozialer Kontakt und Sexualität. Die untersuchten Parameter sind in Tabelle 7 aufgeführt. 
Tabelle 7: Analyseparameter des Fragebogens QLQ-H\&N35 der EORTC

\begin{tabular}{lcc}
\hline EORTC QLQ-H\&N35 & & \\
Parameter & Punkte & Anzahl der Fragen \\
\hline Symptom-bezogene Parameter & & 4 \\
Schmerzen & $1-4$ & 4 \\
Schluckfunktion & $1-4$ & 2 \\
Geruchs- und Geschmackssinn & $1-4$ & 3 \\
Sprechfunktion & $1-4$ & 4 \\
Probleme mit „sozialem Essen“ & $1-4$ & 5 \\
Probleme mit sozialem Kontakt & $1-4$ & 2 \\
Einschränkungen in der Sexualität & $1-4$ & 1 \\
Zähne & $1-4$ & 1 \\
Mundöffnung & $1-4$ & 1 \\
Xerostomie & $1-4$ & 1 \\
Klebriger Speichel & $1-4$ & 1 \\
Husten & $1-4$ & 1 \\
Subjektives Krankheitsgefühl & $1-4$ & 1 \\
Analgetika & $1-2$ & 1 \\
Nahrungssupplemente & $1-2$ & 1 \\
Ernährungssonde & $1-2$ & 1 \\
Gewichtsverlust & $1-2$ & 1 \\
Gewichtszunahme & $1-2$ & 35 \\
Gesamt & & \\
\hline
\end{tabular}

EORTC = European Organisation for Research and Treatment of Cancer

\section{Interpretation und Scoring-System}

Mit Auswertung des Fragebogens erhielt man einen Interpretationswert, welcher sich an der Höhe der erreichten Punktezahlen orientierte und unter Anwendung von bestimmten Formeln errechnete.

Zunächst wurde der raw score (RS) berechnet, der als Mittelwert in der Rechnung fungierte:

$$
R S=\frac{I_{1}+I_{2}+\cdots+I_{n}}{n}
$$

Dann wurde für die Berechnung der „Allgemeinzustand/Lebensqualität“ und die „Symptom-bezogenen Parameter“ folgende Formel verwendet: 


$$
\text { Score }=100 \frac{R S-1}{\text { range }}
$$

Die range war aus einer Tabelle des „Scoring Manuals“ der EORTC zu entnehmen (Fayers et al. 2001). Die range war die Differenz aus dem möglichen Maximum und Minimum der Antwort zu den individuellen Parametern. Die meisten Parameter beliefen sich zwischen 1 bis 4 und ergaben somit eine range von 3.

Funktionelle Parameter errechneten sich durch die im Folgenden dargestellte Formel:

$$
\text { Score }=100\left(1-\frac{R S-1}{\text { range }}\right)
$$

Hohe Werte bei funktionellen Parametern oder Allgemeinzustand sprachen für eine gute Funktionalität. Dahingegen korrelierten hohe Werte bei den Symptom-bezogenen Parametern mit der Intensität der Krankheitssymptome und gingen somit mit einer Einschränkung der Lebensqualität einher (Fayers et al. 2001).

Die Einteilung reichte von „überhaupt nicht“, „,wenig“, „mäßig“ bis „,sehr“" (Punkte 1-4) oder wurde mit einer Skalierung von „sehr schlecht“ (1 Punkt) bis ,ausgezeichnet“ (7 Punkte) bewertet. Einige Fragen konnten mit „nein“ (1 Punkt) oder ,ja“ (2 Punkte) beantwortet werden.

\subsection{Management der Tumorpatienten}

\subsubsection{Präoperative Vorbereitungen}

Alle Patienten mit einer malignen Kopf-Halstumorerkrankung wurden zunächst klinisch im Rahmen der HNO-ärztlichen Spiegeluntersuchung des oberen Aerodigestivtrakts mit zervikaler Lymphknotenpalpation untersucht. Danach erfolgte eine Panendoskopie mit Probenentnahme in Vollnarkose zur histologischen Sicherung der Diagnose. Nach Erhalt des histopathologischen Ergebnisses wurden zur Festlegung des Stagings eine kontrastmittelgestützte Computertomographie des Hals- und Thoraxbereichs sowie eine sonographische Untersuchung des Abdomens durchgeführt. Im Anschluss daran erfolgte die Diskussion und Therapieentscheidung des onkologischen Kasus im interdisziplinären Tumorboard für obere Luft- und Speisewege. 


\subsubsection{Chirurgische Therapie}

Die Tumorresektion wurde je nach Lokalisation und Zugänglichkeit transoral mikroskopisch mit dem Kohlenstoffdioxid $\left(\mathrm{CO}_{2-}\right)$ Laser durchgeführt. An der HNOKlinik der UMG wurde die TLM, wie von W. Steiner und W. Ambrosch technisch beschrieben, durchgeführt (Steiner 1984). Je nach TNM-Stadium (Bierley et al. 2016) und Beschluss des interdisziplinären Tumorboards erfolgte eine ipsilaterale oder bilaterale ND.

\subsubsection{Postoperative Behandlung}

\section{Postoperative Überwachung auf der Intensivstation}

Direkt postoperativ wurden alle Patienten nach Lappenrekonstruktion zumindest für einige Stunden auf der Intensivstation überwacht. Die Indikation wurde zum einen durch die Kollegen der Anästhesie auf Grund der verhältnismäßig langen Narkose gestellt. Zum anderen wurde somit eine reduzierte Mobilität des Patienten gewährleistet, sodass die mikrovaskuläre Anastomose für die ersten Stunden geschont wurde.

\section{Verbandswechsel und Wundpflege}

Bei allen Patienten, die mit einem SCAIF zur Defektdeckung versorgt worden waren, erfolgte postoperativ eine regelmäßige klinische Kontrolle des Transplantats in mehrstündigen Abständen. Der erste Verbandswechsel wurde standardmäßig am zweiten postoperativen Tag durchgeführt. Danach erfolgten täglich Verbandswechsel mit Wundkontrolle und gegebenenfalls Dokumentation des Wundstatus bei Wundheilungsstörung und Komplikationen. Gegebenenfalls wurde ein klinikinterner Wundmanager (speziell ausgebildetes Pflegepersonal für komplizierte Wundversorgung) hinzugezogen. Eine Betreuung durch den Wundmanager wurde in regelmäßigen Abständen von zwei bis drei Tagen durchgeführt und abgeschlossen, sobald sich die Wundverhältnisse konsolidierten. Die Entfernung der intraoperativ applizierten Drainagen erfolgte, sobald diese weniger als $30 \mathrm{ml} / 24 \mathrm{~h}$ förderten.

\section{Postoperative Funktionsevaluation und „Schlucktraining“6}

Bei allen Patienten wurde intraoperativ eine nasogastrale Ernährungsonde appliziert, welche etwa zehn Tage postoperativ zur oralen Nahrungskarenz mit parenteraler 
Ernährung belassen wurde und zudem als Platzhalter fungierte. Um den 10. postoperativen Tag wurde die Evaluierung des Schluckvermögens mit einer Röntgenkinematographie mit Kontrastmittel durchgeführt. Wenn es keinen Hinweis für eine Fistel oder Aspiration gab, erfolgte stationär im Beisein eines HNO-Arztes und Schlucktherapeuten der klinische Schluckversuch mit jeweils unterschiedlich festen Medien (breiig bis wässrig). Im Anschluss wurde unter täglichem logopädischen Schlucktraining mit dem oralen Kostaufbau begonnen. Bei protrahierten Verläufen wurde vorübergehend eine PEG-Sonde durch die Kollegen der Gastroenterologie angelegt.

\section{Adjuvante Therapie}

Sofern in der interdisziplinären Tumorkonferenz festgelegt, schloss sich an die primäre Tumorbehandlung mit Tumorresektion und ND bei höhergradigen Tumorstadien eine adjuvante RCT an (Brierley et al. 2016).

\section{Nachstationäre Betreuung}

Alle Patienten mit einem Kopf-Halsmalignom wurden in regelmäßigen Abständen in der Tumornachsorgesprechstunde in der HNO-Klinik der UMG betreut. Die erste Nachsorge erfolgte in der Regel sechs bis 12 Wochen nach Abschluss des therapeutischen Konzepts und umfasste eine HNO-ärztliche Spiegeluntersuchung inklusive Sonographie der Halsweichteile.

\subsection{Statistische Auswertung}

Die statistische Analyse wurde mit dem Programm $R$ Version 3.3.3 ( $R$ Foundation for Statistical Computing, Wien, Österreich) durchgeführt. Zur Prüfung der Normalverteilung wurde vor der Vergleichsanalyse zwischen Spenderextremität und kontralateraler Extremität der Kolmogorov-Smirnov-Test angewandt. Da keine Normalverteilung vorlag, wurde die Daten auf gleiche Varianzen mit dem Levene-Test untersucht. Für die Vergleichsanalyse wurden der Chi-Quadrat-Test und WilcoxonMann-Whitney U-Test verwendet. Unterschiede wurden als signifikant definiert, wenn der p-Wert kleiner als 0,05 war. 


\section{$4 \quad$ Ergebnisse}

\subsection{SCAIF-Gesamtkollektiv}

\subsubsection{Demographie des SCAIF-Gesamtkollektivs}

Aus insgesamt 114 Patienten konnte nach Anwendung der Ein- und Ausschlusskriterien ein Patientenkollektiv von 50 konsekutiven SCAIF-Patienten mit fortgeschrittenen Plattenepithelkarzinomen der Kopf-Halsregion in die Auswertung aufgenommen werden. Das Durchschnittsalter betrug 67,46 Jahre $( \pm 10,81)$. Davon waren $36(72,0 \%)$ der Patienten männlich. Der Nachbeobachtungszeitraum betrug im Mittel 10,32 Monate $( \pm 10,03)$.

Die Analyse der Indikationsstellung zur SCAIF-Operation ergab, dass die Rekonstruktionstechnik mittels SCAIF bei 66,0\% auf Grund der Resektion des Primärtumors, bei 16,0\% auf Grund des Rezidivtumors, bei 12,0\% auf Grund einer Fistel, bei 4,0\% auf Grund eines vorherigen Lappenverlusts und bei 2,0\% $(n=1)$ auf Grund einer posttherapeutischen Pharynxstenose notwendig war. Mehr als die Hälfte (52,0\%) der Tumoren waren im Bereich des Oropharynx lokalisiert. In der Mundhöhle waren es lediglich $16,0 \%$, gefolgt von Larynx $(14,0 \%)$ und Hypopharynx $(10,0 \%)$. Vier Patienten $(8,0 \%)$ hatten anderweitige Lokalisationen, davon jeweils ein Patient $(2,0 \%)$ am Gehörgang und der Concha auris. Bei Betrachtung der Verteilung der UICC-Stadien fällt auf, dass die Mehrheit der Patienten (90,0\%) an einem fortgeschrittenen PECA litt. 10,0\% hatten einen Stadium-II-Tumor, 24,0\% Stadium III und 66,0\% Stadium IV.

Bei der Evaluation der Nebendiagnosen und Noxenanamnese zeigten sich bei 18 Patienten (36,0\%) keine bekannten Vorerkrankungen zum Erstvorstellungszeitpunkt. 16,0\% des Kollektivs litten an einer systemischen Erkrankung (kardiovaskuläre Erkrankung 10,0\%, Malignom 4,0\% oder andere), 24,0\% an zwei systemischen Erkrankungen, $8,0 \%$ an drei und $16,0 \%$ an mehr als drei Erkrankungen. In unserer Datenanalyse konnten wir von 36,0\% der Patienten keine Angaben zur Noxenanamnese erhalten. 60,0\% der Kohorte waren Raucher, 46,0\% konsumierten täglich Alkohol und bei nur einem Patienten lag weder ein Nikotin- noch Alkoholkonsum vor (2,0\%). Diese und weitere Daten über die Demographie sind in Tabelle 8 aufgeführt. 
Tabelle 8: SCAIF-Gesamtkollektiv Demographie

\begin{tabular}{|c|c|c|}
\hline Demographie & & \\
\hline Indikation & $\mathrm{n}$ & $(\%)$ \\
\hline Primärtumor & 33 & $(66,0)$ \\
\hline Rezidiv & 8 & $(16,0)$ \\
\hline Stenose & 1 & $(2,0)$ \\
\hline Fistel & 6 & $(12,0)$ \\
\hline Vorheriger Lappenverlust & 2 & $(4,0)$ \\
\hline \multicolumn{3}{|l|}{ Lokalisation } \\
\hline Oropharynx & 26 & $(52,0)$ \\
\hline Hypopharynx & 5 & $(10,0)$ \\
\hline Mundhöhle & 8 & $(16,0)$ \\
\hline Larynx & 7 & $(14,0)$ \\
\hline Gehörgang und Concha auris & 2 & $(4,0)$ \\
\hline Andere & 2 & $(4,0)$ \\
\hline \multicolumn{3}{|l|}{ UICC-Stadium } \\
\hline II & 5 & $(10,0)$ \\
\hline III & 12 & $(24,0)$ \\
\hline IV & 33 & $(66,0)$ \\
\hline \multicolumn{3}{|l|}{ Nebendiagnosen } \\
\hline Keine & 18 & $(36,0)$ \\
\hline Kardiovaskuläre Erkrankung & 5 & $(10,0)$ \\
\hline Zwei Erkrankungen & 12 & $(24,0)$ \\
\hline Drei Erkrankungen & 4 & $(8,0)$ \\
\hline Mehr als drei Erkrankungen & 8 & $(16,0)$ \\
\hline Anderes Malignom & 2 & $(4,0)$ \\
\hline Andere Erkrankung & 1 & $(2,0)$ \\
\hline \multicolumn{3}{|l|}{ Noxenanamnese } \\
\hline keine & 1 & $(2,0)$ \\
\hline Kein Alkohol & 7 & $(14,0)$ \\
\hline Kein Nikotin & 2 & $(4,0)$ \\
\hline Nikotinkonsum & 30 & $(60,0)$ \\
\hline Alkoholkonsum & 23 & $(46,0)$ \\
\hline Keine Angabe & 18 & $(36,0)$ \\
\hline
\end{tabular}

SCAIF $=$ supraclavicular island flap; UICC = Union for International Cancer Control;

Die Analyse der durchgeführten Therapie zeigte, dass bei mehr als der Hälfte des Kollektivs (56,0\%) eine Tumorresektion mit bilateraler ND und SCAIF, bei 12,0\% mit ipsilateraler ND durchgeführt wurde. $16,0 \%$ der Patienten erhielten ausschließlich die Rekonstruktion mittels SCAIF, 8,0\% die Tumorresektion einschließlich der SCAIF- 
Operation und jeweils 4,0\% eine Tumorresektion mit mehr als einer Lappenplastik oder ausschließlich eine Zungenrekonstruktion mittels SCAIF. Im Rahmen einer adjuvanten Therapie wurde bei annähernd der Hälfte der Patienten (46,0\%) eine RCT durchgeführt. $18,0 \%$ der Patienten entwickelten im Beobachtungsverlauf ein Rezidiv und erhielten eine anderweitige Therapie oder befanden sich dann in einem palliativen Therapiekonzept. Bei $30,0 \%$ wurde keine adjuvante Therapie durchgeführt, sondern nur klinische Kontrollen im Rahmen der Tumornachsorge. Ein Patient (2,0\%) lehnte eine adjuvante Therapie ab und zwei Patienten $(4,0 \%)$ verstarben, bevor mit der adjuvanten Therapie begonnen werden konnte. Eine Übersicht der Daten kann aus Tabelle 9 entnommen werden.

Tabelle 9: SCAIF-Gesamtkollektiv Onkologische Therapie

\begin{tabular}{lrl}
\hline Onkologische Therapie $(\mathbf{n = 5 0 )}$ & $\mathrm{n}(\%)$ \\
\hline Therapie & $8(16,0)$ \\
Rekonstruktion mit SCAIF & $28(56,0)$ \\
Tumorresektion, ND bilateral, SCAIF & $6(12,0)$ \\
Tumorresektion, ND ipsilateral, SCAIF & $2(4,0)$ \\
Tumorresektion, mehr als eine Lappenplastik & $4(8,0)$ \\
Tumorresektion, SCAIF & $2(4,0)$ \\
Zungenrekonstruktion mit SCAIF & \\
Adjuvante Therapie & $15(30,0)$ \\
Keine & $23(46,0)$ \\
RCT & $9(18,0)$ \\
Rezidiv/palliativ & $1 \quad(2,0)$ \\
Abgelehnt & $2(4,0)$ \\
gestorben &
\end{tabular}

$\mathrm{ND}=$ Neck Dissection; RCT $=$ Radiochemotherapie; SCAIF = supraclavicular island flap;

Bei 18 Patienten $(35,0 \%)$ lag bereits vor der SCAIF-Rekonstruktion ein Malignom im Kopf-Halsbereich vor, zusätzlich zur Operation erhielten elf Patienten eine adjuvante RCT in dem Bereich (siehe Tabelle 10).

Tabelle 10: SCAIF-Gesamtkollektiv vorangegangene Therapie

\begin{tabular}{lrl}
\hline \multicolumn{2}{l}{ Vorrangegangene Therapie im Kopf-Halsbereich } \\
\hline & $\mathrm{n}$ & $(\%)$ \\
Malignom & 18 & $(35,0 \%)$ \\
Operation Halsbereich & 20 & $(40,0 \%)$ \\
Adjuvante RCT & 11 & $(22,0 \%)$ \\
\hline
\end{tabular}

RCT $=$ Radiochemotherapie; SCAIF = supraclavicular island flap; 


\subsubsection{Perioperative Daten und Personalkosten des SCAIF- Gesamtkollektivs}

Die Analyse der perioperativen Daten schloss Daten zur Operationsdauer und Personalkosten ein. Die Schnitt-Naht-Zeit lag im Mittel bei 361,70 min $( \pm 118,46)$, die Operationsvorbereitungszeit bei $51,94 \mathrm{~min}( \pm 21,05)$. Alle perioperativen Daten sind zur Übersicht in Tabelle 11 aufgeführt.

Tabelle 11: SCAIF-Gesamtkollektiv Perioperative Daten

\begin{tabular}{lrl}
\hline Perioperative Daten & & \\
\hline Schnitt-Naht-Zeit [min \pm SD] & 361,70 & $\pm 118,46$ \\
Präoperative Zeit [min \pm SD] & 51,94 & $\pm 21,05$ \\
Lappenprozedurzeit [min \pm SD] & 177,11 & $\pm 70,05$ \\
Lappenhebezeit [min \pm SD] & 39,39 & $\pm 13,93$ \\
Fläche des Lappens $\left[\mathrm{cm}^{2}\right.$ ] & 45,59 & $\pm 35,45$ \\
\hline
\end{tabular}

$\mathrm{SCAIF}=$ supraclavicular island flap; $\mathrm{SD}=$ standard deviation;

Die ermittelten Personalkosten schlossen Informationen zur Kosten der Operateure, OPPflegekräfte, Anästhesisten und die summierten Gesamtkosten jeder SCAIF-Operation ein.

Die Kostenanalyse wurde anhand der Errechnung der Personalkosten pro Stunde durchgeführt. Für die Operateurkosten ergaben sich ein Mittelwert von 411,19 € $( \pm 134,67)$, für die Kosten der OP-Pflegekraft waren es $259,34 €( \pm 84,94)$ und die der Anästhesie $233,06 €( \pm 76,33)$. Für die gesamten Personalkosten pro Operation wurden $903,59 €( \pm 265,93)$ ermittelt. Zehn Patienten $(20,0 \%)$ waren auf der Intensivstation und verbrachten im Mittel 19,90 h $( \pm 50,66)$ dort. Als Intensivstationskosten wurden im Mittel $974,02 €( \pm 3082,76)$ errechnet. Im Durchschnitt waren unsere Patienten für 30,96 Tage $( \pm 18,68)$ stationär. Eine Übersicht der Daten ist aus Tabelle $12 \mathrm{zu}$ entnehmen. 
Tabelle 12: SCAIF-Personalkosten für das Gesamtkollektiv $(n=50)$

\begin{tabular}{|c|c|}
\hline Personalkosten im Mittel für eine SCAIF-Operation & \\
\hline Operateur [€ $\pm \mathrm{SD}]$ & $411,19 \pm 134,67$ \\
\hline OP-Pflegekraft $[€ \pm \mathrm{SD}]$ & $259,34 \pm 84,94$ \\
\hline Anästhesist $[€ \pm \mathrm{SD}]$ & $233,06 \pm 76,33$ \\
\hline Gesamtpersonalkosten $[€ \pm \mathrm{SD}]$ & $903,59 \pm 265,93$ \\
\hline Intensivaufenthalt $[\mathrm{h} \pm \mathrm{SD}]$ & $19,90 \pm 50,66$ \\
\hline Intensivstationskosten $[€ \pm \mathrm{SD}]$ & $974,02 \pm 3082,76$ \\
\hline Gesamter stationärer Aufenthalt $[\mathrm{d} \pm \mathrm{SD}]$ & $30,96 \pm 18,68$ \\
\hline
\end{tabular}

$\mathrm{SCAIF}=$ supraclavicular island flap; $\mathrm{SD}=$ standard deviation;

\subsubsection{Postoperative Morbidität: Schluckfunktion und Komplikationen der} Spender- und Empfängerregion

Bei fast allen Patienten $(n=49 ; 98,0 \%)$ wurde zehn Tage postoperativ eine Röntgenbreischluckuntersuchung durchgeführt. Dabei wiesen 51,0\% vom Gesamtkollektiv keine Pathologien oder Komplikationen auf, 22,4\% hatten eine Stenose, 14,3\% der Patienten aspirierten während der Untersuchung, 10,2\% wiesen eine Fistel auf und bei einem Patienten (2,0\%) traten sowohl eine Fistel wie auch Aspiration auf. Von den 50 Patienten wurde bei 58,0\% eine Tracheotomie durchgeführt. Eine PEG-Sonde wurde bei 46,0\% unserer Patienten auf Grund des protrahierten Kostaufbaus angelegt. Lediglich zwei Patienten (4,0\%) lehnten die Ernährung über eine PEG-Sonde ab. Weitere Daten sind aus Tabelle $13 \mathrm{zu}$ entnehmen.

\section{Tabelle 13: Funktionelle Parameter}

\begin{tabular}{lrl}
\hline Funktionelle Parameter & & \\
\hline Röntgenbreischluck & 25 & $(51,0)$ \\
Keine Komplikationen & 7 & $(14,3)$ \\
Aspiration & 5 & $(10,2)$ \\
Fistel & 1 & $(2,0)$ \\
Aspiration und Fistel & 11 & $(22,4)$ \\
Stenose & 1 & $(2,0)$ \\
Nicht durchgeführt & & \\
PEG & 23 & $(46,0)$ \\
Angelegt & 2 & $(4,0)$ \\
Abgelehnt & 29 & $(58)$ \\
Tracheotomie & & \\
\hline
\end{tabular}

PEG = perkutane endoskopische Gastrostomie; SCAIF = supraclavicular island flap; 
Die Analyse der Komplikationen zeigte im Bereich der Spenderregion bei 32 Patienten $(64,0 \%)$ keine Komplikationen, bei acht Patienten (16,0\%) traten Dehiszenzen oder eine protrahierte Wundheilung auf, und zwei Patienten (4,0\%) entwickelten eine partielle Nekrose. Bei 68,0\% der Patienten ( $\mathrm{n}=34)$ war keine zusätzliche Intervention notwendig. Bei 28,0\% heilte die Wunde sekundär gut ab und zwei Patienten (4,0\%) benötigten eine chirurgische Intervention im Sinne einer Wundrevision. Im Bereich der Empfängerregion zeigte sich in 58,0\% keine Komplikationen. Bei 18,0\% trat eine Fistel auf, bei jeweils 10,0\% war die Wundheilung protrahiert bzw. die Region partiell nekrotisch, und ein Patient (2,0\%) entwickelte eine Wunddehiszenz. Somit war bei 64,0\% vom Gesamtkollektiv keine weitere Therapie zusätzlich notwendig, 20,0\% heilten in sekundärer Wundheilung ab. Chirurgisch interveniert wurde bei acht Patienten (16,0\%), davon wurde bei einem Patienten (2,0\%) ein Debridement durchgeführt, bei zwei Patienten (4,0\%) eine Wundrevision, vier Patienten (8,0\%) benötigten die Anlage eines Pharynxstents und bei nur einem Patienten (2,0\%) musste der Defekt mit einem weiteren Gewebetransplantat gedeckt werden. Alle Daten sind in Tabelle 14 aufgeführt. 
Tabelle 14: SCAIF-Komplikationen der Spender- und Empfängerregion

\begin{tabular}{lr}
\hline Komplikationen und Therapie & $\mathrm{n}(\%)$ \\
\hline Komplikationen Spenderregion & $32(64,0)$ \\
Keine & $8(16,0)$ \\
Protrahierte Wundheilung & $8(16,0)$ \\
Dehiszenz & $2(4,0)$ \\
Partielle Nekrose & \\
Therapie Spenderregion & $34(68,0)$ \\
Keine & $14(28,0)$ \\
Sekundäre Wundheilung & $1(2,0)$ \\
Debridement & $1(2,0)$ \\
Chirurgische Wundrevision & \\
Komplikationen Empfängerregion & $29(58,0)$ \\
Keine & $5(10,0)$ \\
Protrahierte Wundheilung & $1(2,0)$ \\
Dehiszenz & $5(10,0)$ \\
Partielle Nekrose & $9(18,0)$ \\
Fistel & $1(2,0)$ \\
Andere & \\
Therapie Empfängerregion & $32(64,0)$ \\
keine & $10(20,0)$ \\
Sekundäre Wundheilung & $1(2,0)$ \\
Debridement & $2(4,0)$ \\
Chirurgische Wundrevision & $4(8,0)$ \\
Stent & $1(2,0)$ \\
\hline Lappenplastik & \\
\hline
\end{tabular}

SCAIF = supraclavicular island flap;

\subsubsection{Outcome: Kaplan-Meier-Schätzer-Überlebenskurven}

Es wurde eine Berechnung der Überlebensrate durchgeführt und in Form einer Überlebenskurve nach Kaplan-Meier-Schätzer (siehe Abbildung 3) dargestellt. Analysiert wurden insgesamt 50 SCAIF-Patienten mit Stadium II-IV Plattenepithelkarzinomen im Kopf-Halsbereich (Demographie siehe Tabelle 8). Insgesamt verstarben 21 Patienten (42,0\%) unseres Kollektiv im Zeitraum von Januar 2011 bis Mai 2017. 
Abbildung 3: Kaplan-Meier-Schätzer Überlebenskurve der SCAIF-Patienten

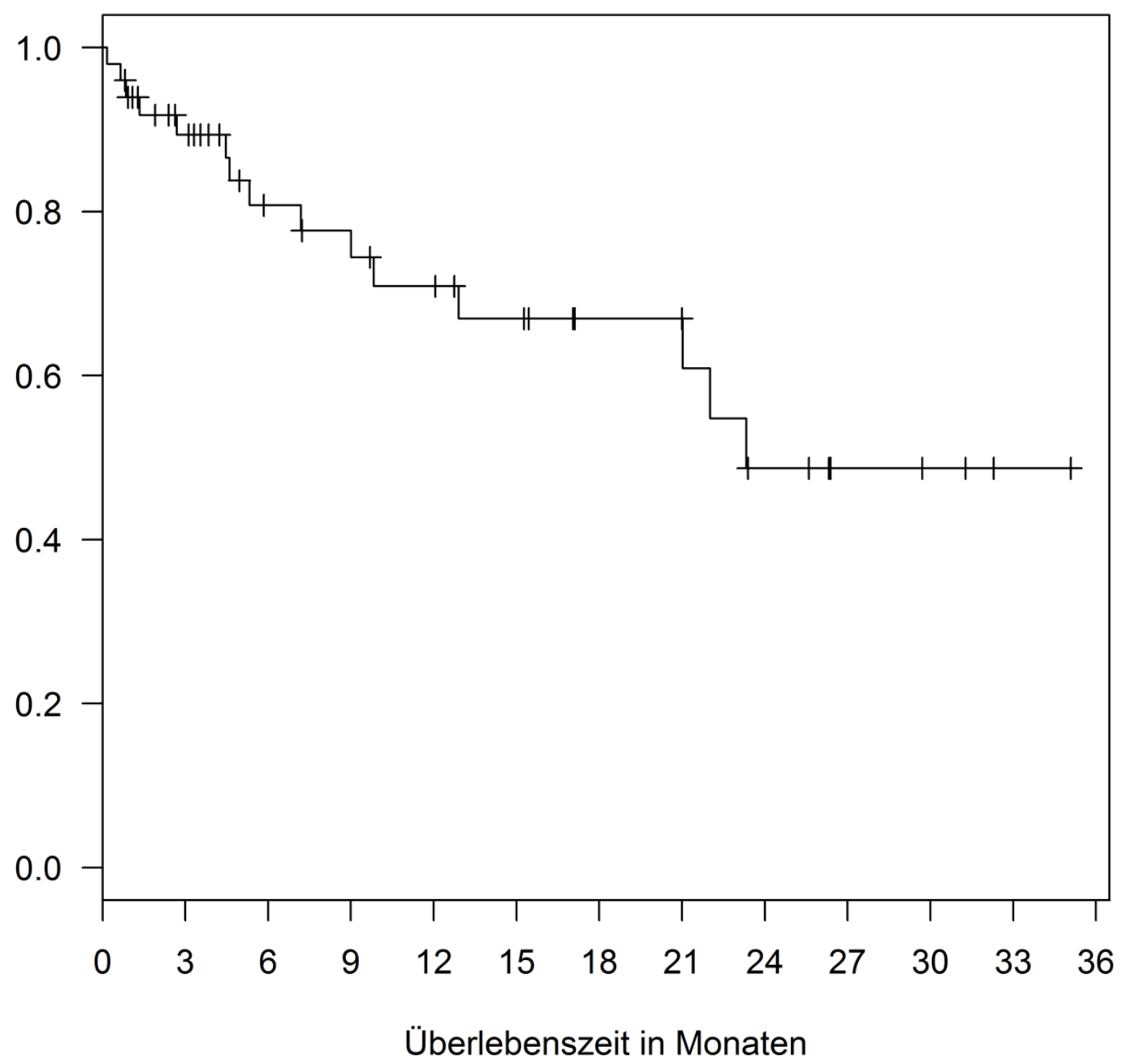

SCAIF = supraclavicular island flap; 


\subsection{Analyse der prä-, peri- und postoperativen Daten: Vergleich des SCAIFs mit dem RFFF}

Für die ökonomische Analyse wurden aus dem Gesamtkollektiv insgesamt 25 Patienten, die an einem Oropharynxkarzinom erkrankt waren und eine Tumorresektion mit Rekonstruktion des Defektes mittels SCAIF $(n=25)$ oder RFFF $(n=25)$ erhalten hatten, eingeschlossen. Folgende Parameter wurden dabei erfasst und zwischen beiden Kohorten verglichen:

- Demographie und Verlauf

- Tumorlokalisation

- Kostenkalkulation

- Perioperative Daten

- Operationsdauer

- Komplikationen

- Kostenanalyse

\subsubsection{Demographie}

Das mittlere Alter der SCAIF-Patientengruppe betrug 67,67 Jahre $( \pm 10,9)$ und war statistisch signifikant höher als das der RFFF-Patienten mit 60,12 Jahre $( \pm 7,9)$ im Mittel. Anteilig waren in der Gruppe der SCAIF 76,0\% der Patienten männlich, bei den RFFFs waren es $88,0 \%$. In beiden Gruppen war das untersuchte Plattenepithelkarzinom des Oropharynx bei 12,0\% der Patienten ein Rezidiv oder Zweitkarzinom, dabei hatten alle dieser Patienten in der SCAIF-Gruppe bereits eine vorherige RCT im Kopf-Halsbereich erhalten. In der RFFF-Gruppen dahingegen war kein Patient mit einer RCT vorbehandelt. Der Beobachtungszeitraum erstreckte sich in der SCAIF-Gruppe von 2,12 bis 26,54 Monate, bei den RFFFs waren es dagegen 3,12 bis 73,1 Monate. Beim Vergleich der Verteilung der pathologischen TNM-Stadien zwischen den Gruppen zeigte sich statistisch kein signifikanter Unterschied Gruppen $(p(T)=0,448 ; p(N)=0,514)$. Bei Aufschlüsselung in die UICC-Stadien zeigte sich ein signifikanter Unterschied zwischen den Gruppen bezüglich des Alters. Die SCAIF-Kohorte war im Mittel älter als die der RFFF-Patienten $(p=0,007)$ Genauere Informationen sind aus Tabelle 15 zu entnehmen. 
Tabelle 15: SCAIF versus RFFF ökonomische Analyse; Demographie und Verlauf

\begin{tabular}{lrlrll}
\hline Demographie und Vorgeschichte & \multicolumn{2}{c}{ SCAIF } & \multicolumn{1}{c}{ RFFF } & p-Wert \\
\hline Alter (a) \pm SD & 67,67 & $\pm 10,9$ & 60,12 & $\pm 7,9$ & $\mathbf{0 , 0 0 7}$ * \\
Männer in n (\%) & 19 & $(76,0)$ & 22 & $(88,0)$ & 0,274 \\
Frauen in n (\%) & 6 & $(24,0)$ & 3 & $(12,0)$ & \\
vorheriges Kopf-Halsmalignom in n (\%) & 3 & $(12,0)$ & 3 & $(12,0)$ & \\
vorherige RCT in n (\%) & 3 & $(12,0)$ & 0 & $(0,0)$ & \\
Nachbeobachtungszeitraum (mo) \pm SD & 10,82 & $\pm 8,7$ & 22,86 & $\pm 22,4$ & \\
TNM-Stadium in n (\%) & & & & & \\
T2 & 4 & $(16,0)$ & 2 & $(8,0)$ & 0,448 \\
T3 & 17 & $(68,0)$ & 18 & $(72,0)$ & \\
T4a & 4 & $(16,0)$ & 5 & $(20,0)$ & \\
N0 & 8 & $(32,0)$ & 6 & $(24,0)$ & 0,514 \\
N1 & 1 & $(4,0)$ & 8 & $(32,0)$ & \\
N2 & 15 & $(60,0)$ & 10 & $(40,0)$ & \\
N3 & 1 & $(4,0)$ & 1 & $(4,0)$ & \\
UICC-Stadium in n (\%) & & & & & $>\mathbf{0 , 0 5}$ * \\
UICC III & 8 & $(32,0)$ & 12 & $(48,0)$ & \\
UICC IVA & 17 & $(68,0)$ & 13 & $(54,0)$ & \\
\hline
\end{tabular}

* statisch signifikant $(\mathrm{p}<0,05)$;

$\mathrm{a}=\mathrm{Jahre} ; \mathrm{mo}=$ Monate; $\mathrm{RCT}=$ Radiochemotherapie; $\mathrm{RFFF}=$ radial free forearm flap SCAIF $=$ supraclavicular island flap; $\mathrm{SD}=$ standard deviation $; \mathrm{UICC}=$ Union of International Cancer Control;

Es wurden die Sublokalisationen „Tonsille, Weichgaumen, Rachenhinterwand“, „Zungengrund, Zungenkörper“ und „Zungenrand“ der Oropharynxkarzinomen in beiden Patientengruppen untersucht. Die Verteilung zwischen den Gruppen zeigte statistisch keinen signifikanten Unterschied. Bei den SCAIF-Patienten war der Tumor und somit der Defekt vorwiegend mit $44,0 \%$ an Weichgaumen, Tonsille oder Rachenhinterwand lokalisiert. Weitere Daten sind in Tabelle 16 aufgelistet.

Tabelle 16: SCAIF versus RFFF ökonomische Analyse; Sublokalisationen

\begin{tabular}{lrlll}
\hline Tumorlokalisation & \multicolumn{2}{c}{ SCAIF } & \multicolumn{2}{c}{ RFFF } \\
& $\mathrm{n}$ & $(\%)$ & $\mathrm{n}$ & $(\%)$ \\
\hline Tonsille, Weichgaumen, Rachenhinterwand & 11 & $(44,0)$ & 9 & $(36,0)$ \\
Zungengrund, Zungenkörper & 7 & $(28,0)$ & 7 & $(28,0)$ \\
Zungenrand & 7 & $(28,0)$ & 9 & $(36,0)$ \\
Gesamt & 25 & $(100,0)$ & 25 & $(100,0)$ \\
\hline
\end{tabular}

$\mathrm{RFFF}=$ radial free forearm flap; SCAIF = supraclavicular island flap; 


\subsubsection{Perioperative Daten Vergleich SCAIF- versus RFFF-Gruppe}

Perioperativ konnten folgende Daten ermittelt werden: Rate der Tracheotomien, Operationsdauer inklusive der Gesamtoperationsdauer, Lappenoperationsdauer und Lappenhebezeiten. Die Rate der Tracheotomien war in der SCAIF-Gruppe mit 64,0\% um $25,0 \%$ signifikant niedriger als in der RFFF-Gruppe mit 88,0\%, (p-Wert 0,049). Die Analyse konnte auch signifikante Unterschiede in der Dauer der Gesamtoperationsdauer, Lappenoperationsdauer und Lappenhebezeiten zwischen SCAIF und RFFF zeigen (pWerte $<0,001$, siehe Abbildung 4). Die Operationsdauer bei SCAIF-Patienten ( $n=14)$ war jeweils signifikant kürzer als die der RFFF-Patienten $(n=25)$. So dauerte die Lappenoperation bei den SCAIF-Patienten im Mittel 179,4 min $( \pm 62,4)$ und bei den RFFF waren es 404,2 $\min ( \pm 86,9)$ ( $\mathrm{p}$-Wert < 0,001). Auch der Vergleich der Lappenhebezeiten zeigte einen signifikanten Unterschied auf (p-Wert $<0,001)$. Bei der SCAIF-Kohorte waren es im Mittel 43,1 min $( \pm 16,3)$ und der RFFF-Kohorte waren es 100,7 min $( \pm 31,3)$. Ebenfalls wurde die postoperative intensivmedizinische Betreuung analysiert. In der RFFF-Gruppe war bei signifikant mehr Patienten ( $\mathrm{p}$-Wert $<0,001)$ ein Aufenthalt auf einer Intensivstation notwendig (92,0\%) als in der SCAIF-Gruppe (32,0\%). Einzelheiten sind Tabelle $17 \mathrm{zu}$ entnehmen.

Tabelle 17: SCAIF versus RFFF ökonomische Analyse; Perioperative Daten

\begin{tabular}{lrlrll}
\hline Perioperative Daten & \multicolumn{1}{c}{ SCAIF } & \multicolumn{2}{c}{ RFF } & p-Wert \\
\hline Tracheotomie in n (\%) & 16 & $(64,0)$ & 22 & $(88,0)$ & $\mathbf{0 , 0 4 9} *$ \\
Präoperative Vorbereitung (min) \pm SD & 54,5 & $\pm 21,6$ & 63,8 & $\pm 21,3$ & 0,136 \\
Lappenhebezeit (min) \pm SD & 43,1 & $\pm 16,3$ & 100,7 & $\pm 31,3$ & $<\mathbf{0 , 0 0 1} *$ \\
Lappenoperationszeit (min) \pm SD & 179,4 & $\pm 62,4$ & 404,2 & $\pm 86,9$ & $<\mathbf{0 , 0 0 1} *$ \\
Gesamte Operationszeit (min) \pm SD & $407,4 \pm 123,9$ & 585,4 & $\pm 142,6$ & $<\mathbf{0 , 0 0 1} *$ \\
Fläche des Transplantats in cm cm $^{2}$ & $74 \pm 37,5$ & 31,4 & $\pm 9,0$ & $\mathbf{0 , 0 0 1} *$ \\
Intensivaufenthalt erfolgt in n (\%) & 8 & $(32,0)$ & 23 & $(92,0)$ & $<\mathbf{0 , 0 0 1} *$ \\
Dauer des Intensivaufenthalts (h) \pm SD & 22,3 & \pm 59 & 35,1 & \pm 28 & 0,337 \\
\hline
\end{tabular}

* statisch signifikant $(\mathrm{p}<0,05)$;

$\mathrm{RFFF}=$ radial free forearm flap; $\mathrm{SCAIF}=$ supraclavicular island flap; $\mathrm{SD}=$ standard deviation 


\section{Abbildung 4: SCAIF versus RFFF, Vergleich der Operationszeiten}
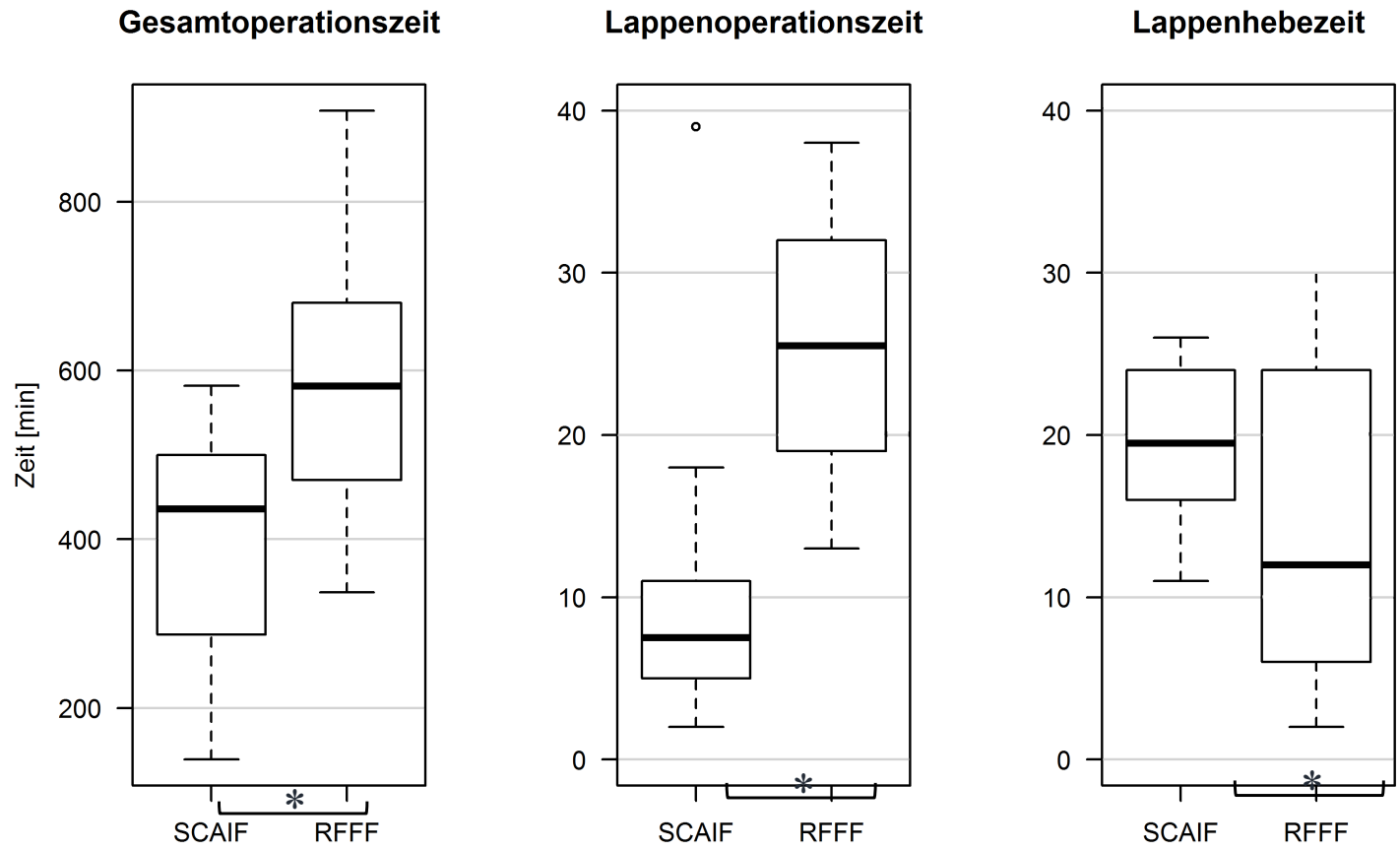

* statistisch signifikant $(\mathrm{p}<0,05) ;{ }^{\circ}$ statistischer Ausreißer-Messwert $\mathrm{RFFF}=$ radial free forearm flap; $\mathrm{SCAIF}=$ supraclavicular island flap;

\subsubsection{Kostenkalkulation Vergleich SCAIF- versus RFFF-Gruppe}

Die Kosten wurden für die beiden Rekonstruktionsarten ermittelt. Für die SCAIFMethode wurden Personalkosten pro Operation von insgesamt $1026,58 €( \pm 303,54)$ errechnet. Dahingegen waren diese signifikant ( $\mathrm{p}$-Wert $<0,001$, siehe Abbildung 5) niedriger als in der RFFF-Gruppe mit 2044,76 $€( \pm 463,69)$. Die Gesamtkosten (Personalkosten plus Intensivstations-Aufenthaltskosten) zeigten ebenfalls signifikante Unterschiede (p-Wert < 0,001). Die Kosten der RFFF pro Patient waren mit 4453,77€ 1,7mal höher als beim SCAIF mit 2621,15€. Graphisch sind die Werte in Abbildung 5 dargestellt. 


\section{Abbildung 5: Kostenanalyse, Vergleich SCAIF versus RFFF}

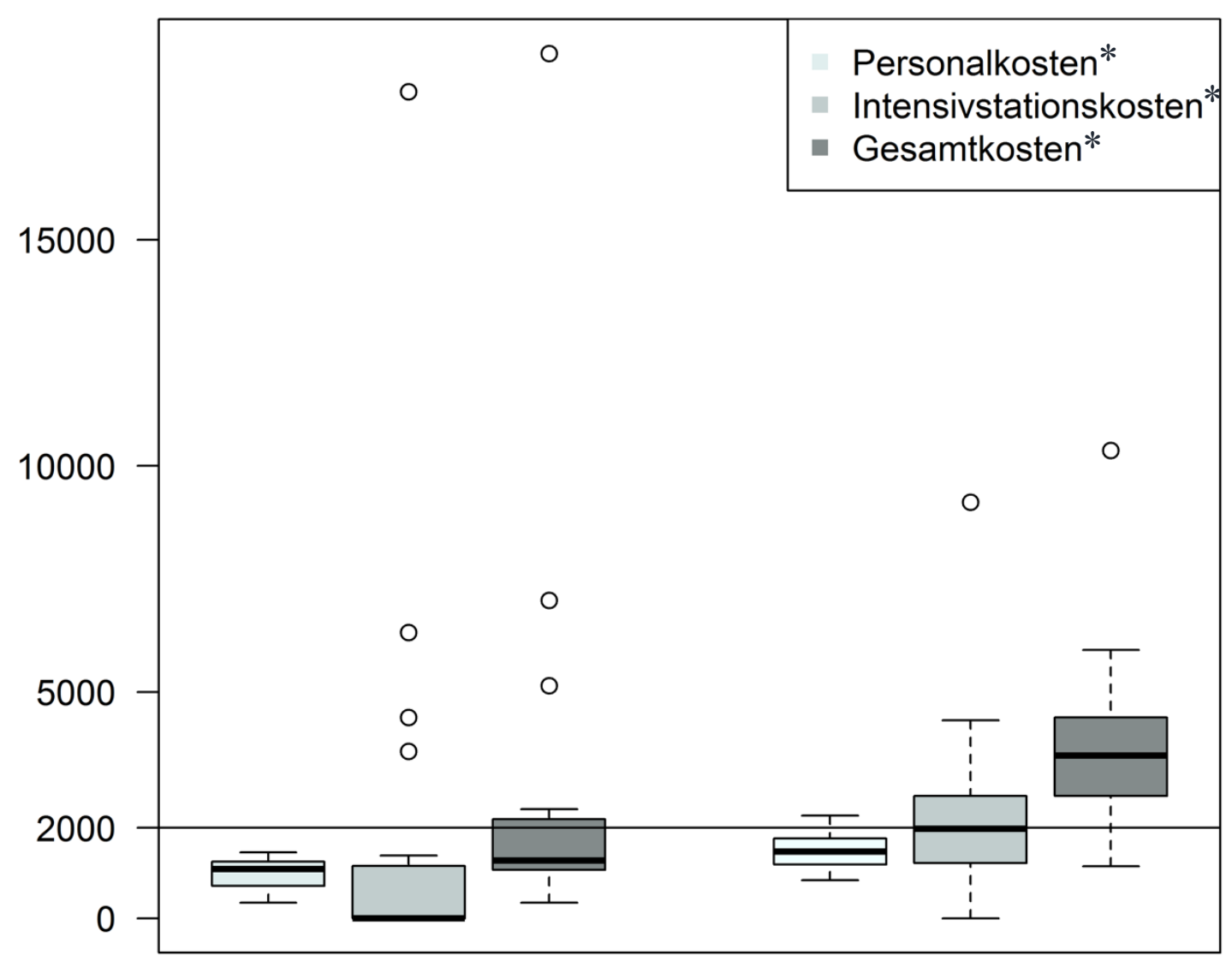

SCAIF

RFFF

* statistisch signifikant $(\mathrm{p}<0,05) ;{ }^{\circ}$ statistischer Ausreißer-Messwert

$\mathrm{RFFF}=$ radial free forearm flap; SCAIF = supraclavicular island flap;

\subsubsection{Postoperative Morbidität: Komplikationen der Spender- und Empfängerregionen}

Der Vergleich der Komplikationsraten sowohl an der Empfängerregion $(p=1,000)$ als auch an der Spenderregion ( $\mathrm{p}=0,651)$ zeigten keinen signifikanten Unterschied zwischen den beiden Gruppen. Hinsichtlich der Empfängerregion waren 68,0\% der SCAIFPatienten komplikationsfrei, in der RFFF-Gruppe waren es 64,0\%. Von den übrigen Patienten entwickelten in der SCAIF-Gruppe 24,0\% Minor-Komplikationen, die mit konservativer Behandlung abheilten. Insgesamt zwei Patienten $(8,0 \%)$ benötigten eine 
chirurgische Intervention. In der Kohorte der RFFF-Patienten benötigten 8,0\% der Patienten mit Komplikationen keine chirurgische Behandlung. Bei den übrigen 28,0\% musste die Wunde entweder revidiert werden oder sogar eine erneute Rekonstruktion mit einem Gewebetransplantat angestrebt werden. Detaillierte Informationen können aus Tabelle 18 entnommen werden.

Tabelle 18: SCAIF versus RFFF: Komplikationen der Empfängerregion

\begin{tabular}{lccccc}
\hline Komplikationen der Empfängerregion & \multicolumn{2}{c}{ SCAIF } & \multicolumn{2}{c}{ RFFF } & p-Wert \\
& $\mathrm{n}$ & $(\%)$ & $\mathrm{n}$ & $(\%)$ & \\
\hline $\begin{array}{l}\text { Komplikationen der Empfängerregion } \\
\text { keine }\end{array}$ & 17 & $(68,0)$ & 16 & $(64,0)$ & \\
$\quad$ minor & & & & & \\
$\quad$ Wundheilungsstörung & 3 & $(12,0)$ & 0 & $(0,0)$ & \\
$\quad$ Wunddehiszenz & 3 & $(12,0)$ & 2 & $(8,0)$ & \\
major & & & & & \\
$\quad$ Partielle Nekrose & 1 & $(4,0)$ & 4 & $(16,0)$ & \\
$\quad$ Fistel & 1 & $(4,0)$ & 0 & $(0,0)$ & \\
$\quad$ Lappenverlust & 0 & $(0,0)$ & 3 & $(12,0)$ & \\
\hline
\end{tabular}

Signifikanzniveau: $\mathrm{p}<0,05$;

$\mathrm{RFFF}=$ radial free forearm flap; SCAIF $=$ supraclavicular island flap;

Die Analyse der komplikationsfreien Rate in der Spenderregion zeigte eine ähnliche Verteilung mit $64,0 \%$ bei den SCAIF-Patienten und 52,0\% bei den RFFF-Patienten. In der SCAIF-Gruppe wiesen 32,0\% der Patienten Minor-Komplikationen und ein Patient (4,0\%) eine major mit chirurgischer Wundrevision. In der RFFF-Kohorte waren es 40,0\% mit minor und zwei (16,0\%) mit Major-Komplikationen (siehe Tabelle 19). 
Tabelle 19: SCAIF versus RFFF: Komplikationen der Spenderregion

\begin{tabular}{lccccc}
\hline Komplikationen der Spenderregion & \multicolumn{2}{c}{ SCAIF } & \multicolumn{2}{c}{ RFFF } & p-Wert \\
& $\mathrm{n}$ & $(\%)$ & $\mathrm{n}$ & $(\%)$ & \\
\hline $\begin{array}{l}\text { Komplikationen der Spenderregion } \\
\text { keine }\end{array}$ & 16 & $(64,0)$ & 13 & $(52,0)$ & 0,651 \\
$\quad \begin{array}{l}\text { minor } \\
\quad \text { Wundheilungsstörung }\end{array}$ & 7 & & & & \\
$\quad$ Wunddehiszenz & 1 & $(4,0)$ & 1 & $(4,0)$ & \\
major & & & & & \\
$\quad$ Partielle Nekrose & 1 & $(4,0)$ & 2 & $(16,0)$ & \\
\hline
\end{tabular}

Signifikanzniveau: $\mathrm{p}<0,05$;

$\mathrm{RFFF}=$ radial free forearm flap; SCAIF = supraclavicular island flap;

\subsection{Schultermorbidität}

Zur Evaluation der Gesamtmorbidität untersuchten wir die Schultermorbidität mittels des Constant-Murley-Scores und des DASH-Scoree. Von den 50 eingeschlossenen SCAIFPatienten konnte von 20 Patienten ein ausgefüllter Fragebogen akquiriert werden. Es folgte ein Vergleich zwischen der Spenderregion und kontralateralen Seite.

\subsubsection{Demographie}

Bei der Mehrheit der Patienten (75,0\%; $n=15)$ wurde mit der Indikation eines Primärtumors simultan die Tumorresektion mit beidseitiger ND und Rekonstruktion mit SCAIF durchgeführt. 15,0\% $(n=3)$ erhielten bei Vorliegen eines Rezidivtumors eine Tumorresektion, mit ipsilateraler ND und SCAIF-Rekonstruktion und bei zwei Patienten $(20,0 \%)$ wurde bei Behandlung einer postoperativen Fistel die alleinige SCAIF-Operation durchgeführt. Weitere Daten sind aus Tabelle $20 \mathrm{zu}$ entnehmen. 
Tabelle 20: SCAIF-Schultermorbidität; Demographie

\section{Demographie und Vorerkrankungen}

\begin{tabular}{|c|c|c|}
\hline Indikation & $\mathrm{n}$ & $(\%)$ \\
\hline Primärtumor & 15 & $(75,0)$ \\
\hline Rezidivtumor & 3 & $(15,0)$ \\
\hline Fistel & 2 & $(10,0)$ \\
\hline \multicolumn{3}{|l|}{ Therapie } \\
\hline Rekonstruktion mit SCAIF & 2 & $(10,0)$ \\
\hline Tumorresektion, ND bilateral, Rekonstruktion mit SCAIF & 15 & $(75,0)$ \\
\hline Tumorresektion, ND ipsilateral, Rekonstruktion mit SCAIF & 3 & $(15,0)$ \\
\hline \multicolumn{3}{|l|}{ Adjuvante Therapie } \\
\hline Keine & 6 & $(30,0)$ \\
\hline $\mathrm{RCT}$ & 11 & $(55,0)$ \\
\hline Rezidivtumor/palliativ & 2 & $(10,0)$ \\
\hline Abgelehnt (tumorfrei) & 1 & $(5,0)$ \\
\hline \multicolumn{3}{|l|}{ UICC-Tumorstadium } \\
\hline II & 2 & $(10,0)$ \\
\hline III & 7 & $(35,0)$ \\
\hline IVA & 11 & $(55,0)$ \\
\hline \multicolumn{3}{|l|}{ Kopf-Hals-Malignom } \\
\hline Vorbekanntes Malignom & 6 & $(30,0)$ \\
\hline Tumorresektion & 6 & $(30,0)$ \\
\hline A priori durchgeführte $\mathrm{RCT}$ & 5 & $(25,0)$ \\
\hline \multicolumn{3}{|l|}{ Nebendiagnosen } \\
\hline Kardiovaskuläre Erkrankung & 1 & $(5,0)$ \\
\hline Zwei Nebendiagnosen & 6 & $(30,0)$ \\
\hline Drei Nebendiagnosen & 2 & $(10,0)$ \\
\hline Mehr als drei Nebendiagnosen & 1 & $(5,0)$ \\
\hline Weitere onkologische Erkrankung & 2 & $(10,0)$ \\
\hline Andere Erkrankung & 1 & $(5,0)$ \\
\hline keine & 7 & $(35,0)$ \\
\hline \multicolumn{3}{|l|}{ Noxenanamnese } \\
\hline Alkoholiker & 8 & $(40,0)$ \\
\hline Raucher & 13 & $(65,0)$ \\
\hline Alkoholiker und Raucher & 8 & $(40,0)$ \\
\hline
\end{tabular}

ND = Neck Dissection; RCT $=$ Radiochemotherapie; SCAIF $=$ supraclavicular island flap $;$ UICC $=$ Union for International Cancer Control; 


\subsubsection{Postoperative Morbidität}

\section{Komplikationen, $\mathbf{N}$. accessorius und Affektion der dominanten Extremität}

Die Analyse der Daten konnte eine niedrige Komplikationsrate nachweisen. Bei nur einem Patienten (5,0\%) war die operative Revision der Wunde notwendig. 60,0\% $(n=12)$ hatten keine Komplikationen in der Spenderregion und 30,0\% (n=6) minor Komplikationen (z. B. Wunddehiszenz), welche durch sekundäre Wundheilung abheilten. Weitere Daten können aus Tabelle 21 entnommen werden. Bei 85,0\% konnte der $N$. accessorius während der ND und SCAIF-Operation erhalten werden. Nur ein Patient benötigte eine radikale ND (5,0\%) mit Resektion des $N$. accessorius auf der ipsilateralen Seite (siehe Tabelle 22). Bei 50,0\% der Patienten wurde die SCAIF-Operation an der dominanten Extremität durchgeführt.

Tabelle 21: SCAIF-Schultermorbidität; Komplikationen

\begin{tabular}{lrl}
\hline Komplikationen der Spenderregion & $\mathrm{n}$ & $(\%)$ \\
\hline Komplikationen & 12 & $(60,0)$ \\
Keine & 5 & $(25,0)$ \\
Protrahierte Wundheilung & 3 & $(15,0)$ \\
Dehiszenz & & \\
Therapie & 13 & $(65,0)$ \\
Keine & 6 & $(30,0)$ \\
Sekundäre Wundheilung & 1 & $(5,0)$ \\
Chirurgische Wundrevision &
\end{tabular}

SCAIF $=$ supraclavicular island flap;

\section{Tabelle 22: SCAIF-Schultermorbidität; Funktionalität}

\begin{tabular}{lrl}
\hline Funktionalität & $\mathrm{n}$ & $(\%)$ \\
\hline N. accessorius & 17 & $(85,0)$ \\
Intakt & 1 & $(5,0)$ \\
Reseziert & 2 & $(10,0)$ \\
Unbekannt & 2 \\
\hline
\end{tabular}

SCAIF = supraclavicular island flap;

\section{Schultermorbidität}

Die statistische Analyse des gesamten Constant-Murley-Scores konnte keinen signifikanten Unterschied zwischen der ipsi- und kontralateralen Seite nachweisen ( $\mathrm{p}=$ 
0,334, siehe Abbildung 6). Der Mittelwert des CS lag bei 65,50 $( \pm 20,04)$ ipsilateral und kontralateral 71,39 $( \pm 28,15)$. Die Analyse fokussierte sich auf die folgenden vier Hauptkategorien: Schmerz, Kraft, Bewegungsumfang und der Umgang mit Alltagsaktivitäten.

\section{Abbildung 6: Gesamter Constant-Murley-Score, Vergleich Spender- zur Gegenseite}

\section{Gesamter Constant-Murley-Score}

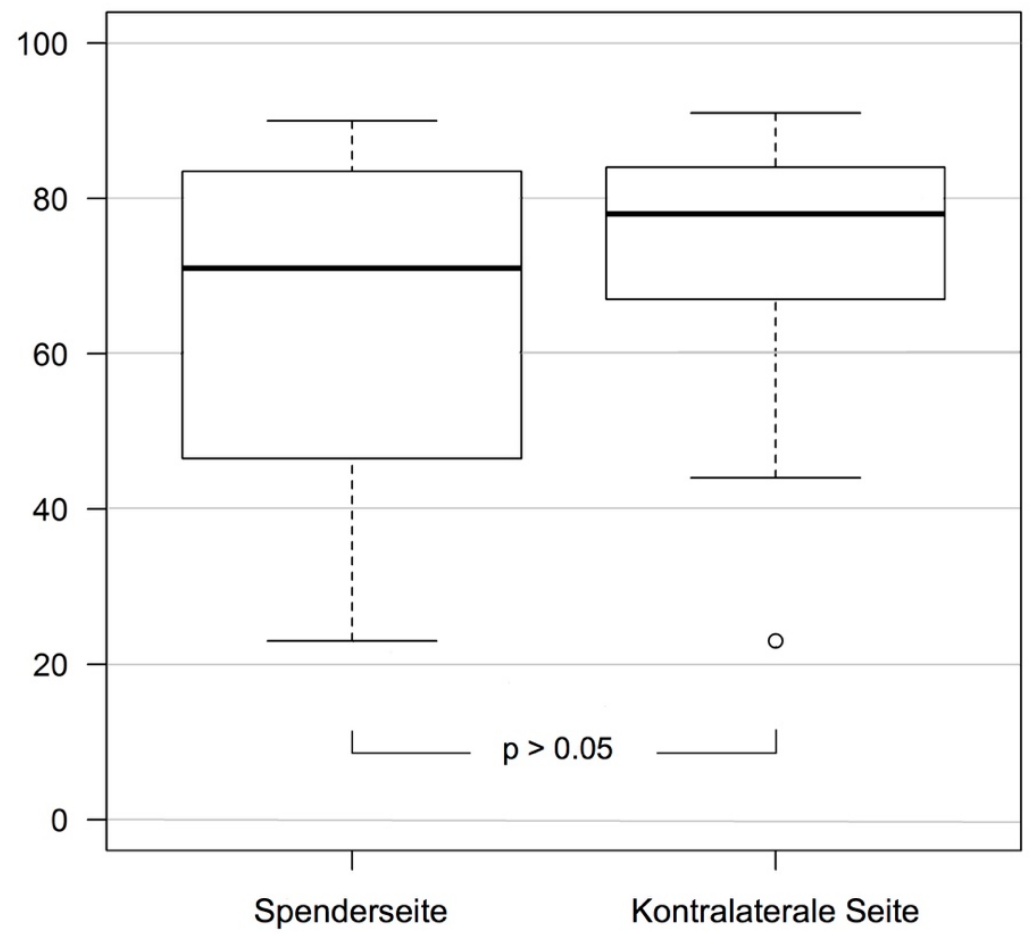

Signifikanzniveau: $\mathrm{p}<0,05$;

Wir evaluierten die Schmerzempfindung anhand einer visuellen Analogskala und konnten dabei keinen signifikanten Unterschied zwischen beiden Schultern feststellen ( $p$ $=0,150$ ) (siehe Abbildung 7). Die Verteilung war ipsilateral stärker gestreut als auf der Gegenseite. Die Mittelwerte betrugen 10,80 $( \pm 5,02)$ ipsilateral und 13,00 $( \pm 5,39)$ für die kontralaterale Seite. Die Hälfte der Patienten verneinte jeglichen Schulterschmerz. 
Abbildung 7: Schmerzempfindung, Vergleich Spender- zur Gegenseite

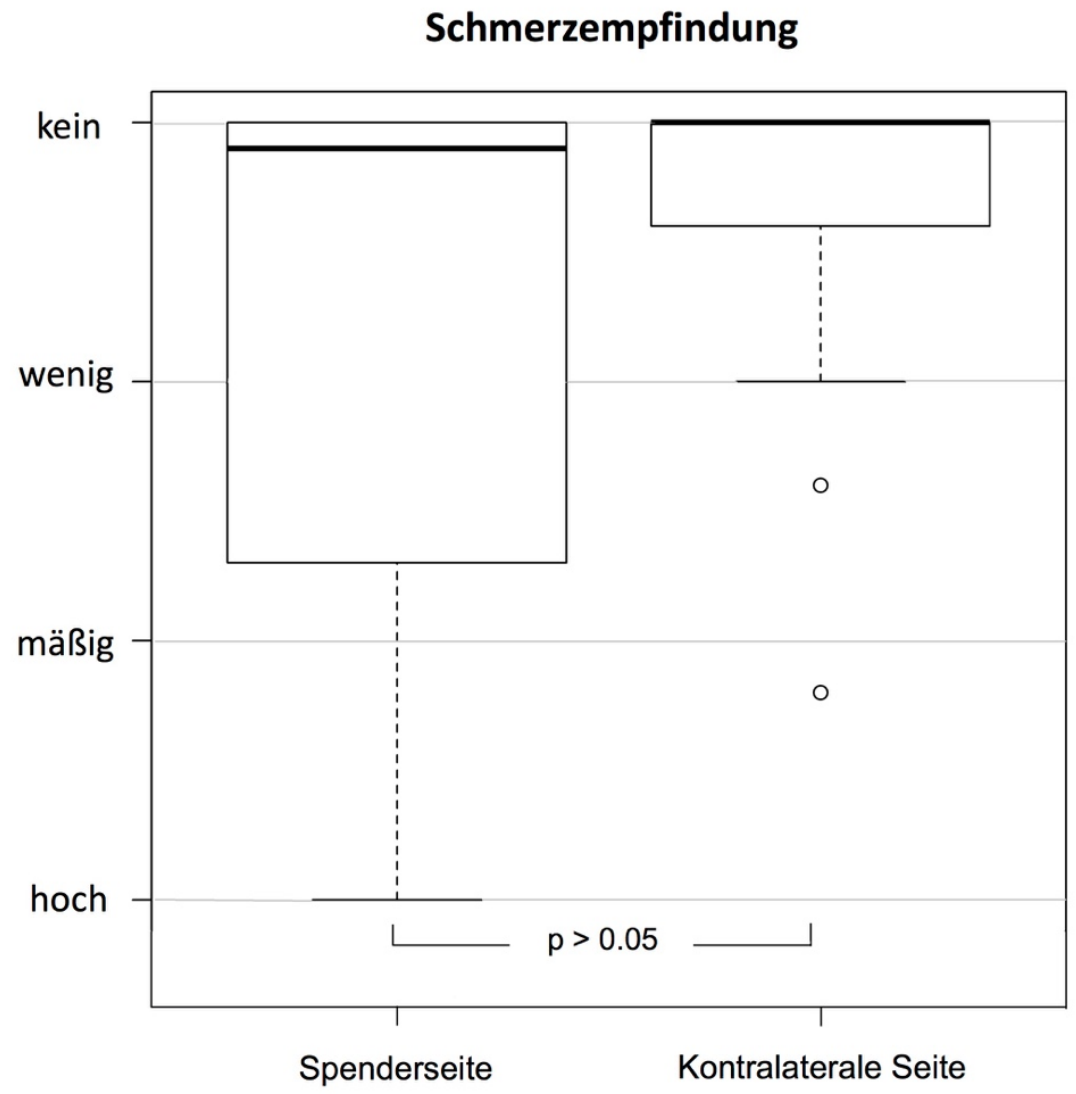

Signifikanzniveau: $\mathrm{p}<0,05$;

Zudem wurde die Kraft der Schulter in Abduktionsbewegung untersucht. Im Seitenvergleich konnte kein signifikanter Unterschied festgestellt werden $(\mathrm{p}=0,638)$. Wie in Abbildung 8 zu sehen ist, sind die Daten nicht normalverteilt, jedoch mit gleicher Varianz in der Messung beider Extremitäten. Der Mittelwert der SCAIF-operierten Seite betrug $6,80( \pm 4,54)$ und 7,17 $( \pm 4,62)$ für die Gegenseite. 
Abbildung 8: Kraft, Vergleich Spender- zur Gegenseite

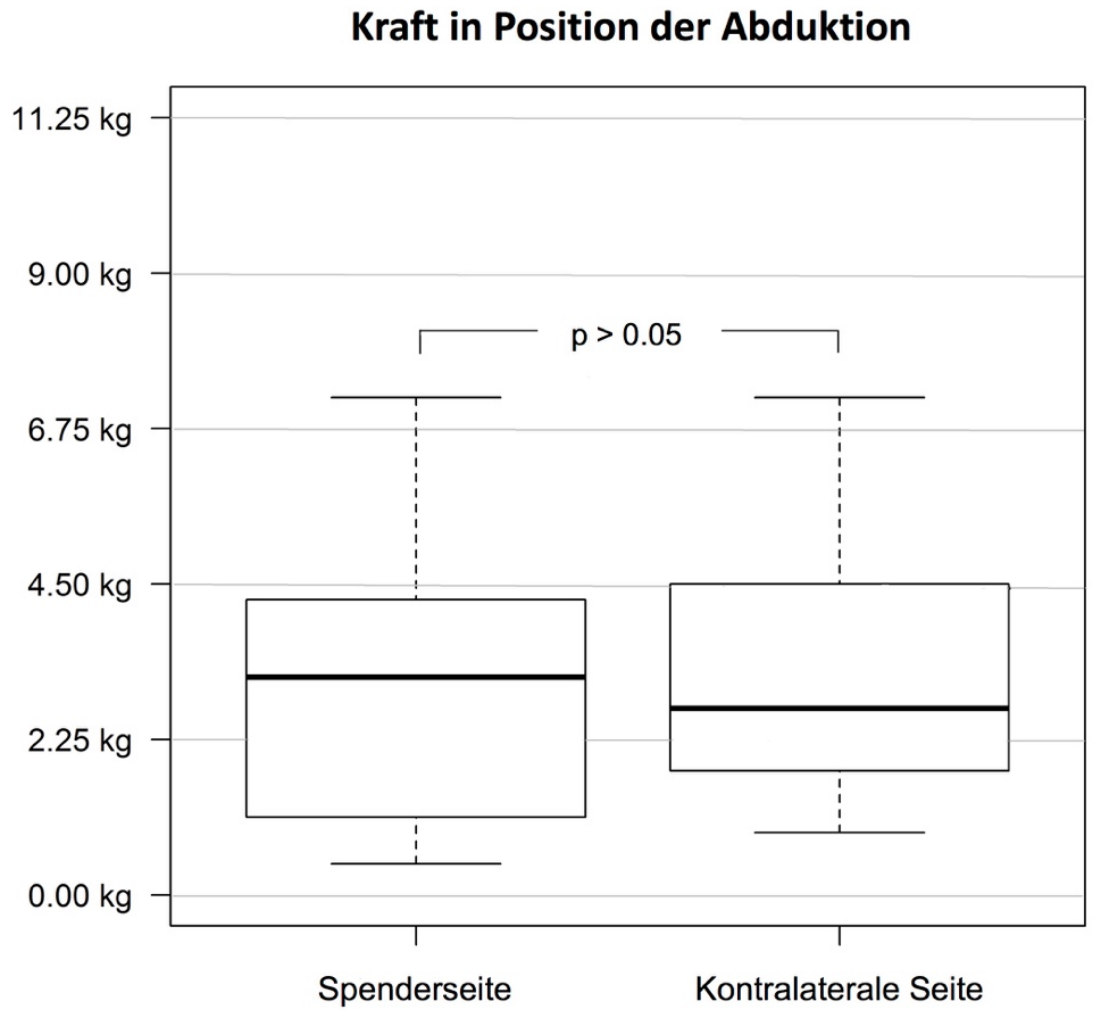

Signifikanzniveau: $\mathrm{p}<0,05$;

Eingeschlossen in die Untersuchung des Bewegungsumfanges war die Armposition in den definierten Positionen der Innenrotation, Außenrotation, Abduktion mit Elevation der Schulter und Flexion (ipsilateral $n=20$; kontralateral $n=18$ ). Hinsichtlich der Armposition konnte kein signifikanter Unterschied im Vergleich gefunden werden $(\mathrm{p}=0,861)$. Der Mittelwert für die ipsilaterale Seite ware 9,0 $( \pm 1,78)$ und 9,22 $( \pm 3,26)$ kontralateral. $70,0 \%$ der Patienten war es möglich, alle untersuchten Bewegungen ohne jegliche Einschränkungen durchzuführen. Die Analyse des Bewegungsumfanges zeigte bei etwa $50,0 \%$ beidseits keine Einschränkung ( $p=0,986$ ). Bei 60,0\% der Patienten war die Schulterflexion problemlos mit der operierten Seite und bei 66,7\% mit Gegenseite möglich $(\mathrm{p}=0,929)$. Die Untersuchung der Innenrotation zeigte, dass jediglich 35,0\% der Patienten problemlos die Interscapularregion mit der operierten Extremität erreichen konnten, wohingegen mehr als die Hälfte der Kohorte diese Bewegung mit der gesunden Extremität durchführen konnte $(\mathrm{p}=0,344)$. Die vorgegebenen Bewegungen zur Messung der Außenrotation konnten 65,0\% der Patienten ohne Einschränkungen mit der ipsilateralen Schulter durchführen, 77,1\% mit der Gegenseite $(p=0,408$, siehe Tabelle 
23). In unserer Analyse führten $40,0 \%$ der Patienten keine Einschränkung alltäglicher Aktivitäten an, und Schlaf war bei $60,0 \%$ der Kohorte ungestört möglich (siehe Tabelle 24).

Tabelle 23: SCAIF-Schultermorbidität; Bewegungsumfang

\begin{tabular}{|c|c|c|c|}
\hline \multirow{2}{*}{$\begin{array}{l}\text { Bewegungsumfang } \\
\text { Armposition }\end{array}$} & Ipsilateral & \multicolumn{2}{|c|}{ Kontralateral } \\
\hline & $\mathrm{n} \quad(\%)$ & $\mathrm{n}$ & $(\%)$ \\
\hline Bis zur Hüfte & $20 \quad(100,0)$ & 18 & $(100,0)$ \\
\hline Bis zum Xiphoid & $20 \quad(100,0)$ & 18 & $(100,0)$ \\
\hline Bis zum Hals & $19(95,0)$ & 17 & $(94,4)$ \\
\hline Bis zum Scheitel & $17 \quad(85,0)$ & 17 & $(11,1)$ \\
\hline Überkopf & $14(70,0)$ & 14 & $(77,8)$ \\
\hline \multicolumn{4}{|l|}{ Abduktion und Elevation } \\
\hline $30^{\circ}-60^{\circ}$ & $20 \quad(100,0)$ & 18 & $(100,0)$ \\
\hline $61^{\circ}-90^{\circ}$ & $20 \quad(100,0)$ & 18 & $(100,0)$ \\
\hline $91^{\circ}-120^{\circ}$ & $17 \quad(85,0)$ & 17 & $(94,4)$ \\
\hline $121^{\circ}-160^{\circ}$ & $13(65,0)$ & 12 & $(66,7)$ \\
\hline $161^{\circ}-180^{\circ}$ & $10 \quad(50,0)$ & 9 & $(50,0)$ \\
\hline \multicolumn{4}{|l|}{ Flexion } \\
\hline $30^{\circ}-60^{\circ}$ & $20 \quad(100,0)$ & 18 & $(100,0)$ \\
\hline $61^{\circ}-90^{\circ}$ & $20 \quad(100,0)$ & 18 & $(100,0)$ \\
\hline $91^{\circ}-120^{\circ}$ & $18 \quad(90,0)$ & 17 & $(94,4)$ \\
\hline $121^{\circ}-160^{\circ}$ & $15(75,0)$ & 14 & $(77,8)$ \\
\hline $161^{\circ}-180^{\circ}$ & $12(60,0)$ & 12 & $(66,7)$ \\
\hline \multicolumn{4}{|l|}{ Innenrotation } \\
\hline Oberschenkel lateral & $20 \quad(100,0)$ & 18 & $(5,6)$ \\
\hline Glutealregion & $19(95,0)$ & 17 & $(94,4)$ \\
\hline Lumbosacraler Übergang & $18(90,0)$ & 16 & $(88,9)$ \\
\hline Hüfte Höhe LWK 3 & $18(90,0)$ & 16 & $(88,9)$ \\
\hline Höhe BWK 12 & $15(75,0)$ & 15 & $(83,3)$ \\
\hline Interscapularregion Höhe BWK 7 & $7 \quad(35,0)$ & 10 & $(55,6)$ \\
\hline \multicolumn{4}{|l|}{ Außenrotation } \\
\hline Hand auf den Scheitel, Ellbogen nach vorne & $20 \quad(100,0)$ & 18 & $(100,0)$ \\
\hline Hand auf den Scheitel, Ellbogen zur Seite & $16(80,0)$ & 16 & $(88,9)$ \\
\hline Hand ans Okziput, Ellbogen nach vorne & $17(85,0)$ & 17 & $(94,4)$ \\
\hline Hand ans Okziput, Ellbogen zur Seite & $13(65,0)$ & 15 & $(83,3)$ \\
\hline Überkopf & $13(65,0)$ & 15 & $(83,3)$ \\
\hline Keine Einschränkungen & $13(65,0)$ & 14 & $(77,8)$ \\
\hline
\end{tabular}

BWK = Brustwirbelkörper; LWK = Lendenwirbelkörper; SCAIF = supraclavicular island flap; 
Tabelle 24: SCAIF-Schultermorbidität; Alltägliche Aktivitäten

\begin{tabular}{lrlrl}
\hline Alltägliche Aktivitäten & Ipsilateral & \multicolumn{2}{c}{ Kontralateral } \\
\hline Freizeitaktivitäten: Einschränkungsgrad & $\mathrm{n}$ & $(\%)$ & $\mathrm{n}$ & $(\%)$ \\
$100 \%$ & 2 & $(10,0)$ & 1 & $(5,6)$ \\
$75 \%$ & 2 & $(10,0)$ & 2 & $(11,1)$ \\
$50 \%$ & 4 & $(20,0)$ & 3 & $(16,7)$ \\
$25 \%$ & 4 & $(20,0)$ & 1 & $(5,6)$ \\
$0 \%$ & 8 & $(40,0)$ & 11 & $(61,1)$ \\
Affizierter Schlaf: Einschränkungsgrad & & & & \\
Stark & 1 & $(5,0)$ & 1 & $(5,6)$ \\
Moderat & 7 & $(35,0)$ & 6 & $(33,3)$ \\
Keine & 12 & $(60,0)$ & 11 & $(61,1)$ \\
Schmerzen & & & & \\
Hoch & 3 & $(15,0)$ & 2 & $(11,1)$ \\
Moderat & 5 & $(25,0)$ & 1 & $(5,6)$ \\
Gering & 2 & $(10,0)$ & 2 & $(11,1)$ \\
Keine & 10 & $(50,0)$ & 13 & $(72,2)$ \\
\hline
\end{tabular}

SCAIF = supraclavicular island flap;

Der DASH-Score wurde ausschließlich an der ipsilateralen Extremität untersucht. Der Mittelwert lag bei 32,52 $( \pm 28,58)$ mit einem Minimum von 0 und Maximum bei 91,67 (siehe Abbildung 9). 
Abbildung 9: DASH-Score der Spenderschulter

DASH-Score

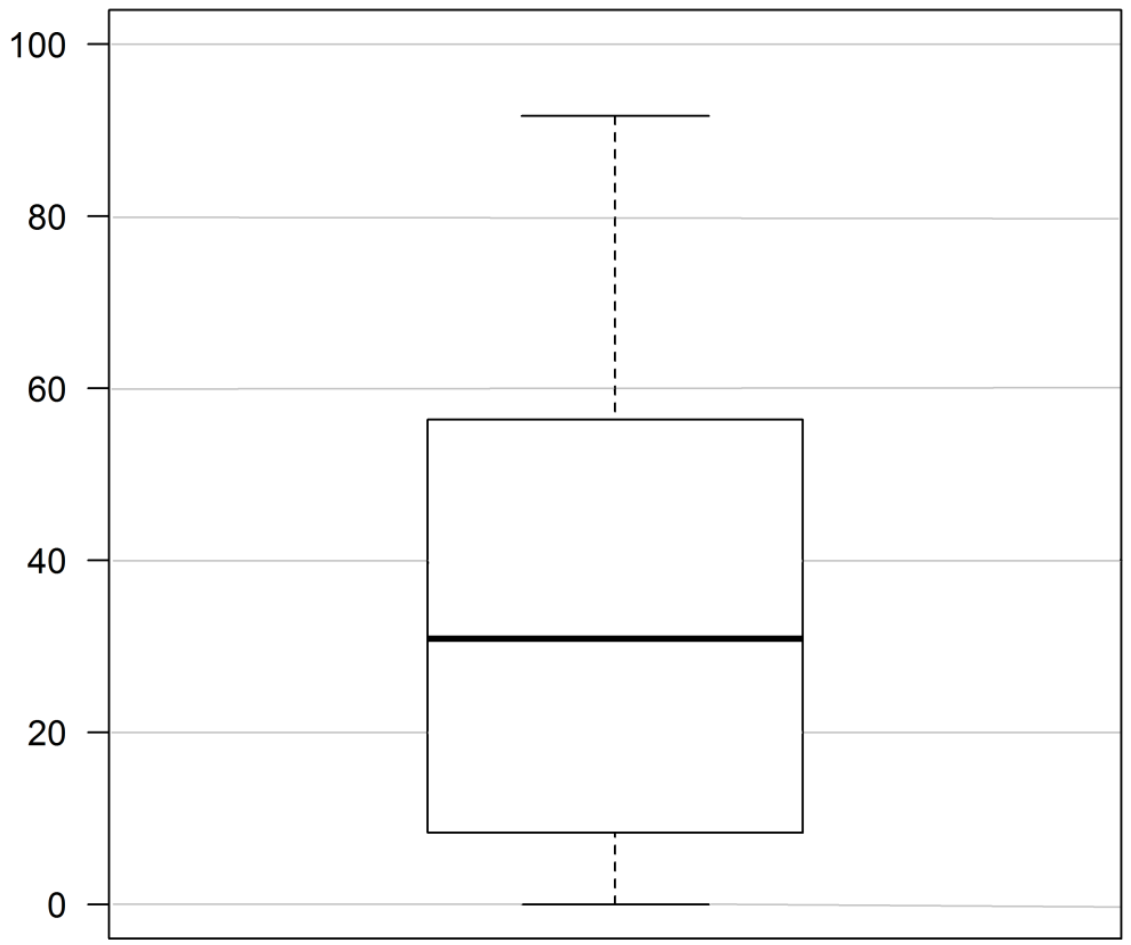

DASH $=$ Disability of the Arm, Shoulder and Hand Measure

Sensibilitätseinschränkungen im Sinne von Taubheit in der Schulterregion wurden von 15 Patienten (75,0\%) berichtet, vier Patienten (20,0\%) berichteten zudem über Kribbelparästhesien. Fünf Patienten $(25,0 \%)$ verneinten jegliche Sensibilitätsprobleme. Keiner der eingeschlossenen Patienten berichtete über Temperaturmissempfindungen (z. B. Kälteempfindung an der betroffenen Schulter beim Trinken von kalter Flüssigkeit) oder Phantomschmerzen.

\subsection{Analyse der Lebensqualität im Vergleich SCAIF versus RFFF}

Von 92 konsekutiven Patienten der Kohorte, die jeweils zur Rekonstruktion einen SCAIF oder RFFF erhielten, wurden - nach Anwendung der Ein- und Ausschlusskriterien und Ausschluss der Patienten, die nicht an der Studie teilnahmen oder die Fragebögen nicht ausfüllten/zurückgaben - 24 Patienten (12 SCAIF versus 12 RFFF) ermittelt. 


\subsubsection{Demographie}

Die Auswertung und der Vergleich der demographischen Daten zwischen den Kohorten zeigten keine statistisch signifikanten Unterschiede und können aus Tabelle 25 entnommen werden. Die Analyse der Röntgenbreischluckuntersuchung zeigte ähnliche Komplikationsraten in beiden Kohorten. In der SCAIF-Kohorte erfolgte der Verlauf bei fünf Patienten $(41,7 \%)$ komplikationslos, bei den RFFF-Patienten waren es sieben (58,3\%). Bei jeweils zwei Patienten wurde keine Breischluckuntersuchung durchgeführt. Die genaue Auflistung der Aspirations- und Fistelraten kann aus Tabelle 25 entnommen werden. Bezüglich der Empfängerregion heilte bei jeweils acht Patienten die Wunde komplikationslos $\mathrm{ab}(\mathrm{p}=0,408)$. Die vier übrigen SCAIF-Patienten benötigten keine chirurgische Intervention und konnten konservativ behandelt werden. Drei der RFFFPatienten kamen ebenfalls nach konservativer Behandlung zur Abheilung und bei einem Patienten war eine chirurgische Wundrevision notwendig. Komplikationsraten in der Spenderregion zeigten keinen signifikanten Unterschied $(p=0,910)$. Die TracheostomaRate war bei den RFFF-Patienten nicht signifikant höher $(\mathrm{p}=0,369)$ mit 83,8\% und $58,3 \%$ bei den SCAIF-Patienten. Auf Grund von postoperativer Einschränkung der Schluckfunktion benötigte die Hälfte der SCAIF-Kohorte die Anlage einer PEG-Sonde, bei den RFFF-Patienten waren es nur 25,0\%. Drei SCAIF-Patienten wurden posttherapeutisch zur Verbesserung der Schluckfunktion phoniatrisch weiterbetreut, dahingegen keiner der RFFF-Patienten. 
Tabelle 25: SCAIF versus RFFF Lebensqualität; Demographie

\begin{tabular}{|c|c|c|c|c|c|c|}
\hline Demographie & \multicolumn{2}{|c|}{ SCAIF } & \multicolumn{2}{|c|}{ RFFF } & \multicolumn{2}{|c|}{ Total } \\
\hline & & SD & & SD & & $\mathrm{SD}$ \\
\hline Beobachtungszeitraum (mo) & 22,2 & $\pm 9,5$ & 22.3 & $\pm 16,3$ & 22,3 & $\pm 13,1$ \\
\hline Alter (a) & 67,9 & $\pm 7,8$ & 59,6 & $\pm 8,6$ & 63,7 & $\pm 9,0$ \\
\hline Geschlecht & $\mathrm{n}$ & $(\%)$ & $\mathrm{n}$ & $(\%)$ & \multicolumn{2}{|c|}{ p-Wert } \\
\hline Männlich & 8 & $(66,7)$ & 10 & $(83,3)$ & \multicolumn{2}{|c|}{0,637} \\
\hline Weiblich & 4 & $(33,3)$ & 2 & $(16,7)$ & & \\
\hline UICC-Tumorstadium & & & & & \multicolumn{2}{|c|}{0,413} \\
\hline III & 5 & $(41,7)$ & 8 & $(66,7)$ & & \\
\hline IV & 7 & $(58,3)$ & 4 & $(33,3)$ & & \\
\hline \multicolumn{7}{|l|}{ Röntgenbreischluck } \\
\hline Keine Komplikationen & 5 & $(41,7)$ & 7 & $(58,3)$ & & \\
\hline Aspiration & 3 & $(25,0)$ & 3 & $(25,0)$ & & \\
\hline Fistel & 1 & $(8,3)$ & 0 & $(0,0)$ & & \\
\hline Aspiration und Fistel & 1 & $(8,3)$ & 0 & $(0,0)$ & & \\
\hline Nicht durchgeführt & 2 & $(16,7)$ & 2 & $(16,7)$ & & \\
\hline PEG & 6 & $(50,0)$ & 3 & $(25,0)$ & \multicolumn{2}{|c|}{0,399} \\
\hline Tracheotomie & 7 & $(58,3)$ & 10 & $(83,3)$ & \multicolumn{2}{|c|}{0,369} \\
\hline Komplikationen Empfängerregion & & & & & \multicolumn{2}{|c|}{0,408} \\
\hline Keine & 8 & $(66,7)$ & 8 & $(66,7)$ & & \\
\hline minor & 4 & $(33,3)$ & 1 & $(8,3)$ & & \\
\hline major & 0 & $(0,0)$ & 3 & $(25,0)$ & & \\
\hline Komplikationen Spenderregion & & & & & \multicolumn{2}{|c|}{0,910} \\
\hline keine & 7 & $(58,3)$ & 6 & $(50,0)$ & & \\
\hline minor & 4 & $(33,3)$ & 5 & $(41,7)$ & & \\
\hline major & 1 & $(8,3)$ & 1 & $(8,3)$ & & \\
\hline Phoniatrische Nachbetreuung & 3 & $(25,0)$ & 0 & $(0,0)$ & & 217 \\
\hline \multicolumn{7}{|l|}{ Adjuvante Therapie } \\
\hline keine & 1 & $(8,3)$ & 1 & $(8,3)$ & & \\
\hline $\mathrm{RCT}$ & 8 & $(66,7)$ & 10 & $(83,3)$ & & \\
\hline Rezidiv-/Palliativsituation & 2 & $(16,7)$ & 0 & $(0,0)$ & & \\
\hline Abgelehnt & 1 & $(8,3)$ & 0 & $(0,0)$ & & \\
\hline Verstorben & 0 & $(0,0)$ & 1 & $(8,3)$ & & \\
\hline \multicolumn{7}{|l|}{ Vorerkrankungen } \\
\hline Keine & 3 & $(25,0)$ & 2 & $(16,7)$ & & \\
\hline Kardiovaskuläres Risiko & 0 & $(0,0)$ & 4 & $(33,3)$ & & \\
\hline Zwei & 5 & $(41,7)$ & 4 & $(33,3)$ & & \\
\hline Drei & 2 & $(16,7)$ & 0 & $(0,0)$ & & \\
\hline Mehr als drei & 1 & $(8,3)$ & 1 & $(8,3)$ & & \\
\hline Andere Krebserkrankung & 1 & $(8,3)$ & 1 & $(8,3)$ & & \\
\hline
\end{tabular}




\begin{tabular}{|c|c|c|c|c|c|}
\hline Rauchen & 7 & $(58,3)$ & & $(66,7)$ & 0,587 \\
\hline Alkohol & 3 & $(25,0)$ & 6 & $(50,0)$ & 0,319 \\
\hline
\end{tabular}

Signifikanzniveau: $\mathrm{p}<0,05$;

$\mathrm{PEG}=$ perkutane endoskopische Gastrostomie; RFFF $=$ radial free forearm flap $; \mathrm{RCT}=$ Radiochemotherapie; SCAIF $=$ supraclavicular island flap $; \mathrm{SD}=$ standard deviation $; \mathrm{UICC}=$ Union for International Cancer Control;

In der Patientengruppe der RFFF zeigte sich eine gleichmäßige Verteilung der Tumorlokalisationen, bei der SCAIF-Gruppe waren der Großteil (58,3\%) Tonsillen-, Weichgaumen- oder Pharynxwandkarzinome. Weitere Daten sind aus Tabelle 26 zu entnehmen.

Tabelle 26: SCAIF versus RFFF Lebensqualität; Tumorlokalisationen

\begin{tabular}{lcccc}
\hline Tumorlokalisation & \multicolumn{2}{c}{ SCAIF } & \multicolumn{2}{c}{ RFFF } \\
& $\mathrm{n}$ & $(\%)$ & $\mathrm{n}$ & $(\%)$ \\
\hline Tonsille, Weichgaumen, Pharynxwand & 7 & $(58,3)$ & 4 & $(33,3)$ \\
Zungengrund, -körper & 2 & $(16,7)$ & 4 & $(33,3)$ \\
Zungenrand & 3 & $(25,0)$ & 4 & $(33,3)$ \\
\hline
\end{tabular}

$\mathrm{RFFF}=$ radial free forearm flap $; \mathrm{SCAIF}=$ supraclavicular island flap $; \mathrm{SD}=$ standard deviation;

\subsubsection{Auswertung der Lebensqualitätsfragebögen}

Die statistische Analyse des EORTC QLQ-C30 Fragebogens zeigte keinen signifikanten Unterschied zwischen beiden Patientengruppen (siehe Abbildung 10 und Abbildung 11). Der Allgemeinzustand wurde bei den SCAIF-Patienten mit 50,7 bei den RFFF-Patienten mit 52,1 (p-Wert = 0,929) bemessen. „Rollenfunktion“ war der Parameter, der in beiden Gruppen am stärksten beeinträchtigt war und „kognitive Funktion“ der, der am wenigsten beeinflusst wurde. Hinsichtlich der Symptom-bezogenen Parameter waren postoperative drei besonders betroffen: „Schlafprobleme“ (SCAIF 50,0; RFFF 44,4), „Erschöpfung“ (SCAIF 49,1; RFFF 47,2) und Dyspnoe (SCAIF 44,4; RFFF 47,2). Die Ergebnisse der SCAIF-Patienten waren marginal besser als die der RFFF-Patienten, jedoch ohne statistisch signifikanten Unterschied. Der Vergleich beider Gruppen geht aus Tabelle 27 und Abbildung 10 hervor. 
Abbildung 10: EORTC QLQ-C30 SCAIF versus RFFF

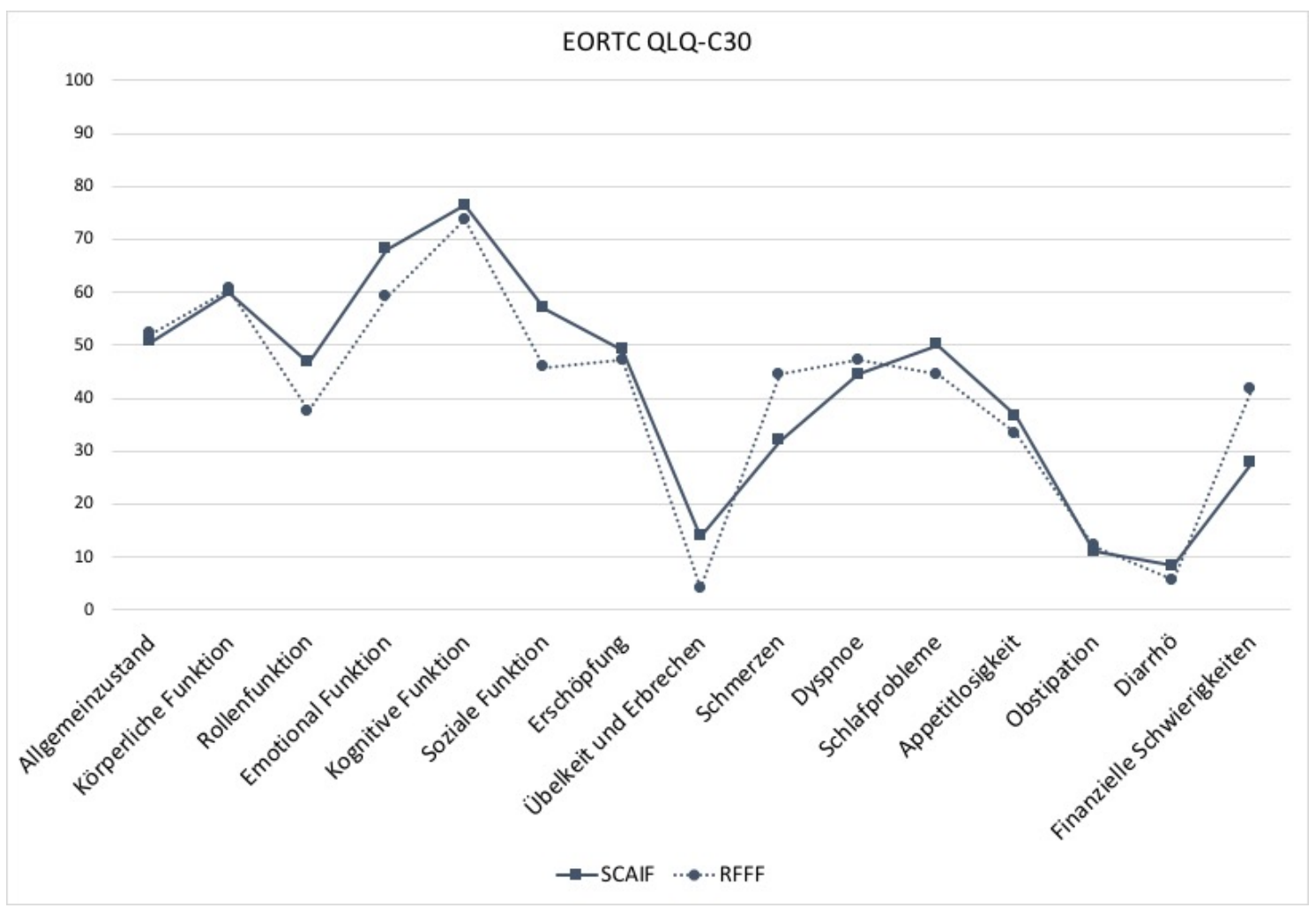

Signifikanzniveau: $\mathrm{p}<0,05$;

EORTC $=$ European Organisation for Research and Treatment of Cancer $;$ RFFF $=$ radial free forearm flap $;$ SCAIF $=$ supraclavicular island flap;

Auch konnte die Analyse des EORTC QLQ-H\&N35-Fragebogens überwiegende keine signifikanten Unterschiede aufzeigen, mit Ausnahme der Parameter „Einschränkungen des Geruchs- und Geschmackssinns“ (SCAIF 12,5; RFFF 44,4; p-Wert 0,02) und „Sprechprobleme“" (SCAIF 35,2; RFFF 44,4; p-Wert 0,018). Diese zeigten jeweils eine geringere Punktezahl in der Gruppe der SCAIF-Patienten, was mit einer besseren Funktion in diesen Bereichen gleichzusetzen ist. Der Vergleich der übrigen Parameter zwischen den beiden Gruppen zeigte keine signifikanten Unterschiede. Die stärksten Symptome in der Gruppe der SCAIF-Patienten waren „Einschränkungen in der Sexualität“ (65,2), „Analgetika“ (60,0), „klebriger Speichel“ (57,6), Probleme mit „Ernährungssupplementen“ (50,0) und mit der „Ernährungssonde“ $(50,0)$. In der RFFFGruppe waren es „Xerostomie“ $(63,9)$, „klebriger Speichel“ $(60,6)$ und Probleme mit „sozialem Essen“ $(55,3)$. Der Vergleich ist in

Tabelle 27 und Abbildung 11 aufgeführt. 


\section{Abbildung 11: EORTC QLQ-H\&N35 SCAIF versus RFFF}

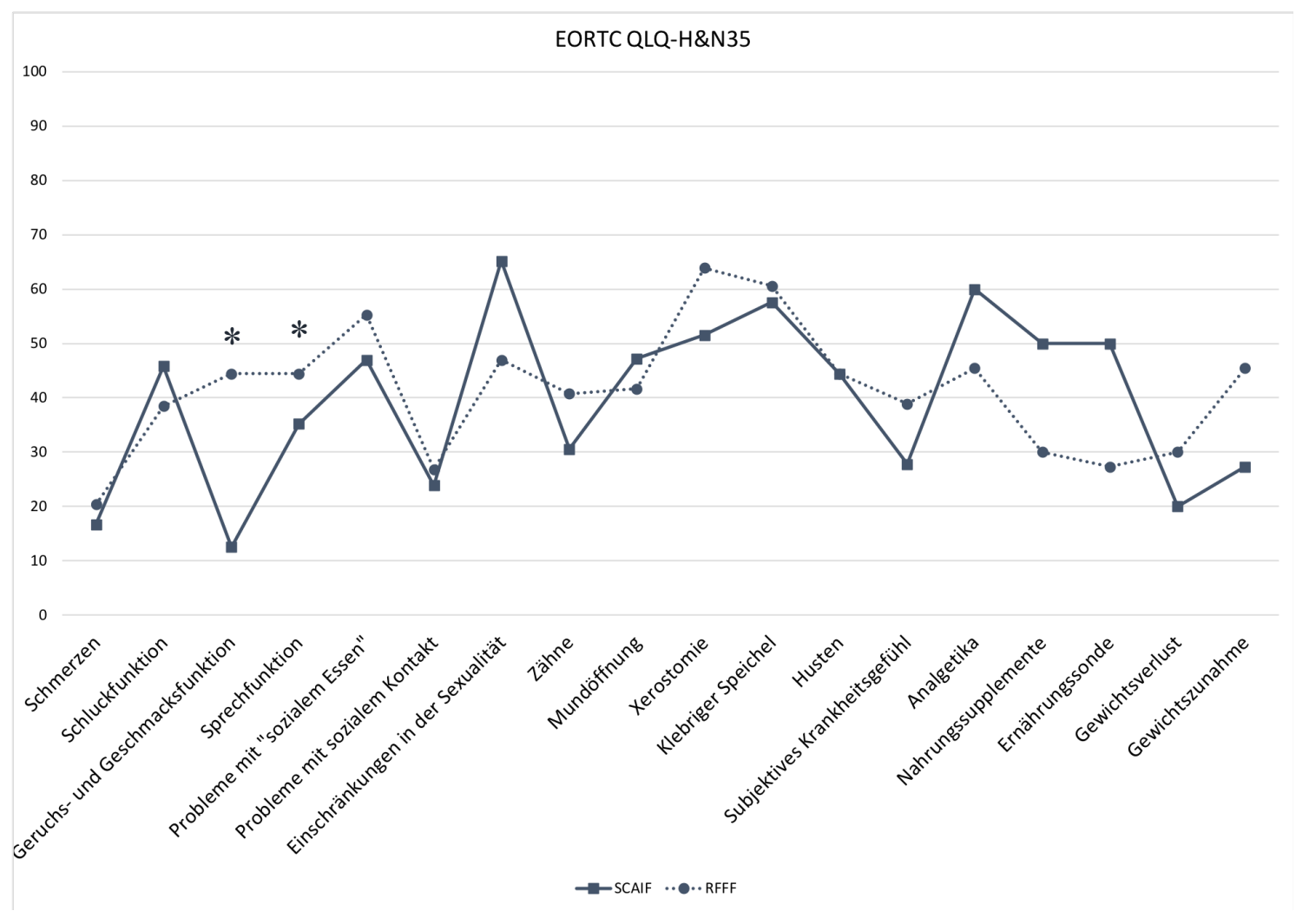

* statisch signifikant $(\mathrm{p}<0,05)$

EORTC = European Organisation for Research and Treatment of Cancer; RFFF = radial free forearm flap; SCAIF = supraclavicular island flap; $\mathrm{SD}=$ standard deviation; 
Tabelle 27: SCAIF versus RFFF: EORTC QLQ-C30 und EORTC QLQ-H\&N35

\begin{tabular}{|c|c|c|c|c|c|}
\hline \multirow[t]{2}{*}{ Lebensqualität } & \multicolumn{2}{|c|}{ SCAIF } & \multicolumn{2}{|c|}{ RFFF } & \multirow[t]{2}{*}{ p-Wert } \\
\hline & Mittel & SD & Mittel & $\mathrm{SD}$ & \\
\hline \multicolumn{6}{|l|}{ EORTC QLQ-C30 } \\
\hline Allgemeinzustand & 50,7 & $\pm 25,7$ & 52,1 & $\pm 26,4$ & 0,929 \\
\hline \multicolumn{6}{|l|}{ Funktionsbezogene Parameter } \\
\hline Körperfunktion & 60,0 & $\pm 33,2$ & 60,6 & $\pm 28,8$ & 1,000 \\
\hline Rollenfunktion & 46,7 & $\pm 37,5$ & 37,5 & $\pm 31,9$ & 0,590 \\
\hline Emotionale Funktion & 68,1 & $\pm 30,0$ & 59,0 & $\pm 20,0$ & 0,379 \\
\hline Kognitive Funktion & 76,4 & $\pm 21,9$ & 73,6 & $\pm 28,8$ & 0,976 \\
\hline Soziale Funktion & 56,9 & $\pm 39,2$ & 45,8 & $\pm 31,1$ & 0,396 \\
\hline \multicolumn{6}{|l|}{ Symptombezogene Parameter } \\
\hline Erschöpfung & 49,1 & $\pm 32,0$ & 47,2 & $\pm 29,3$ & 0,639 \\
\hline Übelkeit und Erbrechen & 13,8 & $\pm 29,2$ & 4,2 & $\pm 7,5$ & 0,538 \\
\hline Schmerzen & 31.9 & $\pm 38,6$ & 44,4 & $\pm 43,4$ & 0,483 \\
\hline Dyspnoe & 44,4 & $\pm 38,5$ & 47,2 & $\pm 26,4$ & 0,690 \\
\hline Schlafprobleme & 50,0 & $\pm 43,8$ & 44,4 & $\pm 35,8$ & 0,788 \\
\hline Appetitlosigkeit & 36,7 & $\pm 36,7$ & 33,3 & $\pm 37,6$ & 0,835 \\
\hline Obstipation & 11,1 & $\pm 29,6$ & 12,1 & $\pm 27,0$ & 0,963 \\
\hline Diarrhö & 8,3 & $\pm 15,1$ & 5,6 & $\pm 13,0$ & 0,651 \\
\hline Finanzielle Schwierigkeiten & 27,7 & $\pm 39,8$ & 41,6 & $\pm 40,5$ & 0,325 \\
\hline \multicolumn{6}{|l|}{ EORTC QLQ-H\&N35 } \\
\hline \multicolumn{6}{|l|}{ Symptombezogene Parameter } \\
\hline Schmerzen & 16,6 & $\pm 21,3$ & 20,4 & $\pm 18,2$ & 0,494 \\
\hline Schluckfunktion & 45,8 & $\pm 35,6$ & 38,4 & $\pm 22,9$ & 0,728 \\
\hline Geruchs- und Geschmackssinn & 12,5 & $\pm 19,0$ & 44,4 & $\pm 35,8$ & $\mathbf{0 , 0 2 0} *$ \\
\hline Sprechprobleme & 35,2 & $\pm 14,9$ & 44,4 & $\pm 26,4$ & $0,018 *$ \\
\hline Probleme mit „sozialem Essen“ & 47,0 & $\pm 35,8$ & 55,3 & $\pm 33,8$ & 0,509 \\
\hline Probleme mit sozialen Kontakt & 23,9 & $\pm 26,4$ & 23,9 & $\pm 24,5$ & 0,725 \\
\hline Einschränkungen in der Sexualität & 65,2 & $\pm 41,8$ & 47,0 & $\pm 38,6$ & 0,250 \\
\hline Zahnprobleme & 30,5 & $\pm 43,7$ & 40,7 & $\pm 49,4$ & 0,780 \\
\hline Mundöffung & 47,2 & $\pm 46,6$ & 41,7 & $\pm 40,5$ & 0,880 \\
\hline Xerostomie & 51,5 & $\pm 43,1$ & 63,9 & $\pm 33,2$ & 0,502 \\
\hline Klebriger Speichel & 57,6 & $\pm 33,6$ & 60,6 & $\pm 25,9$ & 0,804 \\
\hline Husten & 44,4 & $\pm 35,8$ & 44,4 & $\pm 34,3$ & 0,927 \\
\hline Subjektives Krankheitsgefühl & 27,8 & $\pm 34,3$ & 38,9 & $\pm 52,2$ & 0,411 \\
\hline Analgetika & 60,0 & $\pm 70,0$ & 45,5 & $\pm 48,3$ & 0,720 \\
\hline Ernährungssupplemente & 50,0 & $\pm 70,7$ & 30,0 & $\pm 46,7$ & 0,588 \\
\hline
\end{tabular}




\begin{tabular}{llllll}
\hline Ernährungssonde & 50,0 & $\pm 52,7$ & 27,3 & $\pm 48,3$ & 0,316 \\
Gewichtsverlust & 20,0 & $\pm 42,2$ & 30,0 & $\pm 48,7$ & 0,065 \\
Gewichtszunahme & 27,3 & $\pm 46,7$ & 45,5 & $\pm 52,2$ & 0,408 \\
\hline
\end{tabular}

* statistisch signifikant $(\mathrm{p}<0,05)$;

$\mathrm{EORTC}=$ European Organisation for Research and Treatment of Cancer $; \mathrm{RFFF}=$ radial free forearm flap; SCAIF = supraclavicular island flap; $\mathrm{SD}=$ standard deviation; 


\section{Diskussion}

Auf Grund der anatomischen Gegebenheiten von Kopf-Hals-Malignomen kann bereits bei vergleichbar kleinen Tumoren ein substantieller Defekt entstehen, der unausweichlich mit einer Einschränkung der Schluck-, Sprech- und Atemfunktion einhergeht. Der Einsatz der rekonstruktiver Tumorchirurgie ermöglicht eine Wiederherstellung der Funktion, Senkung der Morbidität und Steigerung der Lebensqualität (Canis et al. 2016); (Pierre et al. 2014). Dies erfordert spezialisierte Zentren mit versierten und erfahrenen Ärzten in der mikrovaskulären Chirurgie. Derzeitiger Goldstandard in der rekonstruktiven KopfHals-Tumor-Chirurgie ist das freie Gewebetransplantat der A. radialis (RFFF) (Gurtner und Evans 2000); (Hurvitz et al. 2006); (Mühlbauer et al. 1982). Nach derzeitigem Kenntnisstand werden freie Gewebetransplantate, abhängig von Lokalisation, Größe des Defekts und notwendigem Volumen und auf Grund geringerer postoperativen Morbiditätsraten sowie besserer Perfusion des Gewebes gestielten Lappen vorgezogen (Hurvitz et al. 2006). Der Einsatz freier Transplantate ist jedoch bei älteren Patienten mit schlechtem Gefäßstatus und multiplen Komorbiditäten limitiert. Hier haben sich gestielte Lappen als Alternative erwiesen (Ariyan 1979); (Gurtner und Evans 2000). In den letzten Jahren erfolgte eine zunehmende Etablierung des SCAIFs wobei eine wissenschaftliche Untersuchung und der Vergleich zum Goldstandard bisher fehlte. Zur wissenschaftlichen Bewertung des Stellenwertes wurden folgende drei Themenbereiche ausgewählt und innerhalb dieser Studie evaluiert:

1. Therapieerfolg, Einsetzbarkeit und Analyse der prä-, peri- und postoperativen Daten: der SCAIF im Vergleich mit dem RFFF

2. Schultermorbidität nach SCAIF-Operation im Vergleich zur Gegenseite

3. Lebensqualitätsanalyse: der SCAIF im Vergleich mit dem RFFF 


\subsection{Analyse der prä-, peri- und postoperativen Daten: SCAIF versus RFFF}

Kosten und Effizienz sind sozialpolitisch ein wichtiges Thema geworden, um die finanzielle Belastung des Sozialsystems zu optimieren und damit für jeden Einzelnen zu minimieren. Daher wurde für den SCAIF eine Kostenanalyse anhand von Operationszeiten und Personalkosten im Sinne einer Vergleichsanalyse mit 50 Patienten mit dem momentanen Goldstandard, dem RFFF (Gurtner und Evans 2000); (Hurvitz et al. 2006), durchgeführt. Es wurden jeweils 25 Patienten untersucht, die nach Diagnosestellung eines fortgeschrittenen Karzinoms des Oropharynx oder der Mundhöhle eine Defektrekonstruktion mit einem SCAIF ( $n=25)$ oder einem RFFF ( $n=25)$ erhielten. Bis dato gibt es nur zwei weitere Veröffentlichungen Granzow et al. (Granzow et al. 2013b) und Kozin et al. (Kozin et al. 2016), die den Behandlungserfolg des SCAIFs mit freien Gewebetransplantaten, dem RFFF und dem freien anterolateralen Oberschenkellappen in der onkologischen Kopf-Hals-Chirurgie verglichen. Die Ergebnisse der vorliegenden Analyse decken sich mit denen der Literatur und konnte zeigen, dass die Gesamtoperationszeit der SCAIF-Rekonstruktion signifikant kürzer war als die der RFFF-Operation (407,7 $\mathrm{min} \pm 123$,9 versus 585,4 $\min \pm 142,6)$. Durch das Fehlen einer Anastomose und kürzere Transplantathebezeiten gelang es dem Ein-MannTeam, bei der SCAIF-Operation Zeit einzusparen. Die Ergebnisse der vorliegenden Studie decken sich mit weiteren Daten aus der Literatur, die ebenfalls bei der Anwendung des SCAIFs im Pharynxbereich von vergleichbar kurzen Gesamtoperationszeiten und Transplantathebezeiten berichten (Paydarfar und Patel 2011); (Zhang et al. 2015); (Alves et al. 2012); (Anand et al. 2012); (Giordano et al. 2016). Man geht in diesen Studien davon aus, dass durch den postoperativen Verlauf mit geringeren Raten an Intensivstationsverlegungen auch geringere Gesamtkosten verursacht werden. So zeigen die Ergebnisse dieser Studie signifikant $(\mathrm{p}<0,001)$ weniger Intensivaufenthalte in der SCAIF-Gruppe mit 22,3 h ( \pm 59$)$ versus 35,1 h ( \pm 28$)$ in der RFFF-Gruppe.

Für die geringere Intensivpflichtigkeit in der SCAIF-Kohorte können zwei Ursachen verantwortlich sein. Zum einen werden Patienten mit freien Transplantanten, wie dem RFFF, routinemäßig postoperativ auf einer Intensivstation engmaschig monitorisiert, um zeitnah einen Verschluss der Anastomose festzustellen und somit rechtzeitig eine mikrochirurgische Revision durchzuführen. Bei SCAIF-Patienten dagegen korreliert die Notwendigkeit einer Intensivbetreuung nur mit längeren Operationszeiten. Wie oben bereits beschrieben, zeigten die SCAIF-Patienten insgesamt kürzere Operationszeiten. 
Die Tracheostoma-Rate war signifikant häufiger in der RFFF-Gruppe mit $88,0 \%$ als in der SCAIF-Gruppe mit 64,0\% (p-Wert 0,049). Durch kürzere Operationszeiten, eine geringere Rate an intraoperativer Manipulation und die möglicherweise darin resultierende Schwellung lässt sich in der SCAIF-Kohorte eine geringere Notwendigkeit zur Anlage eines Tracheostomas erklären. Dennoch ist die Entscheidung zur Tracheotomie individuell vom Operateur abhängig. Das Vorliegen eines Tracheostomas postoperativ erhöht die Dauer des stationären Aufenthalts (Hashmi et al. 2010) und somit natürlich die Gesamtkosten.

Die Morbidität hängt sowohl in der Spender- als auch in der Empfängerregion von der Entwicklung postoperativer Komplikationen ab. Die Ergebnisse der vorliegenden Analyse weisen gleiche Gesamtkomplikationsraten der Spender- (p-Wert 0,651) und Empfängerregion (p-Wert 1,0) der SCAIF-Gruppe im Vergleich zur RFFF-Gruppe auf, welche sich mit Daten aus der Literatur decken (Herr et al. 2014); (Kozin et al. 2016). Jedoch zeigte bei der Aufteilung in gering- und hochgradige Komplikationen die vorliegende SCAIF-Kohorte deutlich weniger hochgradige Komplikationen der Empfängerregion, sowohl im Vergleich zur RFFF-Gruppe als auch zur Literatur (Herr et al. 2014); (Kozin et al. 2016). Die in der vorliegenden Arbeit untersuchte SCAIF-Kohorte verzeichnete keinen Verlust des Transplantats, eine partielle Nekrose oder eine Fistel entwickelten jeweils ein SCAIF- (4,0\%) und ein RFFF-Patient (4,0\%) (Chiu et al. 2009); (Kokot et al. 2013); (Razdan et al. 2015); (Sandu et al. 2012); (Vinh et al. 2009). In beiden Kohorten entwickelten jeweils zehn von 25 Patienten Komplikationen der Spenderregion, dabei war der Großteil (>90\%) davon minor. Dies entspricht auch den Beobachtungen von Teymoortash et al. (Ver Haalen et al. 2010); (Teymoortash et al. 2014), Su et al. (Su et al. 2013) und Zhang et al. (Zhang et al. 2015). In der vorliegenden SCAIF-Gruppe gab es einen Fall mit einer hochgradigen Komplikation der Spenderregion, eine partielle Nekrose im Bereich der bekanntlich kritischen Region um das Acromion. In dieser Region herrscht auf Grund anatomischer Gegebenheiten ein starker Zug an der adaptierten Haut. In diesem Fall konnte ein kleiner Rotationshautlappen den Defekt erfolgreich decken, der komplikationslos verheilte.

In der Vergleichsanalyse der perioperativen Kosten für die Rekonstruktion mit dem SCAIF zum RFFF zeigte sich eine deutliche Reduktion der Kosten um den Faktor 1,7 bei Einsatz des SCAIF. 
Unsere Gesamtkohorte bestand aus Patienten mit ausschließlich Stadium III und IV von Oropharynx- oder Mundhöhlenkarzinomen, welche eine Defektrekonstruktion mit entweder einem SCAIF oder RFFF erhielten. Durch die Einschlusskriterien, wie Tumorstadium und Lokalisation, entstand ein homogenes Kollektiv in beiden Gruppen, womit sich die Aussagekraft der Studie erhöht. Wie schon oben erwähnt, gibt es bisher zur Kostenanalyse des SCAIFs nur zwei weitere Arbeiten (Granzow et al. 2013b); (Kozin et al. 2016); (Granzow et al. 2013b). Diese Studien zeigen ähnliche Ergebnisse, obwohl sie im Patientenkollektiv mit der vorliegenden Studie nur bedingt vergleichbar sind. Sowohl in der Studie von Granzow et al. (Granzow et al. 2013b) als auch Kozin et al. (Kozin et al. 2016) wurden Defekte im Bereich des Os temporale, der Glandula parotidea, und des Pharynx, und Hautdefekte diverser Regionen nach onkologischer oder traumatischer Operation mit dem SCAIF gedeckt. Somit waren die Einschlusskriterien dieser Studien weiter gestreut. Zudem bestand die Vergleichskohorte ausschließlich aus Patienten, die mit einem RFFF versorgt wurden. Das Vergleichskollektiv sowohl von Granzow et al. (Granzow et al. 2013b) als auch Kozin et al. (Kozin et al. 2016) schloss sowohl RFFF- als auch ALT-Patienten ein.

Zusammenfassend konnte die Kostenanalyse im Sinne von kürzeren Operationszeiten und geringen Gesamtkosten eine signifikante Überlegenheit des SCAIFs gegenüber dem RFFF darstellen und somit die Vorteile einer Defektrekonstruktion mit dem SCAIF unterstreichen.

\subsection{Schultermorbidität}

Ein weiterer Aspekt, um den Stellenwert des SCAIFs zu eruieren, ist die Untersuchung der Morbidität der Spenderregion, welche bei Verwendung des SCAIFs die Schulterfunktion miteinbezieht. Der derzeitige Goldstandard, der RFFF, ist nach wie vor mit einer recht hohen postoperativen Morbidität der Spenderregion verbunden (Granzow et al. 2013b).

In der vorliegenden Analyse konnten im Bewegungsausmaß zwischen der operierten und nicht operierten Schulter zwar keine signifikanten, jedoch geringe Unterschiede gefunden werden. Im Vergleich zur Gegenseite konnte eine geringfügige Einschränkung der Gesamtbewegung sowie ihrer Unterkategorien an der operierten Extremität beobachtet werden. 
Des Weiteren war im Vergleich zur Gegenseite ein eingeschränkter Bewegungsumfang aufgefallen, welcher mit einer postoperativen Schonhaltung der betroffenen Seite assoziiert ist. Zudem wurde bei der Hebung des Transplantats das subkutane Gewebe direkt oberhalb des Muskels präpariert. Donordefekte bis zu $7 \mathrm{~cm}$ Breite können noch primär verschlossen werden (Granzow et al. 2013a). Dies kann Adhäsionsprozesse im Bereich des M. deltoideus und M. trapezius zum subkutanen Fettgewebe und der Haut generieren. Diese Adhäsionen sowie Fibrosierung der darunterliegenden Muskeln resultieren in einer Einschränkung der Schulterbewegung und erhöhen somit das Risiko für eine adhäsive Kapsulitis und myofasziale Schmerzen (Bradley et al. 2011). Prolongierte Wundheilung trägt ebenfalls zu Fibrosierung und Adhäsionsprozessen bei, wie man bei Patienten mit Major-Komplikationen beobachten kann, die die schlechteste Gesamtpunktezahl aufwiesen.

Die Vergleichsuntersuchung zwischen der operierten Schulter und der kontralateralen Seite konnte in Bezug auf den Parameter Schmerz keinen signifikanten Unterschied zeigen.

Wie gut die Patienten des vorliegenden Kollektivs nach einer SCAIF-Rekonstruktion im Alltag zurechtkamen, wurde mit Hilfe des DASH-Fragebogens untersucht. In dieser Analyse wurde ein Mittelwert von 32,5 $( \pm 28,6)$ ermittelt, was auf eine Einschränkung der Morbidität hinweist. Dieser relativ hohe Wert kann zum einen durch die fortgeschrittenen Tumorstadien der Kohorte erklärt werden. Zum anderen wurde bei einem Großteil der Patienten ( $\mathrm{n}=18 / 20)$ simultan zur SCAIF-Operation eine ND durchgeführt. Es ist bekannt, dass die postoperative Morbidität nach ND per se mit einer eingeschränkten Schulterfunktion einhergeht. In einer Studie von Goldstein et al. wurde bei 96 Patienten mit Zustand nach selektiver ND, modifiziert radikaler ND und radikaler ND ein Mittelwert von 12,9 (Bandbreite 7,5-17,7) ermittelt (Goldstein et al. 2015). Somit ist es schwierig, den quantitativen Anteil der Schultermorbidität bei Simultaneingriffen (SCAIF+ND) der SCAIF-Operation zuzuordnen, sogar wenn der N. accessorius während des Eingriffs identifiziert und geschont werden kann (Dijkstra et al. 2001); (Goldstein et al. 2015); (Salerno et al. 2002); (Wilgen et al. 2004). Ein Großteil der Morbiditätseinschränkung kann somit allein durch die ND erklärt werden und geht damit in den oben gefundenen Wert ebenfalls ein.

In den letzten Jahren wurde der Phantomschmerz bereits gründlich untersucht (Giummarra et al. 2007). Jedoch gibt es bisher noch keine Daten zu Phantomempfindungen bei gestielten Lappen. In der vorliegenden Kohorte berichtete 
kein einziger Patient über Phantomschmerzen oder -empfindungen, dennoch klagten alle Patienten über Taubheitsgefühl im Operationsgebiet bis zu 35 Monate nach der Operation. Das Ausbleiben von Phantomempfindungen und Temperaturmissempfindungen kann durch die gründliche Hebetechnik mit Durchtrennung aller sensorischen Nerven in der Spenderregion erklärt werden (Granzow et al. 2013a); (Welz et al. 2017).

In der Literatur gibt es bisher nur eine Studie, welche die Schulterfunktion nach SCAIFOperationen untersuchte (Herr et al. 2014). Herr et al. schlossen zehn Patienten mit einem Plattenepithelkarzinom nach SCAIF-Rekonstruktion ein. Der Großteil wies einen normalen Bewegungsumfang in der Schulter mit geringer Einschränkung in der Abduktion und Außenrotation auf. Komplikationen im Spenderbereich wurde nicht beobachtet. In der vorliegenden Studie wurde eine größere Patientenanzahl untersucht, und es konnte ebenfalls kein signifikanter Unterschied zwischen der operierten und nichtoperierten Seite gezeigt werden. Zudem wurden weitere Parameter analysiert, wie das Vorliegen einer simultanen ND mit Resektion des Level V und eine weitere Evaluation der Funktionen der Schulter mit dem DASH-Score. Herr et al. konnten von einen Nachbeobachtungszeitraum von sechs Monaten im Mittel (1-18 Monate) berichten, wohingegen die vorliegende Studie einen längeren Nachbeobachtungszeitraum von 17 Monaten im Mittel (4-35 Monaten) hatte und somit Ergebnisse nach abgeschlossener Wundheilung aufweist. Bekannterweise benötigt die primäre Wundheilung Wochen bis Monate und die sekundäre Wundheilung bis zu 24 Monate nach Operation oder Trauma (Stroncek und Reichert 2008).

Zusammenfassend sind die Morbiditätsraten der Spenderregion der vorliegenden SCAIFKohorte als gering einzustufen. Es zeigte sich kein signifikanter Unterschied zwischen der operierten und kontralateralen Seite. Die Morbiditätsrate bei anderen etablierten Gewebetransplantattechniken, wie dem RFFF, ist in der Literatur als deutlich höher beschrieben, sogar bei Langzeit-Beobachtungszeiträumen bis zu 24 Monaten (Hekner et al. 2013); (Orlik et al. 2014). In diesen Studien wurden signifikante Unterschiede (p-Wert $<0,05)$ zwischen dem operierten Unterarm und der gesunden Gegenseite gefunden. 


\subsection{Lebensqualität}

Die Lebensqualität als Messinstrument für den Erfolg der Behandlung von Patienten mit Kopf-Halsmalignomen spielt eine entscheidende Rolle im Rahmen der Evaluation des Therapieerfolges (Hurvitz et al. 2006). Behandlungskonzepte von fortgeschrittenen KopfHalsmalignomen greifen dabei substantiell in die Lebensqualität und Alltag von Tumorpatienten ein. Diese Patienten erleben Einschränkungen des Sprechens, Essens und Atmens häufig in Kombination mit fazialer Entstellung. Messbar werden die Lebensqualitätsparameter durch Anwendung von Punktwerten von Fragebögen. Die in dieser Studie angewandten Fragebögen (EORTC QLQ-C30 Version 3.0, EORTC QLQH\&N35) sind multidimensional, reagieren sehr sensitiv auf Änderungen im Rahmen der Therapie, und ermöglichen ein Widerspiegeln der Perspektive des Patienten.

In der Auswertung fanden sich keine signifikanten Unterschiede bei Anwendung der Lebensqualitätsfragebögen der EORTC (EORTC QLQ-C30 Version 3.0 und EORTC QLQ-H\&N35) im Vergleich des SCAIF- mit dem RFFF-Kollektiv in Hinblick auf Tumorstadium, PEG-Sondenanlage, Tracheostomaanlage, Komplikationsraten der Spender- und Empfängerregion, Nikotin- und Alkoholkonsum. Des Weiteren wurden ausschließlich fortgeschrittene Oropharynx- und Mundhöhlenkarzinomen mit einem Nachbeobachtungszeitraum von mindestens vier Monaten, 12 Wochen nach Abschluss der adjuvanten Therapie eingeschlossen, um ein homogenes Patientenkollektiv zu schaffen. Die Auswertung der Lebensqualitätsfragebögen zeigte signifikante Unterschiede bei den Subskalen „Geschmacks- und Geruchssinn“ ( $p=0,020)$ und „Sprechprobleme“ $(p=0,018)$. Hier zeichnete sich in der Gruppe der SCAIF-Patienten eine signifikant höhere Lebensqualität $a b$. In der Literatur ist die Analyse der vorliegenden Arbeit die bisher einzige, die Lebensqualität von SCAIF-Patienten mit der Lebensqualität von RFFF-Patienten direkt vergleicht.

Im Vergleich zu Patienten mit anderen Tumorentitäten, z. B. Kolonkarzinom, Lungenkarzinom oder Melanom, geben die in dieser Studie analysierten Patienten mit Kopf-Halsmalignomen und nach erfolgter Defektrekonstruktion mit einem SCAIF oder RFFF schlechtere Punktzahlen in Bezug auf den Allgemeinzustand an. Eine Studie von Quinten et al. von 2015 analysierte insgesamt 6024 Tumorpatienten mit verschiedenen Tumorlokalisationen (Melanom, Kolonkarzinom, Lungenkarzinom, etc.) in einer Altersgruppe zwischen 50 und 70 Jahren (Quinten et al. 2015). Sie verglich die Ergebnisse der Fragebögen mit denen von Probanden aus einer Normalpopulation. Die Ergebnisse waren im Gesamten besser als die unserer SCAIF- oder RFFF-Patienten. Da 
in unserer Analyse ausschließlich Patienten mit fortgeschrittenem Tumorstadium nach UICC III und IV eingeschlossen wurden, lassen sich die Unterschiede und schlechteren Ergebnisse damit erklären.

In einer vorangegangenen Publikation der Arbeitsgruppe konnte gezeigt werden, dass die Lebensqualität in den QLQ-H\&N35-Parametern „Schluckfunktion“, „Sprechfunktion“ und „Probleme mit sozialem Essen“ bei Patienten mit Zustand nach Tumorresektion eines pT3-Zungenkarzinoms im Vergleich zum Primärverschluss signifikant höher war, wenn eine Defektrekonstruktion mit einem mikrovaskulären Lappen durchgeführt worden war (Canis et al. 2016). Auch im Vergleich mit gestielten Lappen werden mit freien Gewebetransplantaten (RFFF oder ALT) bessere Ergebnisse der Lebensqualität erreicht (Hsing et al. 2014); (Su et al. 2003); (Xiao et al. 2013).

In der letzten Dekade berichtete eine zunehmende Zahl an Publikationen von erfolgreichen Ergebnissen mit dem SCAIF hinsichtlich Rekonstruktionen verschiedener Lokalisationen im Kopf-Halsbereich (Chiu et al. 2009). Insbesondere bei bereits voroperierten Patienten oder bei denen kein adäquater Gefäßanschluss für eine Anastomose zu erwarten war, konnten zufriedenstellende Ergebnisse hinsichtlich Morbidität und Effizienz gezeigt werden (Chiu 2009); (Teymoortash et al. 2014). Dennoch gibt es bis dato keinen direkten Vergleich hinsichtlich der Lebensqualität bei Patienten nach SCAIF oder mikrovaskulären Transplantaten. Die vorliegende retrospektive Analyse zeigte, wie oben erwähnt, keine signifikanten Unterschiede hinsichtlich der QLQ-C30-Punktezahlen und nur kleine Unterschiede in den QLQH\&N35-Punktezahlen zwischen den beiden Rekonstruktionsmodalitäten. Dies hebt die Vorteile des SCAIF hervor, welches ein einfach anzupassendes, gut einsetzbares und perfundiertes Transplantat ist mit den oben erwähnten Vorteilen (geringe Morbidität und Kosten) gegenüber herkömmlichen regionalen und freien Transplantaten (Giordano 2016); (Bruchhage et al. 2017); (Granzow et al. 2013b); (Welz et al. 2017).

Auf Grund von unterschiedlichen Studienkollektiven (z. B. Tumorlokalisationen) und Methoden (z. B. Anwendung von verschiedenen Fragebögen) kann ein Vergleich verschiedener Studien aus der Literatur nur sehr eingeschränkt erfolgen. Neben dem EORTC QLQ-C30 und EORTC QLQ-H\&N35, die in der vorliegenden Analyse verwendet wurden, werden häufig auch der University of Washington Quality of Life Scale (UW-QOL v4), der Oral Health Impact Profile Questionnaire (OHIP-14), der Medical Outcomes Study Short Form 36 (SF-36) und der Functional Assessment of 
Cancer Therapy-Head and Neck (FACT-H\&NV4) eingesetzt, wenn es um die Erfassung der Lebensqualität von Kopf-Halstumorpatienten geht.

Insgesamt zeigten die Ergebnisse zur Auswertung der Lebensqualität nach SCAIFRekonstruktion gegenüber Patienten nach RFFF-Operation eine Gleichwertigkeit des SCAIFs.

\subsection{Limitationen}

Die Limitation der vorliegenden Studie liegt in der Natur einer retrospektiven Datenauswertung, die eine Präselektion des Kollektivs beinhaltet.

Die Subgruppenanalyse der prä-, peri- und postoperativen Daten zeigt einige signifikante Unterschiede in der Demographie zwischen den Vergleichsgruppen auf. In der vorliegenden Analyse waren die SCAIF-Patienten älter als die der RFFF-Gruppe (67,7 Jahre $\pm 10,9$ versus 60,1 Jahre $\pm 7,9$ ). Weil der SCAIF bei Patienten mit Komorbiditäten wie schlechtem Gefäßstatus oder einem pathologischen Allentest (Cable et al. 1999) bevorzugt eingesetzt wird, ist der Altersunterschied durch diese selektive Indikation zu erklären (Gurtner und Evans 2000); (Hurvitz et al. 2006). Des Weiteren zeigte sich ein signifikanter Unterschied zwischen den beiden Patientengruppen hinsichtlich der Analyse des Nachbeobachtungszeitraums. Dies liegt daran, dass sich innerhalb der HNO-Klinik der UMG die SCAIF-Operation erst ab 2014 etabliert hatte. Davor wurden vorwiegend freie Gewebstransplantate zur Rekonstruktion von Oropharynx- oder Mundhöhlenkarzinomen verwendet.

Für die Analyse der Schultermorbidität und Lebensqualität ist es schwierig, beide Aspekte allein nach SCAIF-Operation zu untersuchen, da allgemein Tätigkeiten im Alltag onkologischer Patienten mit Kopf-Hals-Malignomen bekannterweise durch Tumorresektion und adjuvante Radiochemotherapie beeinflusst werden. Daher ist es schwierig diese Parameter isoliert nach SCAIF-Operation zu analysieren (Murphy et al. 2007).

Durch die strengen Ein- und Ausschlusskriterien sind die Größen der Kohorten aller Analysen (Analyse der prä-, peri- und postoperativen Daten: 50 Patienten, 25 SCAIF versus 25 RFFF; Auswertung der Schultermorbidität: 20 Patienten; Analyse der Lebensqualität: 24 Patienten, 12 SCAIF versus 12 RFFF) verhältnismäßig klein ausgefallen. Insgesamt bildet dies die Grundlage für eine prospektive Studie mit größeren Kohorten, um die vorliegen Ergebnisse zu bestätigen. 


\section{$6 \quad$ Zusammenfassung}

Auf Grund von strukturellen und anatomischen Gegebenheiten in der Kopf-Halsregion entstehen bereits nach Resektion von kleinen Malignomen funktionell maßgeblich einschränkende Defekte. Der Einsatz der rekonstruktiven Tumorchirurgie ermöglicht Wiederherstellung der Funktion, Morbiditätssenkung und Lebensqualitätssteigerung. Als Goldstandard gilt derzeit der RFFF. In den letzten Jahren wurde zunehmend der SCAIF eingesetzt, wobei eine wissenschaftliche Untersuchung und der Vergleich zum Goldstandard bisher fehlte. Die vorliegende retrospektive Analyse bewertet den Stellenwert des SCAIFs durch eine Eruierung prä-, peri- und postoperativer Daten und Langzeitmorbidität im Vergleich zum RFFF, durch die Beurteilung der postoperativen Morbidität der Spenderregion im Sinne der Schulterfunktion nach SCAIF-Operation und durch die Bewertung und den Vergleich eines neue Endpunktes - die Lebensqualität.

Für die Auswertung der operativen Daten und Langzeitmorbidität wurden aus dem Gesamtkollektiv insgesamt 50 Patienten eingeschlossen. All diese Patienten litten an einem Oropharynxkarzinom und erhielten eine Tumorresektion mit Rekonstruktion des Defektes mittels SCAIF ( $\mathrm{n}=25)$ oder RFFF $(n=25)$. Die Auswertung zeigte kürzere Operationszeiten und geringe Gesamtkosten des SCAIFs im Vergleich zum RFFF. Zur Evaluation der Schultermorbidität mit den Fragenbögen zum Constant-Murley-Score und DASH-Score konnten 20 SCAIF-Patienten eingeschlossen werden. Der Vergleich zwischen der Spenderregion und der kontralateralen Seite zeigte keine statistisch signifikanten Unterschiede. Für die Analyse und der Vergleich der Lebensqualität anhand der Fragebögen der EORTC konnten insgesamt 24 Oropharynxpatienten eingeschlossen werden (jeweils 12 SCAIF und 12 RFFF), und es fanden sich keine signifikanten Unterschiede.

Die vorliegende Analyse konnte zeigen, dass der SCAIF als ideale Alternative zum Goldstandard einzusetzen ist. Der Behandlungserfolg inklusive Morbidität der Spenderund Empfängerregion und Lebensqualität der SCAIF-Patienten gegenüber dem der RFFF-Patienten war mindestens gleichwertig. Zudem ist der SCAIF einfach zu präparieren und zu heben, und im Vergleich zum RFFF kann Zeit eingespart und Kosten gesenkt werden. In der vorliegenden Auswertung konnte gezeigt werden, dass der SCAIF auch bei Oropharynxrekonstruktionen eingesetzt werden kann, wodurch er dem RFFF gleichgestellt wird und sogar über anderen gestielten Transplantaten steht. 
Somit ist der SCAIF eine zuverlässige Alternative zum RFFF und erscheint dem RFFF sogar überlegen hinsichtlich einer Versorgung von Patienten mit diversen Komorbiditäten. 


\section{$7 \quad$ Anhang}

Tabelle 28: Ausgeschlossene Patienten

\begin{tabular}{lrl}
\hline & $\begin{array}{r}\text { Patientenanzahl } \\
n\end{array}$ & $(\%)$ \\
\hline Ausschlussgrund & 5 & $(8,3)$ \\
Palliativer Therapieansatz & 2 & $(3,3)$ \\
Kein Transplantat erhalten & 2 & $(3,3)$ \\
Mehr als zwei Transplantate erhalten & 2 & $(3,3)$ \\
Kein Kopf-Halsmalignom & 33 & $(55,0)$ \\
RFFF (keine Oropharynxkarzinome) & 12 & $(20,0)$ \\
PMF & 2 & $(3,3)$ \\
ALT & 2 & $(3,3)$ \\
Submentales Gewebetransplantat & 60 & $(100,0)$ \\
Gesamt & & \\
\hline
\end{tabular}

$\mathrm{ALT}=$ anterior thigh flap, $\mathrm{PMF}=$ pectoral muscle flap, $\mathrm{RFFF}=$ radial free forearm flap; 


\section{$8 \quad$ Literaturverzeichnis}

Aaronson NK, Ahmedzai S, Bergman B, Bullinger M, Cull A, Duez NJ, Filiberti A, Flechtner H, Fleishman SB, de Haes JC (1993): The European Organisation for Research and Treatment of Cancer QLQ-C30: A quality-of-life instrument for use in international clinical trials in oncology. J Natl Cancer Inst $\underline{85}$, 365-376

Ahrens W, Pohlabeln H, Foraita R, Nelis M, Lagiou P, Lagiou A, Bouchardy C, Slamova A, Schejbalova M, Merletti F, et al. (2014): Oral health, dental care and mouthwash associated with upper aerodigestive tract cancer risk in Europe: the ARCAGE study. Oral Oncol $\underline{50}, 616-625$

Alves HR, Ishida LC, Ishida LH, Besteiro JM, Gemperli R, Faria JC, Ferreira MC (2012): A clinical experience of the supraclavicular flap used to reconstruct head and neck defects in late-stage cancer patients. J Plast Reconstr Aesthet Surg 65, 1350-1356

Amin MB, Edge S, Greene F, Byrd DR, Brooland RK, Washington MK, Gershenwald JE, Compton CC, Hess KR, Sullivan DC, et al.: AJCC Cancer Staging Manual. 8. Auflage; Springer Verlag, New York 2017

Anand AG, Tran EJ, Hasney CP, Friedlander PL, Chiu ES (2012): Oropharyngeal reconstruction using the supraclavicular artery island flap: a new flap alternative. Plast Reconstr Surg $\underline{129}, 438-441$

Ariyan S (1979): The pectoralis major myocutaneous flap. A versatile flap for reconstruction in the head and neck. Plast Reconstr Surg $\underline{63}, 73-81$

Bardsley AF, Soutar DS, Elliot D, Batchelor AG (1990): Reducing morbidity in the radial forearm flap donor site. Plast Reconstr Surg 86, 287-292; discussion 293-284

Bertelsen C, Liu C, Kokot N (2017): Reconstruction of parotidectomy and lateral skull base defects. Curr Opin Otolaryngol Head Neck Surg 25, 431-438

Blevins PK, Luce EA (1980): Limitations of the cervicohumeral flap in head and neck reconstruction. Plast Reconstr Surg $\underline{66}$, 220-224

Bonaparte J, Corsten M, Allen M (2001): Cosmetic and functional outcomes after preoperative tissue expansion of radial forearm free flap donor sites: a cohort study. J Otolaryngol Head Neck Surg $\underline{40}, 427-435$

Bradley PJ, Ferlito A, Silver CE, Takes RP, Woolgar JA, Strojan P, Suárez C, Coskun H, Zbären P, Rinaldo A (2011): Neck treatment and shoulder morbidity: still a challenge. Head and Neck 33, 1060-1067 
Brierley JD, Gospodarowicz MK, Wittekind C: TNM Classification of Malignant Tumours. 8. Auflage; Wiley-Blackwell, Oxford, Hoboken 2016

Brown EN, Chaudhry A, Mithani SK, Bluebond-Langner RO, Feiner JM, Shaffer CK, Call D, Rodriguez ED (2014): Long-term vascular, motor, and sensory donor site outcomes after ulnar forearm flap harvest. J Reconstr Microsurg $\underline{30}$, 115-120

Brown MT, Couch ME, Huchton DM (1999): Assessment of donor-site functional morbidity from radial forearm fasciocutaneous free flap harvest. Arch Otolaryngol Head Neck Surg $\underline{125}, 1371-1374$

Bruchhage KL, Leichtle A, Wollenberg B (2017): Rekonstruktion mit dem supraklavikulären Insellappen. HNO $\underline{65}, 53-57$

Bunnell A, Pettit N, Reddout N, Sharma K, O'Malley S, Chino M, Kingsley K (2010): Analysis of primary risk factors for oral cancer from select US states with increasing rates. Tob Induc Dis $\underline{8}, 5$

Cable DG, Mullany CJ, Schaff HV (1999): The Allen test. Our surgical heritage. Ann Thorac Surg $\underline{67}, 876-877$

Canis M, Weiss BG, Ihler F, Hummers-Pradier E, Matthias C, Wolff HA (2016): Quality of life in patients after resection of pT3 lateral tongue carcinoma: Microvascular reconstruction versus primary closure. Head Neck $\underline{38}$, 89-94

Cappiello J, Piazza C, Giudice M, Maria GD, Nicolai P (2005): Shoulder disability after different selective neck dissections (level II-IV versus levels II-V): A comparative study. Laryngoscope $\underline{115}, 259-263$

Chandu A, Smith AC, Rogers SN (2006): Health-related quality of life in oral cancer: a review. J Oral Maxillofac Surg 64, 495-502

Chang JS, Lo HI, Wong TY, Huang CC, Lee WT, Tsai ST, Chen KC, Yen CJ, Wu YH, Hsueh WT, et al. (2013): Investigating the association between oral hygiene and head and neck cancer. Oral Oncology 49, 1010-1017

Chiu ES, Liu PH, Friedlander, PL (2009): Supraclavicular Artery Island Flap for Head and Neck Oncologic Reconstruction: Indications, Complications, and Outcomes. Plast Reconstr Surg 124, 115-123

Chiu ES, Liu PH, Baratelli R, Lee MY, Chaffin AE, Friedlander PL (2010): Circumferential pharyngoesophageal reconstruction with a supraclavicular artery island flap. Plast Reconstr Surg 125, 161-166

Constant CR, Murley AH (1987): A clinical method of functional assessment of the shoulder. Clin Orthop Relat Res 214, 160-164 
Dayyani F, Etzel C, Liu M, Ho C, Lippman S, A Tsao (2010): Meta-analysis of the impact of human papillomavirus (HPV) on cancer risk and overall survival in head and neck squamous cell carcinomas (HNSCC). Head Neck Oncol 2, 15

Di Benedetto G, Aquinati A, Pierangeli M, Scalise A, Bertani A (2005): From the "charretera" to the supraclavicular fascial island flap: revisitation and further evolution of a controversial flap. Plast Reconstr Surg 115, 70-76

Dijkstra PU, van Wilgen PC, Buijs RP, Brendeke W, de Goede CJ, Kerst A, Koolstra M, Marinus J, Schoppink EM, Stuiver MM, et al. (2001): Incidence of shoulder pain after neck dissection: A cloinical explorative study for risk factors. Head Neck $\underline{23}$, 947-953

Dowrick AS, Gabbe BJ, Williamson OD, Cameron PA (2005): Outcome instruments for the assessment of the upper extremity following trauma: a review. Injury $\underline{36}, 468-476$

Drake RV, Vogel AW, Mitchell, A: Gray's Anatomy for Students. 2. Auflage; Churchill Livingstone, New York 2009

Eliot MN, Michaud DS, Langevin SM, McClean MD, Kelsey KT (2013): Periodontal disease and mouthwash use are risk factors for head and neck squamous cell carcinoma. Cancer Causes Control 24, 1315-1322

Emerick KS, Herr MW, Lin DT, Santos F, Deschler DG (2014): Supraclavicular Artery Island Flap for Reconstruction of Complex Parotidectomy, Lateral Skull Base, and Total Auriculectomy Defects. JAMA Otolaryngol Head Neck Surg 140, 861-866

Epps MT, Cannon CL, Wright MJ, Chaffin AE, Newsome RE, Friedlander PL, Chiu ES (2011): Aesthetic restoration of parotidectomy contour deformity using the supraclavicular artery island flap. Plast Reconstr Surg 127, 1925-1931

Fayers PM, Aaronson NK, Bjordal K, Groenvold M, Curran D, Bottomley A, on behalf of the EORTC Quality of Life Group: The EORTC QLQ-C30 Scoring Manual. 3. Auflage; European Organisation for Research and Treatment of Cancer, Brüssel 2001

Fleissig A, Jenkins V, Catt S, Fallowfield L (2006): Multidisciplinary teams in cancer care: are they effective in the UK?. Lancet Oncol $\underline{7}$, 935-943

Friemel J, Foraita R, Gunther K, Heibeck M, Gunther F, Pflueger M, Pohlabeln H, Behrens T, Bullerdiek J, Nimzyk R, et al. (2016): Pretreatment oral hygiene habits and survival of head and neck squamous cell carcinoma (HNSCC) patients. BMC Oral Health $\underline{16}, 33$

Furness S, Glenny AM, Worthington HV, Pavitt S, Oliver R, Clarkson JE, Macluskey M, Chan KK, Conway DI, Panel CE (2010): Interventions for the treatment of oral cavity and oropharyngeal cancer: Chemotherapy. Cochrane Database Syst Rev $\underline{9}$ 
Gedlicka C, Formanek M, Selzer E, Burian M, Kornfeld J, Fiebinger W, Cartellieri M, Marks B, Kornek GV (2002): Phase II study with docetaxel and cisplatin in the treatment of recurrent and/or metastatic squamous cell carcinoma of the head and neck. Oncology $\underline{63}$, $145-150$

GEKID (2017). Atlas der Krebsinzidenz und -mortalität in Deutschland (GEKID-Atlas). Datenlieferung: Gesellschaft der epidemiologischen Krebsregister in Deutschland e. V. Atlas der Krebsinzidenz und -mortalität in Deutschland (GEKID-Atlas). Datenlieferung: Juli 2017, Lübeck, 2017. Verfügbar über: http://www.gekid.de; Zugriff am 16.10.2018

Germann G, Wind G, Harth A (1999): The DASH (Disability of Arm-Shoulder-Hand) Questionnaire - a new instrument for evaluating upper extremity treatment outcome. Handchirurgie, Mikrochirurgie, Plast Chir $\underline{31}$, 149-151

Giordano L, Bondi S, Toma S, Biafora M (2014): Versatility of the supraclavicular pedicle flap in head and neck reconstruction. Acta Otorhinolaryngol Ital 34, 394-398

Giordano L, Santo DD, Occhini A, Galli A, Bertino G, Benazzo M, Bussi M (2016): Supraclavicular artery island flap (SCAIF): a rising opportunity for head and neck reconstruction. Eur Arch Otorhinolaryngol 273, 1-10

Giummarra MJ, Gibson SJ, Georgiou-Karistianis N, Bradshaw JL (2007): Central mechanisms in phantom limb perception: The past, present and future. Brain Res Rev $\underline{54}, 219-232$

Goldstein DP, Ringash J, Irish JD, Gilbert R, Gullane P, Brown D, Xu W, Bel RD, Chepeha D, Davis AM (2015): Assessment of the Disabilities of the Arm, Shoulder, and Hand (DASH) questionnaire for use in patients after neck dissection for head and neck cancer. Head Neck $\underline{37}, 234-242$

Goyal N, Emerick KS, Deschler DG, Lin DT, Yarlagadda BB, Rich DL, Durand ML (2016): Risk factors for surgical site infection after supraclavicular flap reconstruction in patients undergoing major head and neck surgery. Head and Neck $\underline{38}$, 1615-1620

Granzow JW, Suliman A, Roostaeian J, Perry A, Boyd JB (2013a): The Supraclavicular Artery Island Flap (SCAIF) for Head and Neck Reconstruction: Surgical Technique and Refinements. Otolaryngol Head Neck Surg 148, 933-940

Granzow JW, Suliman A, Roostaeian J, Perry A, Boyd JB (2013b): Supraclavicular Artery Island Flap (SCAIF) vs Free Fasciocutaneous Flaps for Head and Neck Reconstruction. Otolaryngol Head Neck Surg $\underline{148}$, 941-948

Greenberg JS, Fowler R, Gomez J, Mo V, Roberts D, Naggar AKE, Myers JN (2003): Extent of extracapsular spread: a critical prognosticator in oral tongue cancer. Cancer $\underline{97}, 1464-$ 1470 
Gurtner GC, Evans GR (2000): Advances in Head and Neck Reconstruction. Plast Reconstr Surg 106, 672-683

Hashmi NK, Ransom E, Nardone H, Redding N, Mirza N (2010): Quality of life and self-image in patients undergoing tracheostomy. Laryngoscope 120, S196

Havet E, Duparc F, Tobenas-Dujardin A, Muller J, Freger P (2007): Morphometric study of the shoulder and subclavicular innervation by the intermediate and lateral braches of supraclavicular nerves. Surg Radiol Anat 29, 605-610

Hekner D, Abbink J, van Es P, Rosenberg A, Koole R, Cann EV (2013): Donor site morbidity of the radial forearm free flap versus the ulnar forearm free flap. Plast Reconstr Surg 132, 287-393

Herr MW, Bonanno A, Montalbano LA, Deschler DG, Emerick KS (2014): Shoulder function following reconstruction with the supraclavicular artery island flap. Laryngoscope 124 , $2478-2483$

Heth JA, Funk GF, Karnell LH, McCulloch TM, Traynelis VC, Nerad JA, Smith RB, Graham SM, Hoffman HT (2002): Free tissue transfer and local flap complications in anterior and anterolateral skull base surgery. Head Neck 24, 901-911

Heutte N, Plisson L, Lange M, Prevost V, Babin E (2014): Quality of life tools in head and neck oncology. Eur Ann Orothinolaryngol Head Neck Dis 131, 33-47

Hsing CY, Wong YK, Wang CP, Wang CC, Jiang RS, Chen FJ, Liu SA (2014): Comparison between free flap and pectoralis major pedicled flap for reconstruction in oral cavity cancer patients - a quality of life analysis. Oral Oncology $\underline{47}, 522-527$

Hurvitz KA, Kobayashi M, Evans GR (2006): Current options in head and neck reconstruction. Plast Reconstr Surg 118, 122e-133e

Ihrler S, Weiler C: Tumorentitäten und pathohistologische Grundlagen. In: Mast G (Hrsg.): Kopf- und Halsmalignome. 4. Auflage; Zuckerschwerdt Verlag, München 2009

Kennedy C, Beaton D, Solway S, McConnel S, Bombardier C: The DASH and Quick DASH Outcome Measure User's Manual. 3. Auflage; Institute for Work \& Health, Toronto 2011 Kimmeyer J, Kurzweg T, Hoffmann TK, Knecht R, Veit JA, Möckelmann N, Münscher A, Laban S (2016): Oncologic treatment landscape for head and neck squamous cell carcinoma. HNO $\underline{64}, 494-500$

Kokot N, Mazhar K, Reder LS, Peng GL, Sinha UK (2013): The supraclavicular artery island flap in head and neck reconstruction: applications and limitations. JAMA Otolaryngol Head Neck Surg 139, 1247-1255 
Kozin ED, Sethi RK, Herr M, Shrime MG, Rocco JW, Lin D, Deschler DG, Emerick KS (2016): Comparison of Perioperative Outcomes between the Supraclavicular Artery Island Flap and Fasciocutaneous Free Flap. Otolaryngol Head Neck Surg 154, 66-72 Lamberty BG (1979): The supraclavicular axial patterned flap. Br J Plast Surg 32, 207-212 Langer CJ, Li Y, Jennings T, DeConti RC, Nair S, Cohen RB, Forastiere AA, EasternCooperativeOncologyGroup (2004): Phase II evaluation of 96-hour paclitaxel infusion in advanced (recurrent or metastatic) squamous cell carcinoma of the head and neck: a trial of the Eastern Cooperative Oncology Group Cancer. Invest 22, 823-831

Lubin JH, Purdue M, Kelsey K, Zhang ZF, Winn D, Wei Q, Talamini R, Szeszenia-Dabrowska N, Sturgis EM, Smith E, et al. (2009): Total exposure and exposure rate effects for alcohol and smoking and risk of head and neck cancer: A pooled analysis of case-control studies. Am J Epidemiol 170, 937-947

Mehta S, Sarkar S, Kavarana N, Bhathena H, Mehta A (1996): Complications of the pectoralis major myocutaneous flap in the oral cavity: a prospective evaluation of 220 cases. Plast Reconstr Surg 98, 31-37

Melo-Filho MR, Rocha BA, Pires MB, Fonseca ES, Freitas EM, Martelli-Jr. H, Santos FB (2013): Quality of life of patients with head and neck cancer. Braz J Otorhinolaryngol 79 , $82-88$

Meurmann JH (2010): Infectious and dietary risk factors of oral cancer. Oral Oncology $\underline{46}, 411$ 413

Mork J, Lie AK, Glattre E, Hallmans G, Jellum E, Koskela P, Møller B, Pukkala E, Schiller JT, Youngman L, et al. (2001): Human papillomavirus infection as a risk factor for squamous-cell carcinoma of the head and neck. N Engl J Med 344, 1125-1131

Mühlbauer W, Herndl E, Stock W (1982): The forearm flap. Plast Reconstr Surg 70, 336-344 Murphy BA (2009): Late treatment effects: reframing the questions. Lancet Oncol 10, 530-531 Murphy BA, Ridner S, Wells N, Dietrich M (2007): Quality of life research in head and neck cancer: a review of the current literature. Crit Rev Oncol Hematol 62, 251-267

Nathe T, Tseng S, Yoo B (2011): The Anatomy of the Supraclavicular Nerve During Surgical Approach to the Clavicular Shaft. Clin Orthop Relat Res $\underline{469}$, 890-894

Orlik J, Horwich P, Bartlett C, Trites J, Hart R, Taylor S (2014): Long-term functional donor site morbidity of the free radial forearm flap in head and neck cancer survivors. $J$ Otolaryngol Head Neck Surg $\underline{43}, 1$ 
Pallua N, Machens HG, Rennekampff O, Becker M, Berger A (1996): The Fasciocutaneous Supraclavicular Artery Island Flap for Releasing Postburn Mentosternal Contractures. Plast Reconstr Surg 99, 1878-1786

Pallua N, Noah EM (1999): The Tunneled Supraclavicular Island Flap: An Optimized Technique for Head and Neck Reconstruction. Plast Reconstr Surg 105, 842-851

Parfenov M, Pedamallu CS, Gehlenborg N, Freeman SS, Danilova L, Bristow CA, Lee S, Hadjipanayis AG, Ivanova EV, Wilkerson MD, et al. (2014): Characterization of HPV and host genome interactions in primary head and neck cancers. Proc Natl Acad Sci U S A $\underline{111}, 15544-15549$

Paydarfar JA, Patel UA (2011): Submental island pedicled flap vs radial forearm free flap for oral reconstruction: comparison of outcomes. Arch Otolaryngol Head Neck Surg 137, 8287

Pierre CS, Dassonville O, Chamorey E, Poissonnet G, Ettaiche M, Santini J, Peyrade F, Benezery K, Sudaka A, Bozec A (2014): Long-term quality of life and its predictive factors after oncologic surgery and microvascular reconstruction in patients with oral or oropharyngeal cancer. Eur Arch Otorhinolaryngol 271, 801-807

Pignon J, le-Maître A, Maillard E, Bourhis J, MACH-NC-CollaborativeGroup (2009): Metaanalysis of chemotherapy in head and neck cancer (MACH-NC): an update on 93 randomised trials and 17,346 patients. Radiother Oncol 92, 4-14

Plataniotis GA, Theofanopoulou ME, Kalogera-Fountzila A, Haritanti A, Ciuleanou E, Ghilezan N, Zamboglou N, Dimitriadis A, Sofroniadis I, Fountzilas G (2004): Prognostic impact of tumor volumetry in patients with locally advanced head-and-neck carcinoma (non-nasopharyngeal) treated by radiotherapy alone or combined radiochemotherapy in a randomized trial. Int J Radiat Oncol Biol Phys 포, 1018-1026

Pluvy I, Panouillères M, Garrido I, Pauchot J, Saboye J, Chavoin JP, Tropet Y, Grolleau JL, Chaput B (2015a): Smoking and plastic surgery, part I. Pathophysiological aspects: update and proposed recommendations Ann. Chir. Plast. Esthétique 60, e3-e13

Pluvy I, Panouillères M, Garrido I, Pauchot J, Saboye J, Chavoin JP, Tropet Y, Grolleau JL, Chaput B (2015b): Smoking and plastic surgery, part II. Clinical implications: a systematic review with meta-analysis. Ann Chir Plast Esthétique $\underline{60}$, e15-49

Quinten C, Coens C, Ghislain I, Zikos E, Sprangers M, Ringash J, Martinelli F, Ediebah D, Maringwa J, Reeve BB, et al. (2015): The effects of age on health-related quality of life in cancer populations: A pooled analysis of randomized controlled trials using the 
European Organisation for Research and Treatment of Cancer (EORTC) QLQ-C30 involving 6024 cancer patients. Eur J Cancer 51, 2808-2819

Razdan SN, Albornoz CR, Ro T, Cordeiro PG, Disa JJ, McCarthy CM, Stern CS, Garfein ES, Matros E (2015): Safety of the supraclavicular artery island flap in the setting of neck dissection and radiation therapy. $\mathrm{J}$ Reconstr Microsurg $\underline{31}$, 378-383

Refos J, Witte B, de Goede C, de Bree R (2016): Shoulder morbidity after pectoralis major flap reconstruction. Head and Neck $\underline{38}, 1221-1228$

Richardson D, Fisher S, Vaughan E, Brown J (1997): Radial forearm flap donor-site complications and morbidity: a prospective study. Plast Reconstr Surg 99, 109-115

Salerno G, Cavaliere M, Foglia A, Pellicoro DP, Mottola G, Nardone M, Galli V (2002): The 11 th nerve syndrome in functional neck dissection. Laryngoscope $\underline{112}, 1299-1307$

Sandu K, Monnier P, Pasche P (2012): Supraclavicular flap in head and neck reconstruction: experience in 50 consecutive patients. Eur Arch Otorhinolaryngol 269, 1261-1267

Schöffski P, Catimei G, Planting AS, Droz JP, Verweij J, Schrijvers D, Gras L, Schrijvers A, Wnaders J, Hanauske AR (1999): Docetaxel and cisplatin: an active regimen in patients with locally advanced, recurrent or metastatic squamous cell carcinoma of the head and neck. Results of a phase II study of the EORTC early clinical studies group. Ann Oncol $\underline{10}, 119-122$

Shah J, Haribhakti V, Loree T, Sutaria P (1990): Complications of the pectoralis major myocutaneour flap in head and neck reconstruction. Am J Surg 160, 352-355

Shin DM, Khuri FR, Glisson BS, Ginsberg L, Papadimitrakopoulou VM, Clayman G, Lee JJ, Ang KK, Lippman SM, Hong WK (2001): Phase II study of paclitaxel, ifosfamide, and carboplatin in patients with recurrent or metastatic head and neck squamous cell carcinoma. Cancer 91, 1316-1323

Skoner J, Bascom D, Cohen J, Andersen P, Wax M (2003): Short-term functional donor site morbidity after radial forearm fasciocutaneous free flap harvest. Laryngoscope $\underline{113}$, 2091-2094

So WK, Chan RJ, Chan DN, Hughes BG, Chair SY, Choi KC, Chan CW (2012): Quality-oflife among head and neck cancer survivors at one year after treatment - a systematic review. Eur J Cancer $\underline{48}$, 2391-2408

Stalfors JL, Lundberg C, Westin T (2007): Quality assessment of a multidisciplinary tumour meeting for patients with head and neck cancer. Acta Otolaryngol $\underline{127}, 82-87$

Steiner W (1984): Endoscopic laser surgery of the upper aerodigestive tract. Laryngol Rhinol Otol $\underline{63}, 198-202$ 
Strome SE, Savva A, Brissett AE, Gostout BS, Lewis J, Clayton AC, McGovern R, Weaver AL, Persing D, Kasperbauer JL (2002): Squamous cell carcinoma of the tonsils: A molecular analysis of HPV associations. Clin Cancer Res $\underline{8}, 1093-1100$

Stroncek JD, Reichert WM: Overview of Wound Healing in Different Tissue Types. In: Reichert WM (Hrsg.): Indwelling Neural Implants: Strategies for Contending with the In Vivo Environment. CRC Press/Taylor \& Francis, Boca Raton 2008, Chapter 1

Su T, Pirgousis P, Fernandes R (2013): Versatility of supraclavicular artery island flap in head and neck reconstruction of vessel-depleted and difficult necks. J Oral Maxillofac Surg $\underline{71}$, $622-627$

Su WF, Hsia YJ, Chang YC, Chen SG, Sheng H (2003): Functional comparison after reconstruction with a radial forearm free flap or a pectoralis major flap for cancer of the tongue. Otolaryngol Head Neck Surg $\underline{128}, 412-418$

Teymoortash A, Mandapathil M, S Hoch S (2014): Indications for reconstruction of mucosal defects in oropharyngeal cancer using a supraclavicular island flap. Int J Oral Maxillofac Surg $\underline{43}, 1054-1058$

Tsue TT, Desyatnikova SS, Deleyiannis FW, Futran ND, Stack BC, Weymuller EA, Glenn MG (1997): Comparison of cost and function in reconstruction of the posterior oral cavity and oropharynx. Free vs pedicled soft tissue transfer. Arch Otolaryngol Head Neck Surg $\underline{123}$, $731-737$

van Wilgen CP, Dijkstra PU, van der Laan BF, Plukker JT, Roodenburg JL (2004): Shoulder complaints after neck dissection; is the spinal accessory nerve involved?. Int J Oral Maxillofac Surg 41, 7-11

Ver Haalen JP, Yu P, Skoracki R, Chang D (2010): Reconstruction of massive oncologic defects using free fillet flaps. Plast Reconstr Surg $\underline{125}$, 913-922

Vermorken JB, Mesia R, Rivera F, Remenar E, Kawecki A, Rottey S, Erfan J, Zabolotnyy D, Kienzer HR, Cupissol D, et al. (2008): Platinum-based chemotherapy plus Cetuximab in head and neck cancer. N Engl J Med 359, 1116-1127

Vinh VQ, Anh TV, Ogawa R, Hyakusoku H (2009): Anatomical and clinical studies of the supraclavicular flap: analysis of 103 flaps used to reconstruct neck scar contractures. Plast Reconstr Surg 123, 1471-1480

Warnakulasuriya S (2009): Causes of oral cance - an appraisal of controversies. Br Dent J 207, 471-475 
Weiss BG, Bertlich M, Canis M, Ihler F (2017): Transoral laser microsurgery or total laryngectomy for recurrent squamous cell carcinoma of the larynx: Retrospective analysis of 199 cases. Head and Neck $\underline{39}, 1166-1176$

Welz C, Canis M, Schwenk-Zieger S, Spiegel JL, Weiss BG, Pilavakis Y (2017): Oral Cancer Reconstruction Using the Supraclavicular Artery Island Flap: Comparison to Free Radial Forearm Flap. J Oral Maxillofac Surg 75, 2261-2269

Westin T, Stalfors J (2008): Tumour boards/multidisciplinary head and neck cancer meetings: are they of value to patients, treating staff or a political additional drain on healthcare resources?. Curr. Opin. Otolaryngol. Head Neck Surg $\underline{16}$, 103-107

Wheless SA, McKinney KA, Zanation AM (2010): A prospective study of the clinical impact of a multidisciplinary head and neck tumor board. Otolaryngol Head Neck Surg $\underline{143}, 650$ 654

World Health Organization. Division of Mental Health and Prevention of Substance Abuse. WHOQOL: measuring quality of life. Geneva 1997, http://www.who.int/iris/handle/10665/63482; Zugriff am 16.10.2018

Woolgar JA (2006): Histopathological prognosticators in oral and oropharyngeal squamous cell carcinoma. Oral Oncol $\underline{42}, 229-239$

Xiao Y, Zhu J, Cai X, Wang J, Liu FW (2013): Comparison between anterolateral thigh perforator free flaps and pectoralis major pedicled flap for reconstruction in oral cancer patients - a quality of life analysis. Med Oral Patol Oral Cir Bucal 18, e856-e861

Robert Koch Institut (RKI): Bericht zum Krebsgeschehen in Deutschland 2016. Berlin 2016; http://www.krebsdaten.de/krebsbericht; Zugriff am 16.10.2018

Zhang B, Yan D, Zhang Y, Zhang X, Wan H (2015): [Clinical experience with the supraclavicular flap to reconstruct head and neck defects]. Zhonghua Er Bi Yan Hou Tou Jing Wai Ke Za Zhi 무, 468-472 


\section{Danksagung}

Zunächst möchte ich mich außerordentlich bei meinem Doktorvater und Mentor, Herrn Prof. Dr. med. Martin Canis, für die hilfsbereite und konstruktive Betreuung bedanken, die mir einen kritischen Zugang zur Thematik eröffnete. Ferner gilt mein ganz besonderer Dank meinem Betreuer, Herrn Priv.-Doz. Dr. med. Christian Welz, für die hilfsbereite und wissenschaftliche Unterstützung und den konstruktiven Austausch. Des Weiteren möchte ich meinem Zweitbetreuer Herrn Priv.-Doz. Dr. med. Gunther Felmerer für den methodischen Input danken.

Mein ganz besondere Dank gebührt Dr. Elmar Spiegel, der mit bemerkenswerter Geduld und kritischer Betrachtung die Auswertung der vorliegenden Daten betreut hat. Daneben möchte ich meinen Eltern für die Unterstützung inklusive kritischer Auseinandersetzung mit dem Themenkomplex und Durchsicht meiner Arbeit danken. 